\title{
Alternative Approaches to Development:
}

Social Entrepreneurship in the Philippines

By

\section{Hilda Fatima G. Tantingco}

\author{
A Thesis \\ Submitted to Victoria University of Wellington \\ in partial fulfilment of the requirements \\ for the degree of Master of Development Studies \\ School of Geography, Environment and Earth Sciences
}

\section{Victoria University of Wellington}

March, 2011 


\begin{abstract}
Post-development writers contend that development has failed because it created a worldview in which certain places are deemed 'underdeveloped' and in need of external assistance based on Western ideals of modernity. They argue that development should be abandoned and 'alternatives to development' must now be brought to the fore. However, this proposition is considered to be challenging at best since discussions on 'alternatives to development' have been vague and concrete practical examples are rarely given. Nevertheless, the arguments found within post-development thought are significant to current and future development practice and several researchers have attempted to apply post-development ideas into practice.
\end{abstract}

This thesis looks into Social Entrepreneurship, an emerging development approach that seems to build on some of the ideas from post-development thought. It examines how social entrepreneurship has evolved and is defined within the context of the Philippines. The thesis attempts to understand how social entrepreneurship differs from mainstream development approaches and contributes to alternative pathways, through a case study of an NGO engaged in social entrepreneurship - A Single Drop for Safe Water, Philippines. Qualitative methods of observation, secondary data collection, and semi-structured interviews were utilized.

The study reveals that social entrepreneurship practices have elements that reflect postdevelopment ideas such as highlighting community strengths, being mindful of local culture and practices, and strengthening the autonomy of community groups. However, social entrepreneurship also features activities that are based on market and business principles including having a profit motive and transferring business skills and knowledge to communities. Thus, social entrepreneurship is neither alternative nor mainstream but has the potential to be both. Development practitioners should be careful in utilizing social entrepreneurship practices, as not to expand neo-liberal ideals.

Key Words: Philippines; social entrepreneurship; post-development; alternative development; water and sanitation 


\section{ACKNOWLEDGEMENTS}

I would like to extend my gratitude to Ms. Gemma Bulos, Mr. Kevin Lee, and the staff of A Single Drop for Safe Water for their hospitality and for sharing their story. Many thanks as well to the members of the Bacungan Coastal Development Residents Association and the San Carlos PODS who took the time to speak with me about their experiences.

I am incredibly grateful to the people who have supported me in this endeavour. Thank you to my supervisor, Dr. Andrew McGregor for his guidance and unfaltering trust throughout this process. His input was invaluable to the completion of this research. Next, I would like to say thank you to my family-my parents Nestor and Pelagia, my siblings Happy and Hon for the unconditional love and encouragement even from miles away. A special thanks to my partner, Joel for being patient especially during moments of panic-your love and understanding gives me strength.

Lastly, thank you to the New Zealand Agency for International Development (NZAID) for supporting my Masters study and my stay in Wellington. 
ABSTRACT .......................................................... i

ACKNOWLEDGEMENTS.......................................... ii

TABLE OF CONTENTS ................................................ iii

List of Figures................................................... vi

List of Tables..................................................... vi

List of Boxes...................................................... vi

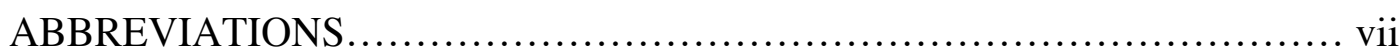

Ch.1 INTRODUCTION .................................................... 1

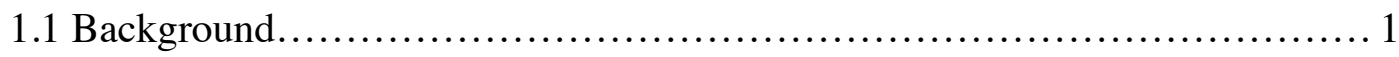

1.2 Research Aim and Questions........................................... 3

1.3 Research Rationale and Significance................................... 4

1.4 Structure of the Thesis.................................................... 5

Ch.2 LITERATURE REVIEW ........................................ 6

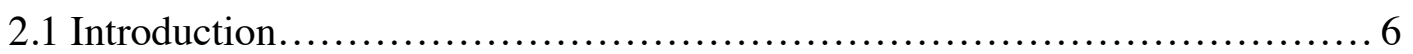

2.2 Post-Development Theory................................................ 7

2.2.1 Development as a Hegemonic Process.......................... 8

2.2.2 Dismantling the Development Discourse.........................10

2.2.3 Critiques of Post-Development................................ 12

2.2.4 Alternatives to Development.................................. 14

2.3 Social Entrepreneurship........................................... 22

2.3.1 Defining Social Entrepreneurship........................... 23

2.3.2 Social Entrepreneurship in Practice............................ 29

2.3.3 Critiques of Social Entrepreneurship......................... 32

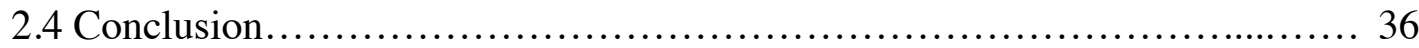

Ch.3 METHODOLOGY.................................................. 39

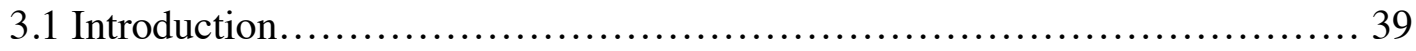

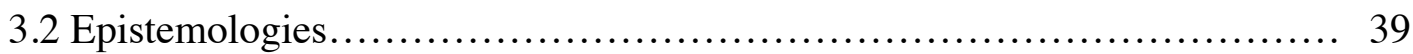

3.3 Methods and Data Sources....................................... 41

3.3.1 Secondary Data Sources................................. 41 
3.3.2 Primary Data Sources........................................... 42

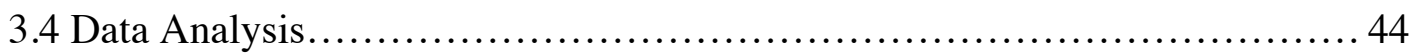

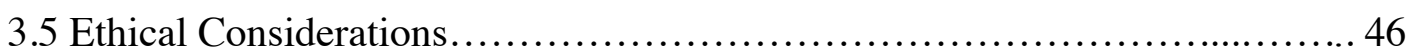

3.6 Reflection on Research Process.................................................. 47

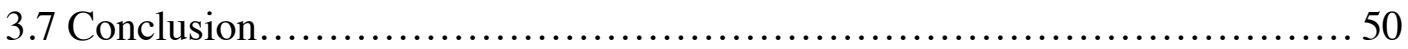

Ch. 4 PHILIPPINE DEVELOPMENT CONTEXT AND

SOCIAL ENTREPRENEURSHIP IN THE PHILIPPINES...................... 51

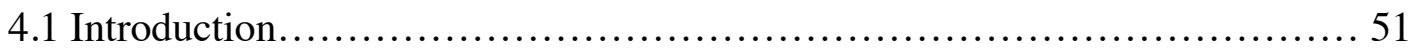

4.2 Philippine Socio-Economic Development Profile............................ 52

4.3 Civil Society Organizations and Social Development......................... 58

4.4 Social Entrepreneurship in the Philippines................................... 63

4.4.1 Promoting Social Entrepreneurship in the Philippines.................. 64

4.4.2 Social Enterprises in the Philippines.................................. 70

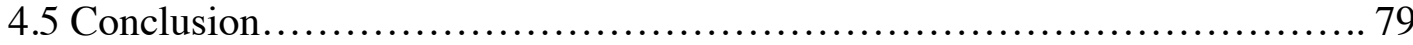

Ch. 5 EXPLORING ALTERNATIVE WAYS: COMMUNITY INITIATIVES

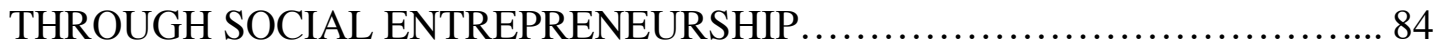

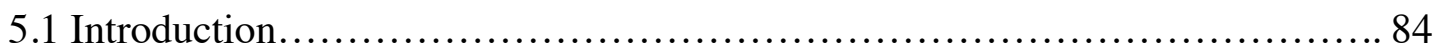

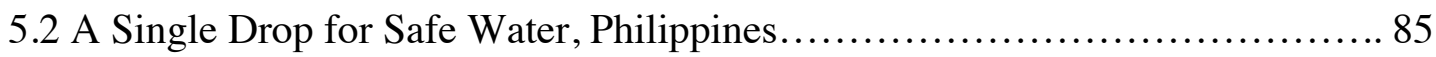

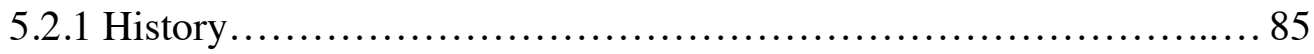

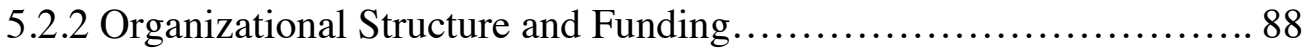

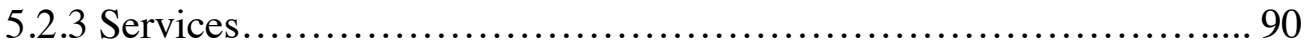

5.2.4 Areas of Operations............................................... 95

5.3 Promoting Community Initiatives: Opportunities and Challenges............... 97

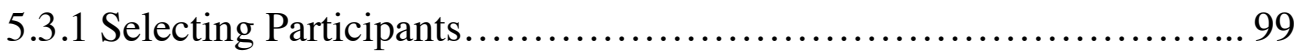

5.3.2 Formulating Community Dream/Vision............................. 101

5.3.3 Setting Project Goals................................................ 105

5.3.4 Making Way for Alternative Possibilities.............................. 108

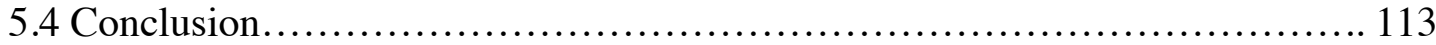

Ch. 6 SOCIAL ENTREPRENEURSHIP: FURTHERING THE INFLUENCE OF

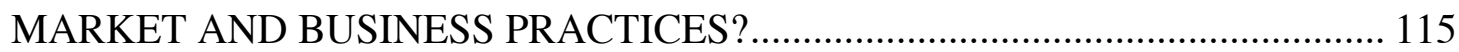

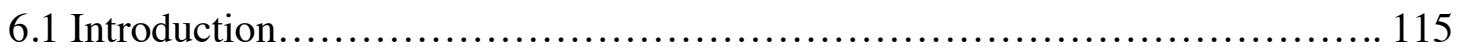

6.2 Effects of Market and Business Practices in Communities....................... 116 
6.2.1 Water Services: Privatization and User Fees...................... 116

6.2.2 Using Profit for Social Objectives.............................. 123

6.2.3 Business Skills Training....................................... 127

6.3 Conclusion....................................................... 130

Ch. 7 CONCLUSION AND RECOMMENDATIONS .......................... 134

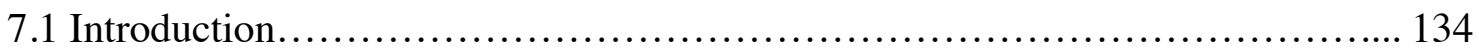

7.2 Significant Findings................................................... 135

7.2.1 Social entrepreneurship: an emerging movement in the Philippines..... 135

7.2.2 Social entrepreneurship: a malleable Concept..................... 138

7.3 Future Research.......................................................... 143

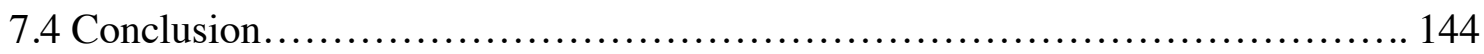

REFERENCES........................................................ 146

APPENDICES ............................................................... 161

Appendix 1: Annual Per Capita Poverty Threshold, Poverty Incidence and Magnitude of Poor Population, by Region................................ 161

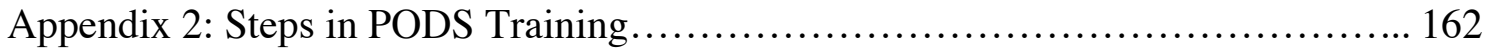




\section{List of Figures}

Figure 2.4.1 Social Entrepreneurship Spectrum.............................. 38

Figure 4.2.1 Philippine Map.......................................... 53

Figure 4.2.2 Philippines Location Map.................................. 54

Figure 4.4.2.2 Hydraulic Ram Pump Diagram................................ 75

Figure 5.2.2 ASDSW Organizational Structure $\ldots \ldots \ldots \ldots \ldots \ldots \ldots \ldots \ldots \ldots \ldots \ldots . \ldots . \ldots 1 . \ldots \ldots$

Figure 5.2.4 ASDSW Program Sites....................................... 96

Figure 6.3 Social Entrepreneurship Spectrum-PODS......................... 131

\section{List of Tables}

Table 2.3.1 The Range of Social Entrepreneurship............................. 26

Table 3.3.1 Information Sources on Social Entrepreneurship Activities

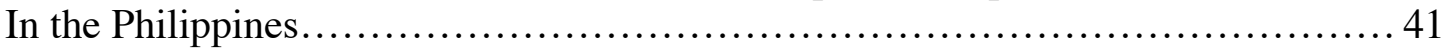

Table 4.2.1 Annual Per Capita Thresholds,

Poverty Incidence and Magnitude of Poor..................................... 55

Table 4.3.1 Number of Base Organizations by Nature of Program................ 61

Table 4.4.1 ASoG's Social Entrepreneurship Programs......................... 65

Table 4.5 The Range of Social Entrepreneurship-Philippine Examples............. 81

Table 5.2.4 Types of Services per Area...................................... 97

Table 5.3.4 PODS Project Status........................................ 109

Table 6.2.1.1 Tariff Rates of Philippine WSPs (2005 Data)....................... 118

Table 6.2.1.2 Water Problems in Developing Countries......................... 121

\section{List of Boxes}

Box 4.4.2.1 Rags2Riches Business Model.................................. 72

Box 4.4.2.3 PRRM's Alternative Rice Production Program...................... 77

Box 5.2.1 ASDSW Organizational Development Timeline......................... 88

Box 5.2.3 The Governance Approach to WASH Defined.......................... 93

Box 5.3.2 ASDSW's The Two Faces of Development............................. 102

Box 5.3.4 Community Vision-Sitio San Carlos, Barangay Bacungan................ 112

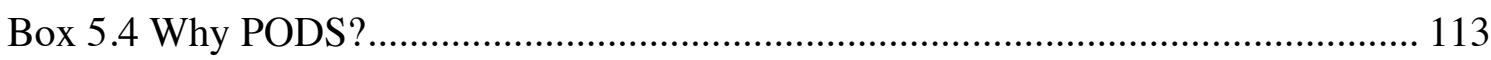

Box 6.2.1 Philippine Water System Classification............................. 117 


\section{ABBREVIATIONS}

AIDFI - $\quad$ Alternative Indigenous Development Foundation, Inc.

ASDSW - $\quad$ A Single Drop for Safe Water

ASoG

Ateneo School of Government

BCDRAI - Bacungan Coastal Development Residents Association

BSF $\quad-\quad$ Bio-Sand Filter

BWSA - $\quad$ Barangay Water and Sanitation Association

CODE-NGO - Caucus of Development NGO Networks

$\mathrm{CSO} \quad$ - $\quad$ Civil Society Organization

CSR - $\quad$ - Corporate Social Responsibility

DAC - - Development Assistance Committee

IRA $\quad$ - Internal Revenue Allotment

ISEA $\quad-\quad$ Institute for Social Entrepreneurship in Asia

LGC - $\quad$ Local Government Code

LGU $\quad$ - $\quad$ Local Government Unit

LWUA $\quad$ - $\quad$ Local Water Utilities Administration

MDG - $\quad$ Millennium Development Goals

MNC - $\quad$ Multi-National Corporation

MSME $\quad$ - $\quad$ Micro, Small, and Medium Enterprise

MTPDP - $\quad$ Medium-Term Philippine Development Plan

MWTF $\quad-\quad$ Municipal WASH Task Force

NGO - $\quad$ Non-Governmental Organization

NIC $\quad$ - Newly Industrialized Country

OCW - Overseas Contract Worker

ODA - - Official Development Assistance

OECD - $\quad$ Organisation for Economic Co-operation and Development

OFW $\quad$ - $\quad$ Overseas Filipino Worker

PhilSEN - Philippine Social Enterprise Network

PO - People's Organization

PODS - $\quad$ People Offering Deliverable Services

PPP $\quad$ - $\quad$ Public-Private Partnership

PRA $\quad$ - $\quad$ Participatory Rural Appraisal

RWSA - $\quad$ Rural Water and Sanitation Association 
SEDPI - $\quad$ Social Enterprise Development Partnerships, Inc.

SEQI $\quad$ - $\quad$ Social Enterprise Quality Index

SRA $\quad$ - $\quad$ Social Reform Agenda

UNDP - $\quad$ United Nations Development Program

WASH - Water, Sanitation and Hygiene

WSA $\quad-\quad$ Water and Sanitation Association

WSP $\quad-\quad$ Water Supply Provider 


\section{CHAPTER 1 \\ Introduction}

\subsection{Background}

"There is an aspect of giving back to the community". This statement came from a member of the Bacungan Coastal Development Residents Association (BCDRAI) as she talked about the enterprises that the community-based organization operates in Sitio San Carlos, a rural community in the province of Palawan, Philippines. The group considers these enterprises as not only sources of additional income and livelihood for the members of BCDRAI, but also as undertakings that contribute to community development and to the wellbeing of other residents. First is an eco-tourism project that is part of the group's efforts in protecting the coastal environment and preserving the livelihood of most residents. They work together in running a 'floating restaurant' that takes visitors on a cruise down the Bacungan River while members of the community perform folk dances, play Cuyunon ${ }^{1}$ music and give short talks about the mangrove ecosystem (Arquiza, 2009). BCDRAI's latest endeavour involves the construction and marketing of Bio-Sand water filters, which they believe will help improve the health of residents. Along with selling these water filters, the group also takes the lead in advocating water, sanitation, and hygiene (WASH) measures among residents (see A Single Drop for Safe Water, 2009c). These enterprises demonstrate their commitment to 'giving back to the community' and not merely earning profits.

Most businesses in the private sector are regarded as being highly motivated by profits and economic gain rather than social benefits, and private sector participation in pro-poor initiatives is often met with scepticism (Gold, 2003). Public-private partnerships (PPP) for the provision of social services, for example, are criticized as an

\footnotetext{
${ }^{1}$ Cuyunon refers to an ethnic group originating from the Cuyo islands in Palawan province
} 
extension of the neo-liberal agenda, while corporate social responsibility (CSR) is cynically viewed as a marketing strategy (see Lorenzo-Molo, 2008). According to Gold (2003, p. 169), the difficulty arises from "the difference between the profit motive, which tends to commodify human need, and the non-profit motive, which depends on a cooperative rationale". However, looking at BCDRAI's enterprises, it seems as though the group is able to balance or reconcile having both a profit motive and non-profit motives. These type of activities are being described as 'social entrepreneurship' and are deemed as an alternative to both market-oriented enterprises (see Anderson, Horig, \& Peredo, 2006; Gold, 2003) and conventional non-commercial development NGOs (Aldaba, Antezana, Valderrama, \& Fowler, 2000; Hechanova-Alampay \& dela Cruz, 2009).

According to Keh (2009), there has been a recent increase in the number of social enterprises in the world, drawn by the possibilities of conducting pro-poor and social development projects while still earning a profit. Academic literature on the topic is also growing, demonstrating an interest in studying the phenomenon and developing theories around it (see J. E. Austin, 2006; Haugh, 2006a; Mair \& Marti, 2006). Despite social entrepreneurship being relevant to development practice, it has little theoretical grounding in development studies. Few authors have attempted to relate social entrepreneurship to broader studies or debates on social change and development (see Fowler, 2000; Mair \& Marti, 2006). It is noticeable that scholarly research on the subject has been linked more with business studies, given that it has an entrepreneurial and income generating aspect.

This research will examine social entrepreneurship from a post-development perspective to analyse whether it is significantly different from mainstream development approaches. Chapter 2 provides an in-depth discussion on the arguments of postdevelopment writers about development. They contend that 'alternatives to development' 
must now be brought to the fore (see Escobar, 2007; Latouche, 1993). However, this proposition is considered to be challenging at best since discussions on 'alternatives to development' have been vague and concrete examples are rarely given (Matthews, 2004). Nevertheless, the arguments found within post-development thought are significant to current and future development practice and several researchers have attempted to apply post-development ideas into practice (see Carnegie, 2008; GibsonGraham, 2005; McGregor, 2007; Prayukvong, 2005). Through a case study on a nonprofit organization engaged in social entrepreneurship, this research will look into whether social entrepreneurship practices contribute to post-development ideas of 'alternatives' or whether it reinforces market-based or neo-liberal principles.

The research is set in the Philippines, where there have been calls for alternative development strategies that could effectively address the social issues besetting the country (La Vina, 2009). In this regard, social entrepreneurship seems to be gaining popularity as a new approach to social development. There have been notable developments towards the promotion of social entrepreneurship in the Philippines. Training programs on social entrepreneurship are now being offered and financial support for potential social entrepreneurs are also available. In addition, there is an umbrella organisation for social entrepreneurship-the Philippine Social Enterprise Network (PhilSEN) that assists their members through advocacy and networking services as well as business development programmes. The study will discuss the dimensions of this emerging industry and the circumstances that led to the emergence of social entrepreneurship in the country.

\subsection{Research Aim and Questions}

The primary aim of the research is to analyse how Social Entrepreneurship differs from conventional development approaches, and therefore contributes to alternatives to 
development, within the particular context of the Philippines. The research focuses on the following questions to investigate the primary aim:

1. How did social entrepreneurship emerge as a development approach in the Philippines?

2. How does social entrepreneurship contribute to alternative pathways that are different from prevailing development approaches?

3. How can social entrepreneurship practices be improved, based on postdevelopment ideas?

\subsection{Research Rationale and Significance}

As mentioned, social entrepreneurship has limited theoretical grounding in the field of development. A critical analysis of social entrepreneurship will be helpful to individuals or organizations already engaged in social entrepreneurship activities, as well as those who are interested in exploring alternative development approaches. The research examines social entrepreneurship through a post-development lens, which will allow for a better understanding of social entrepreneurship seen through the lens of wider debates on development theory and practice. Concurrently, there is an emerging body of research exploring the practical relevance of post-development theory, and this study can contribute to that body of literature. The research is thus positioned between theory and practice. It contributes to the existing body of knowledge on both post-development thought and social entrepreneurship theory. In addition, the lessons learned from the study could assist social entrepreneurs in the Philippines in examining and improving their programmes and become more effective in their efforts at bringing about positive change in the country. 


\subsection{Structure of the Thesis}

The thesis is divided into the following: Chapter 2 reviews related literature on post-development theory and its application in development practice; social entrepreneurship concepts; examples of social entrepreneurship activities; and critiques of social entrepreneurship. Chapter 3 describes the methodology used in the research, including the basis for using qualitative methods of inquiry. Chapter 4 looks into the emergence of social entrepreneurship in the Philippines, as well as the recent developments that contribute to its expansion. A brief discussion on the Philippines' socio-economic context is also provided. Examples of organizations engaged in social entrepreneurship activities are discussed to identify common features that define social enterprises. Chapter 5 details the case study on A Single Drop for Safe Water (ASDSW), a non-profit organization that builds the capacity of community-based organizations such as BCDRAI to implement water and sanitation projects on their own. The chapter examines the potential for ASDSW's activities to broaden alternative pathways for their partner organizations and communities. Chapter 6 looks into ASDSW's programme further, from a post-development perspective, to determine the effects of market-based practices on their partner community. Chapter 7 concludes the thesis with a discussion of significant findings based on the research aim and questions. Recommendations for future research are also identified. 


\section{CHAPTER 2}

\section{Literature Review}

\subsection{Introduction}

The subject of development continues to capture the interest and endeavours of individuals, organisations and governments. Fulfilling the professed benefits of development seems to be a foremost concern for multilateral agencies and 'donor' states in particular. The amount of resources being channelled to address a multitude of issues such as girls' education, family planning, conflict prevention, resource management and so on, is an indication of this. Aid statistics show that the amount of Official Development Assistance (ODA) disbursed by multilateral agencies and member countries of the Development Assistance Committee (DAC) adds up to approximately USD 136.24 billion in 2008 (Organisation for Economic Co-operation and Development, 2010). If the Millennium Development Goals (MDGs) are used as an indication for success or effectiveness of development and aid programmes, then progress certainly has been made. The United Nations (2009) reports that in the period from 1990 to 2005, the number of people living in extreme poverty has decreased from 1.8 billion to 1.4 billion. There have also been steady progress in the other goals such as increase in primary education enrolment and decline in the number of under-five mortality (see United Nations, 2009). However, the United Nations Development Programme (UNDP) observed that "there is a wide variation of progress", with some countries being on-track to achieve some goals but may have difficulties in meeting other targets (2010, p. 14). By 2015, which is the target date for the Millennium Development Goals (MDGs), it is likely that at least 1 billion people would still be living in extreme poverty (United Nations, 2009). This begs the question, what more could be done in order to deliver the promises of development? 
Thus far, there has not been a lack of ideas on the 'how' of development. From modernisation, to dependency, to participatory development, various theories have offered possible approaches to tackling 'underdevelopment'. These have influenced the practices of development institutions and the policies of governments in the South (see D. Storey, Bulloch, \& Overton, 2005). Despite shifts in the mode of development being adopted by institutions and governments, there appears to be agreement among many, that economic and market-oriented principles are necessary for social development. To overcome this focus on economic growth, many other practitioners and ideologists have explored "place-based" approaches that highlight cultural differences and local knowledge (Escobar, 1992).

This chapter seeks to explore the concepts found in post-development and social entrepreneurship literature, which could form an approach to the pursuit of development possibilities that is not limited by the dominant economic framework. The first section reviews the arguments around post-development theory and the potential for applying its constructive insights. The second section examines the social entrepreneurship movement and the techniques it has to offer in tackling social development issues. Based on the understanding of the literature, it is suggested that there is potential to explore whether social entrepreneurship could be an approach that differs from market-based development practices and how post-development ideas can be applied through social entrepreneurship.

\subsection{Post-development theory}

The failure of the development agenda to deliver on its promises has been critiqued by many. Mainstream approaches have attracted criticism from those who argue for a more 'people-centred' development instead of a 'growth-centred' one 
(Thomas, 2000). The advocates of 'alternative development' promote a focus on basic needs and creating a development process that is 'bottom-up' instead of 'top-down' (Pieterse, 1998). The concern is that the perceived trickle-down or redistribution effect of economic growth was not happening. Instead of a market or state led approach, the perceived alternative is that development activities are initiated by those at the grassroots to ensure that their needs are being addressed (Pieterse, 1998). In addition, there is emphasis on indigenous knowledge, sustainable or environmentally sound practices, and inclusiveness (Pieterse, 1998; Thomas, 2000). However, the boundary between alternative and mainstream development has become unclear since most of the ideas espoused by alternative development have been adopted by the mainstream (Pieterse, 1998). This reflects alternative development's critique of the methods employed by mainstream development, rather than directly challenging the general development agenda (Pieterse, 1998).

In contrast, post-structural critiques question the desirability of development itself (Escobar, 2000). Linked to several key authors such as Arturo Escobar, Gustavo Esteva, James Ferguson, Majid Rahnema, and Wolfgang Sachs, post-development thought as it came to be known, claims that not only has development failed to fulfil its promises, it has caused the violent destruction of cultures and societies across the 'Third World' (McGregor, 2009). Although post-development ideas are diverse (Pieterse, 1998; Ziai, 2007), some key themes emerge: critiquing development as a hegemonic process; dismantling the development discourse; and seeking 'alternatives to' development (Escobar, 2007).

\subsubsection{Development as a Hegemonic Process}

As mentioned, post-development not only points out the failures of development but emphasizes the loss of cultural diversity brought about by development due to its 
ethnocentric nature. Wolfgang Sachs contends, "From the start, development's hidden agenda was nothing else than the Westernization of the world. [...] The standardization of desires and dreams occurs deep down in the subconscious of societies" (Sachs, 1992, pp. 3-4). Development is critiqued as a neo-colonial mechanism, which the United States and Western Europe instigated in order to control the perceived 'underdevelopment' in the 'Third World' (Peet, 1999). The emergence of the development agenda and what it entailed is often traced to the inauguration speech given by Harry S. Truman on 20 January 1949 (see Esteva, 1992; Latouche, 1993; Sachs, 1992). The populations of the 'Third World' were depicted as being in a state of backwardness and thereby needing assistance in the form of modern industry and scientific technology (Esteva, 1992). These are the instruments that brought about the prosperity being enjoyed by the Western world and it was believed that the same could be achieved by all (Latouche, 1993). However, traditional values and practices had to be discarded in order to obtain this prosperity (Latouche, 1993). Thus, development's 'pre-packaged solutions' based on Western values of material consumption and commodification were transferred to the 'Third World' (Illich, 1997, p. 95).

The spread of development ideals that emphasized economic wealth also changed the way that people in the 'Third World' viewed their own lifestyle. Poverty and underdevelopment came into being as peoples and places were imparted with the notion that their existence should be something more (N'Dione, de Leener, Perier, Ndiaye, \& Jacolin, 1997). Ivan Illich describes this condition as "a result of [...] reification, the hardening of the perception of real needs into the demand for mass manufactured products" (Illich, 1997, p. 97). Satisfying the needs of the majority was converted into a yearning for commodities and services that they cannot obtain (Illich, 
1997). Hence, poverty and underdevelopment remain due to the demand brought about by development, for consumption and accumulation of goods (N'Dione, et al., 1997).

Post-development writers illustrate that the development project has homogenized the cultures of the 'Third World' by declaring them as 'underdeveloped', hence obscuring the differences between and within these societies (Escobar, 1997). Moreover, development defined on Western standards created the state of 'underdevelopment' in the rest of the world, forming a consciousness that yearned for the very same standards. This 'colonising of the mind' (Rahnema, 1992) is captured by Nanda Shrestha (1995) when recounting his experience of development in Nepal:

\footnotetext{
"So, poor and hungry I certainly was. But underdeveloped? I never thoughtnor did anybody else - that being poor meant being 'underdeveloped' and lacking human dignity. (p. 268)
}

[...] North Atlantic consumer culture penetrated, unchecked, every nook and corner of Nepal, rapidly generating previously non-existent wants and hence scarcities, a situation which only aggravated poverty. (p.272)

The colonial 'civilizing mission' was resurrected as the mission of development." (p. 274) - (Shrestha, 1995)

\subsubsection{Dismantling the Development Discourse}

Related to the critique of development as a hegemonic process, post-development writers further demonstrate that development is a historical discourse that produced a particular reality in the 'Third World' (Escobar, 2000). Drawing from post-structural tools of analysis, they reveal the legitimizing power found within the language and knowledge of development discourses. Part of this is the classification of peoples and places in the 'Third World' as 'underdeveloped', which was discussed above. In addition, the use of statistical data such as GNP per capita to describe these populations 
further constructed the reality of hierarchies of development (Latouche, 1997), which was to be remedied by economic growth through industrialization and modernizationthe first prescribed model of development (Escobar, 1997). This was institutionalized through the establishment of various organizations such as the World Bank and the various UN institutions, whose purpose was to manage the development agenda in the 'Third World' (Escobar, 2007). Escobar identifies "the professionalization of development problems, which included the emergence of expert knowledges and fields to deal with every aspect of 'under-development'" (2007, p.19), as a key normalizing factor. The discourse of development therefore dictated how these countries were to proceed through these experts and institutions. They determined the 'problems' and 'needs' of 'underdeveloped' areas, prescribed solutions and implemented development projects (Escobar, 1997). Ironically, the development discourse gave weight to the knowledge of professionals, thus dismissing the 'knowledge, voices, and concerns' of those it sought to help (Escobar, 2007). Consequently, a view of the world wherein there are 'underdeveloped' areas that need assistance from experts outside of their own society was accepted as a reality.

Post-development also highlights the way in which the development discourse has de-politicized development. The answer to social problems and needs came in the form of technical inputs that were designed by development experts who believed they could plan and manage the way that societies progress (Escobar, 1997). This disposition undermines the capacity of each society to determine and initiate social change based on their own traditions and experiences (Escobar, 1997). However, Nustad (2007), points out that development practitioners' preference for technical solutions may not necessarily be due to their insensitivity towards local cultures and context. They are often faced with the challenge of creating feasible plans given limitations such as 
timelines and budgets that are imposed by their own organisations or donors, which leads them to create and implement simplified projects (Nustad, 2007). However, these limitations can still be considered as consequences of the way development is constructed - as an apolitical process that could be managed and controlled.

Post-development does not only critique the shortcomings of development but it seeks to reveal how development constructed a reality wherein a modern, technocratic, and consumerist way of life should be favoured over other or different means of existence. It challenges the belief that development is good and desirable. What is proposed therefore, is 'to change the practices of knowing and doing' and discover possibilities for creating different discourses that are remote from the development discourse (Escobar, 2007, p. 21). Examples of which can be found in social and grassroots movements (Esteva \& Prakash, 1997) or the informal sector (Latouche, 1993). Before proceeding to explore these ideas of 'alternatives to development', I will provide an overview of the responses to post-development, which provide insights on what could be done next.

\subsubsection{Critiques of Post-Development}

Firstly, critics comment on how post-development portrays the practice of development as homogenous and continually associates it with modernization theory (see Kiely, 1999; Pieterse, 2000). The claim that development is nothing more than the 'Westernization of the world' (Sachs, 1992) is problematic since it implies that “[development's] effects will be similar throughout the world" (Kiely, 1999, p. 38). However, after years of encountering development, significant differences exist between countries in the 'Third World' (Kiely, 1999). In addition, Nederveen Pieterse (1998) contends that post-development's view of development ignores the multifaceted ways in 
which it is practiced on the ground. "Many popular organizations are concerned with access to development, with inclusion and participation, while others are concerned with renegotiating development, or with devolution and decentralization" (Pieterse, 1998, p. 363, emphasis in original). Likewise, Frans Schuurman (1993) argues that social movements in the South, which are viewed as a rejection of modernity, cannot be interpreted as such and these social movements are actually expressions of the need to access modernity. Citing social movements in Chile such as trade unions and the pobladores movement, he contends that these actors are aspiring for participation in the political and socio-economic system so that they can influence government decisions. In other words, they are concerned with democracy and access to welfare, which are part of modernity (Schuurman, 1993).

Secondly, post-development seems to portray development practitioners as being governed by external factors of which they have little control (Lie, 2008). However, in his research of the development field, Lie (2008, p. 119) found that "actors were perfectly aware of what they were doing and acknowledged both the internal and external limitations to what they were trying to achieve". Moreover, local development practitioners who act as mediators between donors and recipients, can have significant influence in the way that external development discourses are interpreted and implemented locally (Lie, 2008). In relation to this, Kiely points out how postdevelopment also has a tendency to depict those in the 'Third World' as inactive subjects. He argues that different localities have the agency to interpret and 'indigenise' the idea of development (1999, p. 48).

Another point of criticism towards post-development is that it 'romanticizes' traditional cultures and communities and takes on an 'uncritical' relativist position (Ziai, 2007). There is a danger that this 'celebration of tradition' ignores and reinforces the 
conflicts and structures of oppression already present in traditional communities (Kiely, 1999). The idealistic representation of pre-modern societies also downplays the struggle of these societies against 'debt, poverty, famine and hunger', which could be due to the lack of development rather than because of it (Corbridge, 1998; Kiely, 1999). In addition, the focus on the negative consequences of development and modernity does not consider the relatively successful experience of some countries such as the NICs of East Asia (Pieterse, 2000), or the way modern science and development has contributed to achievements in health such as increasing life expectancy (Corbridge, 1998).

As mentioned above, local communities could very well be claiming their rights to development and have a desire for it (De Vries, 2007; A. Storey, 2000) What happens then for these people that are struggling with the problems of poverty? The question of 'what comes after post-development?' is a considerable point of contention for criticsPieterse (2000, p. 187) charges post-development as "being directionless in the end, as a consequence of its refusal to, or lack of interest in, translating critique into construction", while Kiely (1999, pp. 45-46) uses the term 'Pontius Pilate politics' to describe postdevelopment's support for any grassroots movement as being "so open-ended and vague that it effectively washes its hands of politics". Thus, post-development's strength lies in its compelling analysis of the development discourse but it is unsuccessful in providing concrete 'models of social change' (A. Storey, 2000). This claim is further considered in the following section.

\subsubsection{Alternatives to Development}

Post-development practice and 'alternative development' seem similar, particularly in their preference for grassroots movements and local or indigenous knowledge. However, post-development writers are concerned with the search for 
'alternatives to development' and not 'alternative development' since the latter is still rooted in the meta-discourse of development. According to Serge Latouche:

"Development has been and still is primarily an uprooting. [...] enunciating 'good development' will unfortunately not prevent the techno-economic dynamism relayed by the national authorities and by most NGOs from uprooting people and plunging them into the dereliction of shantytowns" (1993, p. 160)

It was mentioned beforehand that much alternative development has been absorbed into mainstream development practices. Its principles are now part of the rhetoric of international development institutions as illustrated by the terms 'inclusive growth' and 'sustainable development'. Latouche also demonstrates how three tenets of alternative development - self-sufficiency, basic needs, and appropriate technologies, have become problematic in practice (see 1993, pp. 161-184). He argues that these are still products of Western ideas, and in the end the use of these terms in development policies is vague. For instance, the problem with appropriate technologies is that these technologies are said to fulfil needs but whose needs and how these are determined, remain unclear (Latouche, 1993). In addition, this does not break away from the technocratic approach and economic logic of development. For Latouche, alternatives to development can be illustrated by 'informal communities' that have found truly creative ways of dealing with the problems that development has failed to (and cannot) solve. The informal is composed of "people torn between lost tradition and impossible modernity" (Latouche, 1993, p. 134), who survive through 'novel solutions' that are beyond Western economic logic. The activities of the informal cannot be reduced to 'economic rationality' alone since these operate within a system of social relationships that sustain not only livelihoods but also community solidarity (Latouche, 1993). This case of the informal 
and the relationship between economic and social activities within communities demonstrates non-development practices, or post-development initiatives, at the local scale.

Conversely, Esteva and Prakash (1997) advocate 'thinking and acting locally' when it comes to addressing needs. They cite grassroots Community Supported Agriculture (CSA) to illustrate how local initiatives can make a difference in issues that are deemed to be best tackled by 'global thinking'. "It (CSA) involves urban consumers supporting small local farmers who farm with wisdom and care for local soils, waters and intestines [while] simultaneously ensuring that unknown farmers from far-away places $[\ldots]$ are not exploited with inhuman wages and left sick with cancer or infertility" (Esteva \& Prakash, 1997, pp. 280-281). Again this shows that examples of endogenous social change initiatives exist.

It is difficult to imagine a world without development for what it entails could produce even more adverse effects for those who are already disadvantaged. And as previously mentioned, there are peoples and communities who have a real desire for what development has promised (De Vries, 2007). Escobar asks the following question which could be a starting point in terms of reconciling post-development thought with the possibility of achieving development goals: "How could the very development apparatus be used to cultivate subjects of diverse developments and diverse modernities?" (2007, p. 25, emphasis in original). Several empirical post-development researchers provide ideas towards answering this question. Rather than focusing on the failures, there is an attempt to turn the criticisms into positive means that convey 'hope and possibility' (McGregor, 2009).

This search for possibilities led Gibson-Graham (2005) to an action research project in the Municipality of Jagna, Philippines wherein they proposed the concept of a 
'diverse economy' as an alternative to the dominant capitalist economy. They started by designing an 'assets map' as opposed to the more traditional 'needs map' used by local planners when preparing local development plans (see Gibson-Graham, 2005, pp. 1011). The community's 'diverse economy' shows various socio-economic activities and relationships that do not necessarily follow a capitalist pattern, which is defined by "production by wage labour of commodities for the market within enterprises that privately appropriate surplus from workers" (Gibson-Graham, 2005, p. 13). The complex relationships and traditional practices are emphasized as having significant functions in maintaining the welfare of the community, which is similar to Latouche's description of the informal. By highlighting the strengths of the community instead of defining it by what it lacked, they revealed opportunities for the community's development that does not depend on a capitalist economy. Specifically, they worked with members of the community; the municipal government; and a local NGO, Unlad Kabayan Migrant Services Foundation, Inc., in identifying locally based enterprises that can build on the existing diverse community economy. Remittances from Overseas Contract Workers (OCWs) were seen as possible sources of funds for the enterprises. A critical insight conveyed by the researchers is that, the success of the enterprises may be uncertain but what is important is that this process originated from the community and not from "a model taken from the shelf of an aid agency, government bureaucracy, or university" (Gibson-Graham, 2005, p. 19). The focus on positive aspects and strengths enabled the community to mobilize and initiate their own development efforts.

Michelle Carnegie (2008) adopted the diverse economy approach in her study of livelihoods and development opportunities in the Oelua village of East Indonesia. She found that a range of economic transactions were non-capitalist in nature and these are the predominant sources for sustaining daily life in the community. Again, by 
highlighting the significant non-capitalist, and mostly informal livelihood activities, nonconventional development processes that are meaningful for the people of the community emerge. For Carnegie, one way forward for development actors in the region is to provide support for these existing practices instead of being limited by capitalist oriented strategies. The diverse economy framework illustrates how postdevelopment ideas can be applied by taking the focus away from capitalist centred activities; thereby transforming the way development is practiced.

George Curry (2005b) has a similar position when it comes to making changes to mainstream development, however he is not necessarily against capitalist development. He argues that a slightly 'anti-capitalist stance', limits development opportunities that can be achieved by adapting capitalist development for 'non-capitalist ends' (Curry, 2005b, p. 127). In his own research, Curry draws from the social embeddedness literature to demonstrate that economic or market transactions often have non-market or more social significance (see Curry, 2003, 2005a). In a case study involving Papua New Guineans engaged in smallholder oil palm production for Multinational Corporations (MNCs), Curry (2003) discovered that traditional 'place-based' practices of gift exchange exist despite wide participation in capitalist production. This challenges the notion that capitalist forms of development would lead to the destruction of indigenous cultures and non-capitalist modes of production (Curry, 2003). The smallholder settlers living in land settlement schemes (LSSs) for oil palm production were expected to become an, 'indigenous entrepreneurial class' that would favor the transactions of the cash economy over previous cultural practices (Curry, 2003). However, participation in oil palm production had a different effect than was expected- "an alternative modernity has developed in which indigenous exchange remains important, but cash has greater significance than in their home areas" (p. 414). The trade stores in the LSSs demonstrate 
the connection between indigenous practices and the cash economy. The cash loans from trade stores were often used for "activities in the indigenous exchange economy [following significant occasions] such as births, marriages, deaths" (p. 416). Loans were repaid in the form of oil palm fruit, which is sometimes made by groups of smallholders who harvest oil palm together. Curry emphasizes that this practice is significant for the formation and maintenance of social relationships. Communal labor practices, together with gift exchange are vital to both individual and community wellbeing (Curry, 2003). Deterioration of social relationships and the inability to participate in exchange traditions can have undesirable effects on the cash economy such as "reduced yields of cash crops like oil palm and the failure of chicken projects, trade stores, and other businesses" (p. 417). This situation shows that capitalist development does not automatically result in the displacement of indigenous practices but can be modified or adapted to serve more social or cultural purposes. Curry suggests that paying close attention on how economic and social relations are intertwined within local communities can help improve development practice. This could lead to approaches that support socio-cultural traditions by altering economic initiatives to suit local priorities (Curry, 2003).

Similarly, Anthony Bebbington's (2000) research among indigenous Quichua in the Andes shows how local places transform, and are being transformed by development. He argues that neither post-development nor neo-liberal theories provide a complete depiction of the changes that have occurred in the region, wherein "alternatives to modern capitalism [are being created] even as they incorporate many ideas, practices, and technologies of modernity" (Bebbington, 2000, p. 496). Through a "comparative ethnographies' approach, Bebbington explores how indigenous peoples and places' strive to "make a living and making it meaningful" (2000, p. 498). He finds that despite changes in livelihood practices, many of which are now tied to a market economy, 
Quichua localities are able to preserve their ethnic identities and manage community affairs independently. For instance, the outmigration of locals from rural areas to urban centres is often viewed as a result of the lack of livelihood opportunities in the countryside, which in turn leads to a decline in indigenous agricultural practices (Bebbington, 2000). Contrary to this view, Bebbington learns that in the canton of Colta, outmigration provides a means for the locals to invest in their own households and the community. It enabled the residents to continue their agricultural practices and to organize community associations that promote local governance. On the other hand, the canton of Guamote has experienced various development interventions initiated by the state, the Catholic Church, and NGOs. While these interventions may have served the interests of groups other than the local community, these also resulted in the transfer of control from the haciendas to community-based federations that serve as the "implementing arms of the municipal development policy" (p. 507). Lastly, in Otavalo, the emergence of textile weaving enterprises allowed the Quichuas to engage both in weaving and farming since there was no need to migrate to find other means of livelihood (Bebbington, 2000). These market-oriented enterprises contributed to a vigorous economy and also influenced changes in local politics - "early leaders in [indigenous federations] came from relatively prosperous families" (p. 509). Bebbington notes that, although these changes did not necessarily come about smoothly due to different interest groups, they have resulted in a more inclusive development process that is determined by the locals themselves. The comparative look into these three localities shows that development initiatives, even those linked to the market are not always destructive and that accumulation is not necessarily incompatible with indigenous concerns. Moreover, in these cases, the development process has lead to more empowered communities that are striving for self-governance. As Bebbington proposes, 
there is a need to change the way development is viewed and practiced to acknowledge how peoples' actions and responses can influence the outcomes of development interventions.

The preceding studies illustrate the potential for ways in which post-development thought could become more relevant. Unlike earlier post-development writing, a rejectionist position is replaced with the search for more positive possibilities (McGregor, 2009). There is acknowledgement that mainstream development practices need to be improved but development is not viewed as an endeavour that inevitably leads to loss of traditions and cultural practices in local communities. A more careful and open-minded look into different local situations reveal that peoples and communities are finding unique ways to improve their daily life based on what is significant for them. In some cases, 'modern' development objectives such as housing improvements or increased incomes are being pursued alongside indigenous or local practices that preserve cultural identities and community cohesion. Ziai (2007) notes that postdevelopment writers such as Escobar imply a constructivist understanding of culturetraditions and culture are not static but undergo changes based on the practices and behaviour of societies. These shifting cultural definitions include the meaning of development and what constitutes a good life. It is vital to understand how these changes are contested and determined by different peoples and places so that development can be empowering and locally relevant rather than violent and destructive. It could be suggested that, 'alternatives to development' include those approaches that acknowledge and emphasize the ability of peoples and places to influence and determine development goals, processes, and outcomes, through their actions rather than seeing them as passive subjects of development. Moreover, unlike 'alternative development', truly alternative pathways can be more open-ended rather than leading to pre-determined outcomes, by 
being aware of the power of knowledge and discourse. Mainstream development practice can be changed by shifting the power from the development professionals to those whose 'voices, knowledge, and concerns' have been previously lost or assumed. The next section looks into an emerging social movement that seems to promote postdevelopment ideals of local self-determination. Social entrepreneurship is described by Paola Grenier (2006, p. 139) as "ethical economic activity, where social and economic goals are pursued simultaneously", which seems similar with the concept of place-based and community economies.

\subsection{Social Entrepreneurship}

The above discussions and search for opportunities, raise questions about the possible role of the private sector or business in pursuing post-development goals. Business endeavours have been associated more with neo-liberal policies that promote the growth of the private sector through foreign direct investment (FDI). This can lead to economic growth, which as previously mentioned, is seen as vital to wider development policies. Redistribution is implemented through taxes that the government can utilize to provide welfare services for the poor (Gold, 2003). On the other hand, neo-liberal policies also encourage the privatization of some public services, which can produce negative consequences for the poor. For instance, if the provision of basic services such as healthcare is transferred to private enterprises that charge user fees, the poor may no longer be able to avail of these services.

Despite the doubt and criticisms directed towards private sector participation in pro-poor interventions, there are still attempts by businesses to become involved. Corporate Social Responsibility (CSR), in particular is becoming more popular among local businesses and Multinational Corporations (MNCs). CSR usually involves corporations considering the ethical, social, and environmental implications of business 
practices, as well as producing social value for communities (Contreras, 2004). There is also emphasis on forming partnerships with governments and other civil society organisations (Contreras, 2004). This relationship has come to be known as publicprivate partnerships (PPPs). A major progression in this movement is the Global Compact initiated by the UN in 2000. The Global Compact is a voluntary-based approach to CSR that brings together the aforementioned actors to engage in dialogue and share information regarding solutions to development issues, particularly those brought about by globalization (Soederberg, 2007).

The Compact has been met with the criticism that once again neo-liberal interests are at the forefront and the social interests of NGOs and grassroots organizations are being co-opted into the neo-liberal agenda (Soederberg, 2007). Moreover, it is doubtful whether this kind of partnership is truly an equal one given the size of MNCs and their relative power on a global scale (Gold, 2003). Hence, the possibility for businesses to actually 'do good' is far from guaranteed. Yet there are still a number of organisations and individuals who are finding ways to combine the 'profit motive' of business with 'social motives'. These 'social entrepreneurs' are often described as innovative and creative in the way they address social issues. The following discussion looks into the ideas found in the emerging field of Social Entrepreneurship and how these can provide new ideas for development alternatives.

\subsubsection{Defining Social Entrepreneurship}

Finding a precise definition of social entrepreneurship is challenging despite the growing literature dedicated to the topic. It is a relatively new concept and many authors have sought for a more precise definition (see J. Austin, Stevenson, \& Wei-Skillern, 2006; Haugh, 2006a; Mair \& Marti, 2006; Peredo \& McLean, 2006; J. L. Thompson, 
2008). Part of the difficulty comes from the incidence of 'working definitions' used by several authors in light of their own research (see Fowler, 2000; Mair \& Noboa, 2006; Perrini \& Vurro, 2006; J. Robinson, 2006). In addition, there is a question of whether social entrepreneurship should be a separate field from traditional entrepreneurial studies.

Attempts at clarifying the concept often examine the two elements involved, the social component and the entrepreneurial component. One of the earliest writings aimed at providing a definition for the term comes from J. Gregory Dees, who admitted that social entrepreneurship "means different things to different people" (1998, p. 1). He points out that the use of the concept to describe a range of activities from the integration of social responsibility in business operations; to non-profit organizations engaging in earned-income activities; to just about any non-profit, is a source of confusion. In order to lessen the confusion, Dees proposed that social entrepreneurs are "one species in the genus entrepreneur" (1998, p. 3).

Accordingly, he starts out by reviewing both earlier definitions of entrepreneurship and more recent theoretical study to distinguish the characteristics of business entrepreneurs, before focusing on social entrepreneurs. He credits two economists - Jean Baptiste Say and Joseph Schumpeter as pioneers of the description of entrepreneurs as: "innovators that create economic value by changing or developing different aspects of the production and consumption process' (Dees, 1998). He notes that current interpretations still make use of this definition while adding other characteristics. For instance, Peter Drucker adds the element of opportunity and emphasizes that entrepreneurs do not necessarily need to create change as much as recognize and exploit the opportunities that changes bring. On the other hand, Howard Stevenson views entrepreneurs as resourceful individuals that are not limited by what is available to them 
(Dees, 1998). The abovementioned characteristics form the basis of Dees' definition of social entrepreneurs: "change agents [who] adopt a mission to create social value by pursuing opportunities to fulfil that mission; engaging in continuous innovation; and taking risks without being limited by available resources" (1998, p. 4). In addition, he stressed that social entrepreneurs have a "heightened sense of accountability" towards those that they aim to serve. This interpretation of social entrepreneurship as distinct from traditional entrepreneurship due to an explicit social mission can be found throughout the literature (see Defourny, 2001; Mair \& Seelos, 2005; Nicholls \& Cho, 2006; Smith \& Barr, 2007; Weerawardena \& Mort, 2006).

Despite calls for a more bounded definition, there are some who recommend definitions that will not limit future research, given that social entrepreneurship is a relatively new field. Peredo and McLean (2006) propose that the characteristics conferred on social entrepreneurs need to be more flexible to accommodate the range of social entrepreneurship ventures. They found that most authors' description, including Dees', focus on the positive characteristics, which indicate that entrepreneurs are highly successful individuals. This limits the understanding of entrepreneurial initiatives since there are certainly examples of unsuccessful entrepreneurs (Peredo \& McLean, 2006). They suggest that a definition of the entrepreneurial component of social entrepreneurship should be able to accommodate those social entrepreneurs that may veer away from the ideal description of an entrepreneur. When it comes to the social component, Peredo and McLean identified the level of priority given to the social mission as a point of contention in social entrepreneurship literature. Most authors favour purely non-profit ventures that have exclusively social goals, while there are some who still consider ventures that have both social and profit-oriented goals as social enterprises. In this regard, Peredo and McLean came up with a 'range of social 
entrepreneurship' (see Table 2.3.1) that shows the relative priority of social goals and the possible role of profitable activities. Thus social entrepreneurship is being applied when individuals or groups who possess the characteristics of traditional entrepreneurs aim to produce social value, either exclusively or as a priority (Peredo \& McLean, 2006). However, they maintain that there are still no standards by which social entrepreneurship initiatives could be gauged against.

Table 2.3.1

The Range of Social Entrepreneurship

\begin{tabular}{|c|c|c|}
\hline Place of Social Goods & Role of Commercial Exchange & Example \\
\hline $\begin{array}{l}\text { Enterprise goals are } \\
\text { exclusively social }\end{array}$ & No commercial exchange & NGOs \\
\hline $\begin{array}{l}\text { Enterprise goals are } \\
\text { exclusively social }\end{array}$ & $\begin{array}{l}\text { Some commercial exchange, } \\
\text { any profits directly to social } \\
\text { benefit (integrated) or in } \\
\text { support of enterprise } \\
\text { (complementary) }\end{array}$ & $\begin{array}{r}\text { Grameen Bank (integrated); } \\
\text { Bangladesh Rural } \\
\text { Advancement Committee } \\
\text { printing press, cold storage, } \\
\text { garment factory } \\
\text { (complementary) }\end{array}$ \\
\hline $\begin{array}{l}\text { Enterprise goals are chiefly } \\
\text { social, but not exclusively }\end{array}$ & $\begin{array}{l}\text { Commercial exchange; profits } \\
\text { in part to benefit } \\
\text { entrepreneur } \\
\text { supporters }\end{array}$ & Ciudad Salud ("Healthy City”) \\
\hline $\begin{array}{l}\text { Social goals are prominent } \\
\text { among other goals of the } \\
\text { enterprise }\end{array}$ & $\begin{array}{l}\text { Commercial exchange; profit- } \\
\text { making to entrepreneur and } \\
\text { others is strong objective }\end{array}$ & Ben \& Jerrys \\
\hline $\begin{array}{l}\text { Social goals are among the } \\
\text { goals of the enterprise, but } \\
\text { subordinate to others }\end{array}$ & $\begin{array}{l}\text { Commercial exchange; profit- } \\
\text { making to entrepreneur and } \\
\text { others is prominent or prime } \\
\text { objective }\end{array}$ & $\begin{array}{r}\text { 'Cause branding'; social } \\
\text { objectives undertaken by } \\
\text { corporations }\end{array}$ \\
\hline
\end{tabular}

Source: (Peredo \& McLean, 2006, p. 63)

Similarly, Mair and Marti (2006) state that the social aspect in social entrepreneurship can be quite ambiguous, but they argue against interpretations that view social entrepreneurship as purely altruistic endeavours. Moreover they point out that business enterprises also have social contributions in terms of opening up new markets and job creation. On their examination of three social entrepreneurship cases, they found the following similarity, which may be a distinct feature of social entrepreneurs: "all 
three creatively combine resources-resources that often they themselves do not possess - to address a social problem and thereby alter existing social structures" (Mair \& Marti, 2006, p. 38). The first part reflects previous descriptions of entrepreneurs while the latter part adds a new dimension to understanding social entrepreneurship. It goes beyond the idea of social value creation and considers the wider impact of social entrepreneurship initiatives. They believe future research needs to shift from investigating the qualities of social entrepreneurs towards analysing the different activities that are essential to the social entrepreneurship process (Mair \& Marti, 2006). They encourage exploring different fields and theories that can be used as frameworks to broaden the research agenda for social entrepreneurship.

As indicated above, social entrepreneurship can take on different organizational forms. Jacques Defourny traces the emergence of social enterprises to the increase of what he calls the 'third sector' - "socio-economic activities which belong neither to the traditional for-profit sector nor to the public sector" $(2001$, p. 1). He cites the retreat of the welfare state in industrialised countries, and the limitations of transferring state responsibilities to for-profit business entities as reasons for this development. Two general manifestations of the third sector provide a basis for Defourny's analysis of social entrepreneurship ventures - the social economy and non-profit organizations. The social economy is composed of cooperatives, mutual societies and associations that prioritize the wellbeing of community members over profits. Likewise, the non-profit sector consists of private entities that are self-governing and involve voluntary contributions of money and/or manpower (Defourny, 2001).

According to Defourny, social enterprises can be thought of as belonging to the sphere of the third sector, and they "combine elements of cooperatives and non-profit organizations" (2001, p. 10). Social enterprises are similar to cooperatives in that they 
are not necessarily non-profit, but any surplus generated is reinvested to further the organization's mission or to benefit the larger community, not just those who are part of the organization itself. Yet the resources available to or collected by social enterprises are often a combination of commercial resources and voluntary contributions, the latter of which is more characteristic of non-profit organizations. Defourny's description reflects Peredo and McLean's (2006) range of social entrepreneurship activities, wherein social enterprises may or may not produce profits provided that the social mission takes precedence over profit maximization.

Social entrepreneurship is also viewed as a more sustainable means of providing services or development initiatives. For Fowler (2000), social entrepreneurship could be an alternative option for Non-Government Development Organizations (NGDOs) that have been previously dependent on aid. This dependence on aid limits the type of activities that NGDOs can pursue, which can lead to a loss of legitimacy among its citizens (Fowler, 2000). He comes up with three types of social entrepreneurship initiatives that NGDOs can pursue: integrated social entrepreneurship; reinterpretation; and complementary social entrepreneurship. He describes 'integrated social entrepreneurship' as having "surplus generating activities [that] simultaneously create social benefits" (p. 645), while 're-interpretation' is when NGDOs' "build on and creatively apply their existing activities in ways that reduce costs and/or increase and diversify incomes" (p. 646). Lastly, 'complementary social entrepreneurship' is when a separate enterprise or entity that does not have a social purpose is set-up to crosssubsidize the development activities of the original organization (Fowler, 2000). This account is comparable to Defourny's in that profit generation is a means to support the social goals or activities of the organization instead of an end itself. Hence, this lessens 
the dependence on aid or external resources and NGDOs can have the freedom to choose or implement interventions that fit their goals or those of their constituents.

While the theoretical underpinning of social entrepreneurship needs to be further developed, most of the descriptions above indicate that existing initiatives can be categorized as social entrepreneurship. Conversely, exploring these practical experiences can be useful in trying to have a deeper understanding of the foundations of the concepts and their applicability to development and post-development thinking.

\subsubsection{Social Entrepreneurship in Practice}

Based on the previous discussion, social entrepreneurship initiatives can be nonprofits or a type of non-profit/for-profit hybrid. Innovative solutions and resourcefulness are the qualities that set them apart. An organization that is often cited as a successful social enterprise, and its founder a successful social entrepreneur, is the Grameen Bank in Bangladesh (see Fowler, 2000; Mair \& Seelos, 2005; Peredo \& McLean, 2006). The Grameen Bank started through an action research project initiated by Professor Muhammad Yunus, to explore a system of providing credit services for the rural poor (Grameen Communications, 1998a). Through this initiative, Professor Yunus changed the view that 'the poor are not bankable'. Access to financial services provided by conventional commercial banks usually requires collateral, minimum deposits or other similar assets that a majority of those living in rural areas do not have. Grameen Bank's methodology focuses on what the people of the community have instead of what they do not have. Collateral is not needed to get a loan, but groups of five are formed to build on and strengthen the mutual trust and accountability among members (Grameen Communications, 1998e). Unlike commercial banks, Grameen prioritizes the poorest of the poor and majority of its members are women. Again, innovation is a key 
characteristic of social entrepreneurship and the Grameen Bank demonstrates this through their unique delivery system that ensures repayment of loans despite not requiring collateral. The system, which is designed to fit the members' situation, replaces collateral with conditions such as weekly repayment of small loans; compulsory and voluntary savings; and having an income generating activity (Grameen Communications, 1998b). In addition, if a borrower experiences difficulties in repaying her loan, it can be rescheduled and the interest cannot exceed the premium amount paid.

The overall goal of Grameen Bank is to end the cycle of poverty through the loans and services that they provide. Borrowers use the loans to fund microenterprises they implement themselves. The bank also supports other development projects initiated by the members. Most of these are infrastructure projects such as housing improvements and building of wells and sanitary toilets (Grameen Communications, 1998b). Members are encouraged to adopt the "sixteen decisions", guiding principles pertaining to different aspects of development, including education, health and sanitation, and environmental care. The social mission of the organization is evident from these activities. The bank has been successful with its activities, having a total of 8.07 million borrowers and a loan recovery rate of $96.7 \%$ (Grameen Communications, 1998d). The Grameen Bank is also a concrete example of a social enterprise that has some earned income to support its programme. The deposits from clients and interest from loans are sufficient to fund their operations (Grameen Communications, 1998c). Microfinance institutions have emerged in other countries, replicating the methods introduced by Grameen Bank, thereby institutionalizing microcredit in poorer communities (Martin \& Osberg, 2007). The Grameen Bank demonstrates how a social entrepreneurship initiative can change social structures. 
One of the key features of social entrepreneurs mentioned is that their resources do not hinder them in the pursuit of their goals. Social enterprises like the Grameen Bank have found ways to increase the resources available to them. However, non-profits that do not have earned income activities can also be considered as social entrepreneurship ventures. What is important is that they are creative and their activities are sustainable. In the case of the Barefoot College in India, sustainability means "[any development] initiative must be based in the village as well as managed and owned by those whom it serves" (Barefoot College, 2010a). This unique college started in 1972 when a group of professionals, including founder Bunker Roy, set out to work with rural communities in addressing development needs, such as safe drinking water, education, income generation, and ecological conservation (Barefoot College, 2010d). The innovative idea put forward by the organization is centred on the belief that the people from the communities possess the skills and knowledge needed to improve their quality of life and this should take precedence over external knowledge. The 'Barefoot Professionals' who are trained in the college are men and women who do not possess formal qualifications and are illiterate or semiliterate (Barefoot College, 2010b). The college's approach emphasizes learning by doing through the knowledge that can be gained through interaction in the community. No paper qualifications or degrees are given. Instead the community itself gives recognition when the Barefoot Professionals provide essential services to their villages (Barefoot College, 2010b). The college trains teachers, doctors, midwives, dentists, social engineers, water testers, and community programmers, among others.

Funding for the college and its activities comes from mostly government and international donors. However, the Barefoot Professionals are essentially volunteers who continue to work in the college despite not having any contract (Barefoot College, 
2010b). In addition, "no one at the College earns more than $\$ 150$ a month and the difference between the highest and lowest paid is in not more than 1:2". The principles promoted by the organization such as equality and mutual trust seem to contribute to how they make the most out of their resources. The Barefoot College's achievements include its campus, which was constructed by Barefoot architects and masons, and the only fully solar-powered college in India (The Schwab Foundation for Social Entrepreneurship, 2010). Like the Grameen Bank, Barefoot College's approach has also been replicated in other countries. Villages such as those in Bhutan, Afghanistan, Bolivia, Uganda, and Tanzania now have professionals trained in the Barefoot way (Barefoot College, 2010c).

Based on these two examples, it seems that social entrepreneurship initiatives can contribute to alternative development pathways. It seems that the response to social entrepreneurship has been mostly positive and hopeful. An indication of this is the growth of international organizations such as the Schwab Foundation and Ashoka International being dedicated to providing resources for aspiring social entrepreneurs. However, like post-development, social entrepreneurship has attracted its share of critics.

\subsubsection{Critiques of Social Entrepreneurship}

The lack of a unified 'social entrepreneurship theory' is one of the weak points of this emerging field. Questions of whether it should be a separate field of study from traditional business entrepreneurship indicate that more focus has been given to the entrepreneurship aspect of the concept rather than the social aspect. As can be assumed from the discussion on its definition, social entrepreneurship seems to be the application of entrepreneurial skills and characteristics while adopting a goal or mission that has social relevance. In other words, "the study of Social Entrepreneurship becomes an 
analysis of means oriented towards ends that remain wholly unclear" (Nicholls \& Cho, 2006, p. 105). Nicholls and Cho further assert that any interpretation of social entrepreneurship that does not consider how social objectives are determined, assumes that these objectives remain alike. On the contrary, social interests vary and are usually tied to conflicting ideals or beliefs (Nicholls \& Cho, 2006). Social entrepreneurship seems to be perceived as a method that automatically brings together actors from different sectors in support of certain goals. However, this view could detract from engaging in a process of negotiation when deciding on a 'common good' (Cho, 2006). A truly inclusive process would unavoidably be political due to competing interests. It is important to deliberate on whose interests are really being promoted, and on the possible consequences for others (Nicholls \& Cho, 2006). Thus, social entrepreneurship tends to depoliticize the process of negotiating and resolving the 'social' objectives to be prioritized.

Accounts of social entrepreneurship also have a tendency to focus and commend the characteristics and achievements of individuals. Dees even describes social entrepreneurs as a 'rare breed'. To a great extent, characterization of social entrepreneurs includes "a desire to remake the world in the creator's image, or at least in the image of the utopian vision articulated by the social entrepreneur" (Nicholls \& Cho, 2006, p. 106). It would seem that social entrepreneurs are the only ones with the vision, as well as capability to bring about change. However, just as social objectives can vary, so can the ways in which these objectives are to be achieved. Social entrepreneurship's continued emphasis on the individual brings up questions of whether it is actually based on collaboration (Nicholls \& Cho, 2006). Moreover, it could lead to the disempowerment of possible beneficiaries since it is the few gifted social entrepreneurs who have the control on what actions are needed and to be pursued (Cho, 2006). It can be observed from this 
analysis that there seems to be a contradiction in how social entrepreneurship is conceptualized. On the one hand, it is seen as an approach that inspires partnership among different sectors. Yet it seems that only a few social entrepreneurs can start the process. Based on the practical examples given above, individuals such as Muhammad Yunus and Roy Bunker do have innovative ideas and were able to carry out activities that support these ideas. However, it is also evident that the organizations they have established value cooperation and working with the communities they serve in a participatory manner. In this regard, it would be worthwhile to explore the extent to which social entrepreneurship is a collaborative process and if the title 'social entrepreneur' can be extended to everyone involved in the entire process. As Peredo and McLean's (2006) definition indicates, social entrepreneurship can be carried out by groups as well. Jeffrey Robinson on the other hand, suggests studying social entrepreneurship with an emphasis on the process since "focus on actors alone will lead some to believe that the achievement of social entrepreneurs can only be made by an elite" (2006, p. 97).

Another criticism directed towards social entrepreneurship study is that it continues to be associated with business discourse. This is related to the earlier point that the entrepreneurship aspect is given more focus in the literature. Indeed, most academic articles on social entrepreneurship have been published in business journals and its study is under the business schools of universities such as Stanford and Harvard. Paola Grenier (2006) observes that this could be due to the relative novelty of the field and hence a need to establish legitimacy. She warns however, that this could limit the concept of social entrepreneurship "within ways of thinking and idea which are largely Western" (Grenier, 2006, p. 139). This also points to wider debates of whether neoliberal principles are co-opting various social movements. Dey (2006) contends that the 
rhetoric of social entrepreneurship favours economic rationality and technocratic approaches. As noted above, social entrepreneurship can be expressed through organizations that add an element of income generation. There is an inclination to promote economic activity as the means to gain prosperity. In addition, social entrepreneurship is portrayed "as a rational and technical activity" that can easily lead to the achievement of goals through good business practices (Dey, 2006, p. 130). According to Dey, this assumes that social entrepreneurship is a smooth process that does not encounter conflicts, which is similar to the previous observation that there is a lack of critical analysis of the way social interests are negotiated in social entrepreneurship ventures.

Again there seems to be a disconnect between the literature and actual social entrepreneurship practices. For instance, even though an organization such as the Grameen Bank includes income generation and encourages its borrowers to start microenterprises, it does not focus solely on business solutions. The organization firmly supports other aspects of development as stated in their 'sixteen decisions'. Conversely, the Barefoot College's emphasis on community knowledge differs from the typical depiction of social entrepreneurs as technocratic. A possible area for further examination, particularly for social enterprises that have earned income activities, is how they balance their social goals with a profit motive. Grenier (2006) suggests that social entrepreneurship will be linked more closely to what she calls 'ethical economic activity', wherein social and economic goals are pursued simultaneously.

Social entrepreneurship is an emerging movement that seems to have gained the support of non-profit organizations and the business sector. Broadly defined, the term refers to the use of entrepreneurial skills and characteristics to address different social issues. In addition, social entrepreneurs are often characterised as having the unique 
ability of seeing opportunities where others see problems and crises. The popularity of the approach could also be due to the view that it is financially sustainable since social enterprises seem to refer to non-profit organizations that adopt income-generating activities to support their activities. Recent academic literature also demonstrates an apparent interest in studying the phenomenon and developing a theory around it. Most studies explore the concept in relation to, or using, entrepreneurial or business theories. Given that social entrepreneurship involves addressing social issues, further examination of how it relates to broader studies and debates of social change or development are needed.

\subsection{Conclusion}

The challenge of ending 'underdevelopment' or poverty for the majority of the world's population grows despite the various solutions that have been drawn up. The focus on a so-called globalizing world seems to give weight to neo-liberal principles more and more, and genuine alternatives are becoming less frequent. Several authors have described this as an 'impasse' in development theory (Kiely, 1999). This chapter presented two different concepts that could provide alternative ways to move forward or get past the impasse-post-development theory and social entrepreneurship.

Post-development theory started out as a radical critique of development that rejected the very idea of development. Even before post-development literature emerged, development projects have been criticised for their obvious failure to achieve what they set out to do. Post-development does not only point out these failures but also asserts that development has brought about the destruction of cultures, places and the environment. Using post-structural tools of analysis, post-development writers uncovered the legitimizing power found within the development discourse. This discourse created a 
particular reality wherein an 'underdeveloped Third World' is in need of external development assistance. The diverse cultures that can be found within these nations were categorized as 'traditional' or 'backwards' that had to be transformed in favour of 'Western' ideals of modern development. So-called development experts and professionals were deemed to be the ones capable of providing solutions to the problems of underdevelopment, thereby disregarding indigenous knowledge.

Post-development writers propose opening possibilities for different discourses, starting with grassroots movements, which would replace the dominant development voices. Although post-development gives compelling arguments and other writers sympathize with the sentiments put forward, it has been criticized for many reasons, including not being able to give concrete alternatives. More recent studies on postdevelopment offer possible alternatives. Instead of an outright rejection development, transformation of how it is practiced is proposed. What is shown is that indigenous cultures and modern development are not necessarily incompatible and that local peoples and places find ways to pursue both.

An emerging social movement that may be able to build upon some of the ideas of post-development is social entrepreneurship. Social entrepreneurship is often portrayed as bringing together actors from different sectors of society to come up with innovative solutions to different development issues. There is a focus on opportunities and possibilities that can be found even in difficult situations. Examples of social entrepreneurship endeavours show that development programmes can be sustainable and achievable through local initiatives and ownership. These practices are viewed as being rooted in the socio-economic and cultural circumstances of their communities (Mair \& Marti, 2006), which indicates that there is space for indigenous practices to thrive along with modern economies. Ideally, social entrepreneurship can be an opportunity for 
indigenous communities to engage in the modern economy while maintaining their cultural identities (Anderson, et al., 2006).

Figure 2.4.1

Social Entrepreneurship Spectrum

\section{Social Entrepreneurship}

Promotes self-reliance

Builds communities' capacity

Mobilizes community strengths
Financial sustainability

Profit motivation

Business principles

\section{Neo-liberalism}

While practical cases demonstrate the potential of social entrepreneurship as an approach that is unlike mainstream market-based development practices, social entrepreneurship theory is more closely associated with business studies. Figure 2.4.1 shows which features of social entrepreneurship are linked to either post-development ideals or neoliberal principles. Associating social entrepreneurship with business study heightens the risk that social entrepreneurship will be used to further capitalist and neo-liberal policies. Hence, a critical analysis of social entrepreneurship practices is needed for both present social entrepreneurs and those who are exploring community-based development initiatives. In this regard, post-development thought provides a useful lens for examining social entrepreneurship and determining how truly innovative social entrepreneurship is and whether it is an approach that contributes to diverse and alternative ways. 


\section{CHAPTER 3 \\ Methodology}

\subsection{Introduction}

This chapter describes the methods that were utilized to gather information and explore the research questions. Qualitative research methodology or approaches were utilized for this research. Although quantitative methods can also generate information on the topic, I did not use these, as I did not have access to statistically verifiable or significant data. The purpose of this research is to analyse how social entrepreneurship can be interpreted as an approach to development. An understanding of the subject matter was produced through the perceptions and interpretations of the research participants as well as the researcher's own interpretations. The next section gives a brief discussion on research epistemologies. Next, the qualitative methods used to gather information and the sources of information are described. This will be followed by a brief discussion of the data analysis process. The chapter concludes with ethical considerations and a reflection on the research process.

\subsection{Epistemologies}

Methods of inquiry are part of a wider 'knowledge-building process' with underlying assumptions and beliefs regarding "who can be a knower and what can be known" (Hesse-Biber \& Leavy, 2006, p. 12). These epistemological foundations also establish the validity of knowledge claims by looking into how it is produced (McIntyre, 2005). Research methodologies, which reflect the assumptions of certain epistemologies regarding how knowledge can be obtained, are crucial to the credibility of research findings. Some ways of obtaining knowledge are considered privileged or more valid than others depending on the epistemological belief (McIntyre, 2005). For instance, positivist epistemology differs from interpretive epistemology with regard to beliefs on 
how knowledge should be produced. Positivist epistemology assumes that reality exists outside of the research process and it can be understood by an objective observer (HesseBiber \& Leavy, 2006; Mayoux, 2006). In contrast, interpretive epistemology assumes that meanings are produced through interaction and that the researcher is part of the research process and not an objective observer (Hesse-Biber \& Leavy, 2006). The notion that there is an objective truth 'out there' is dismissed (Stronach, 2005).

Positivist and interpretive epistemologies influence quantitative and qualitative research methodologies, respectively. Quantitative research based on positivism focuses on identifying patterns and proving causation between variables through measurement (Hesse-Biber \& Leavy, 2006). The objective is to generate predictable outcomes and to form scientific laws (Garratt, 2005). In addition, there is an obligation to the researcher to maintain neutrality (Garratt, 2005). The main methods used to gather data in quantitative social science research are surveys and questionnaires, which are analysed statistically (Mayoux, 2006).

While quantitative research is concerned with measurement and proving or falsifying predetermined hypotheses, qualitative research involves understanding subjective interpretations and meanings (Mayoux, 2006). Qualitative research is characterized as emergent rather than predetermined and the research questions may change throughout the research (Creswell, 2003). The interpretive characteristic of qualitative research also means that the researcher will bring their interpretation of the information and draw conclusions from these (Creswell, 2003). Some of the methods used in gathering data for qualitative research are interviews, observation, document analysis, and field notes (Mayoux, 2006). The focus is on "building of descriptive, exploratory, and explanatory knowledge" by both the researcher and research subjects (Hesse-Biber \& Leavy, 2006, p. 15). 


\subsection{Methods and Data Sources}

There were two main sources of data for the research-secondary data sources and primary data from interviews and observation.

\subsubsection{Secondary Data Sources}

Prior to the conduct of fieldwork, secondary information was collected from Philippine newspapers, the websites of institutions and organizations involved in social entrepreneurship in the Philippines (see Table 3.3.1), websites of selected social enterprises in the Philippines, and existing case studies. The gathered information was used in forming a general overview of social entrepreneurship in the Philippines and the latest developments in the industry. Together with the literature review, the secondary data was used to understand how social entrepreneurship emerged as an approach to development practice in the Philippines and to identify features that describe social enterprises in the Philippines, which are discussed in Chapter 4.

Table 3.3.1

Information Sources on Social Entrepreneurship Activities in the Philippines

\begin{tabular}{||l|l|l|}
\hline \multicolumn{1}{|c|}{$\begin{array}{c}\text { Institution/ } \\
\text { Organization } \\
\text { Name }\end{array}$} & \multicolumn{1}{|c|}{ Description } & \multicolumn{1}{c|}{ URL } \\
\hline $\begin{array}{l}\text { Ateneo de Manila } \\
\text { University }\end{array}$ & $\begin{array}{l}\text { Offers several training } \\
\text { programmes on social } \\
\text { entrepreneurship. }\end{array}$ & $\begin{array}{l}\text { http://www.admu.edu.ph (Accessed March } \\
\text { 2010) }\end{array}$ \\
\hline $\begin{array}{l}\text { Philippine Social } \\
\text { Enterprise } \\
\text { Network }\end{array}$ & $\begin{array}{l}\text { A network organization } \\
\text { for social enterprises that } \\
\text { provides capacity- } \\
\text { building services for their } \\
\text { members. }\end{array}$ & $\begin{array}{l}\text { http://www.philsocialenterprisenetwork.com } \\
\text { (Accessed March 2010) }\end{array}$ \\
\hline $\begin{array}{l}\text { Institute for Social } \\
\text { Entrepreneurship } \\
\text { in Asia }\end{array}$ & $\begin{array}{l}\text { A learning and action } \\
\text { network which serves as } \\
\text { a resource and } \\
\text { knowledge base on social } \\
\text { entrepreneurship. }\end{array}$ & http://isea-group.net (Accessed April 2010) \\
\hline $\begin{array}{l}\text { Ashoka } \\
\text { Philippines }\end{array}$ & $\begin{array}{l}\text { Provides financial and } \\
\text { network support to } \\
\text { individual social } \\
\text { entrepreneurs. }\end{array}$ & $\begin{array}{l}\text { http://philippines.ashoka.org (Accessed April } \\
\text { 2010) }\end{array}$ \\
\hline
\end{tabular}


This also helped me in identifying, which aspects of social entrepreneurship I wished to explore further in my own case study, and to analyse through a post-development lens.

\subsubsection{Primary Data Sources}

In order to gain an in-depth understanding of social entrepreneurship, a case study of a social enterprise was conducted. A case study is appropriate for investigating context-dependent or complex situations (Yin, 2003). To select a case for the research, four organizations were identified and communication was sent through e-mail regarding their possible participation in the research. These four organizations were selected based on their activities, which corresponded with the description of social enterprises found in the literature, and the accessibility of their location, which needed to be near Manila, where I was based for the research. Three of the organizations expressed interest in participating in the research but due to conflicting schedules, only one organization - A Single Drop for Safe Water (ASDSW), was able to accommodate me within the timeframe of the fieldwork, which was from May to June 2010. Primary data was gathered through semi-structured interviews and observation.

\subsubsection{Semi-Structured Interviews}

The conduct of face-to-face semi-structured interviews with research participants allows the researcher to ask follow-up questions and to engage in more in-depth conversation with the participants (Creswell, 2003). A one-on-one semi-structured interview was conducted with the organization's founder, Ms. Gemma Bulos. Two semi-structured group interviews were conducted with: 3 members of the staff, and 4 representatives from a community group that ASDSW worked with. The interview with ASDSW's founder provided an insight into the circumstances that lead to the establishment of the organization. Several accounts of social entrepreneurship have focused on the individual social 
entrepreneurs and their experiences. Thus, the interview with Ms. Bulos generated the perspective of someone who fits the description of a social entrepreneur on what social entrepreneurship entails. The interview was focused on the following: how the organization was established; the organization's programme and activities; Ms. Bulos' understanding of social entrepreneurship and how it relates to the organization; and future undertakings for the organization.

I interviewed 3 members of ASDSW's staff who were recommended to me by Ms. Bulos. Each of them held different positions and performed different tasks within the organization, which allowed for a comprehensive understanding of ASDSW's programmes and activities. I travelled to ASDSW's main office in Puerto Princesa, and had the opportunity to visit their partner community in the city. This included an informal group interview with 4 representatives of ASDSW's partner organization in the community, the San Carlos PODS. The discussion revolved around their experiences in project implementation and other development initiatives within their community.

\subsubsection{Participant Observation}

In addition to the interviews, participant observation was also utilized to gather information for the case study. Participant observation is a method of gathering data in the natural environment of the people being studied by observing and/or taking part in their activities, interactions or events (Dewalt \& Dewalt, 2002). According to Gillham (2000, p. 46), "it is the most direct way of obtaining data. It is not what people have written on the topic [or] what they say they do [but] it is what they actually do". 
I observed a 3-day Learning Exchange workshop conducted on 25-27 May 2010, wherein the ASDSW staff and representatives from their partner communities shared experiences and lessons learned from project implementation. The focus of the workshop was on developing their PODS training programme. The results of the workshop will form the basis for an updated training manual to be used by the trainers and facilitators. The workshop gave me the opportunity to look into how the organization enhances their programmes with participation from their partners. During the workshop, I took note of the specific activities that workshop participants identified as needing improvement. I was provided with a copy of the PODS training manual, which I reviewed for more detailed information on the PODS programme.

\subsection{Data Analysis}

Qualitative data analysis involves forming explanations or interpretations of the data collected to gain deeper understanding of what is being investigated (Taylor \& Gibbs, 2010). According to Creswell (2003, p. 190), "it is an ongoing approach", which cannot be strictly separated from the other steps in the research process such as data collection. The following generic steps suggested by Creswell (2003) were used as a guide for analysing the data gathered in this research: organizing the data; reading through the data; generating descriptions and themes; representing the description and themes; and making an interpretation.

The information gathered from secondary sources was the first set of data to be organized. I segregated the texts and materials gathered according to the type of organization it pertained to-social enterprise or support institution for social enterprises. Much of the information was used to provide details in the description of these organizations, which can be found in Chapter 4. From this, I was able to establish 
common characteristics or features of social enterprises in the Philippines and their similarities with accounts of social entrepreneurship activities that were found in the literature. Afterwards, I realized that I still needed to determine how social entrepreneurship emerged in the Philippines as stated in the research questions, so I gathered additional information on the socio-economic background of the country, as well as the development efforts of both national and local governments. Based on this, I identified factors that lead to the emergence, and growth in number of social enterprises in the Philippines.

To organize the primary data gathered, I first transcribed the audio interviews. The interview transcripts together with ASDSW's documents were the primary source for the case study, which illustrates in detail ASDSW's organizational structure, programmes and services, and areas of operation. The case study focuses on ASDSW's PODS programme so specific information relating to the programme such as objectives, target beneficiaries, activities and procedures, were lifted from the interview transcripts and the PODS training manual. Since the amount of data I was working on was not particularly large, I manually labelled the texts and identified key ideas that corresponded with post-development thought. These key ideas were divided into categories, which are stated in Chapters 5 and 6 as sub-headings ${ }^{2}$. In interpreting the data, meanings and understanding can be obtained be comparing the findings with what has been found in the literature or theories (Creswell, 2003). Thus, my analysis draws from literature on development theories, particularly alternative development and postdevelopment.

\footnotetext{
2 These are: sections 5.3.1 to 5.3.4 and 6.2.1 to 6.2.3
} 


\subsection{Ethical Considerations}

Prior to commencement of fieldwork, ethics approval for the research was sought from the Human Ethics Committee of Victoria University of Wellington and approval was granted on 30 March 2010. The information sheet and consent forms that were submitted for ethics review were provided to ASDSW. Informed consent involves two conditions - participants should first understand the nature of the research and their roles within it, and second participants need to agree voluntarily to their involvement in the research (M. Israel \& Hay, 2006). The information sheet was sent to ASDSW, specifically to Ms. Gemma Bulos and Mr. Kevin Lee-ASDSW's Executive Director, when they were initially asked to participate in the research. They agreed that I could do a case study on ASDSW. The information sheet was also provided to the staff members and the representatives of the San Carlos PODS before the conduct of interviews. A Tagalog version of the information sheet was given to the San Carlos PODS representatives. I also gave a brief verbal explanation of the research before the interviews. A tape recorder was used during all the interviews and permission was asked from the participants. All of the participants signed the consent forms.

Part of the process of negotiating consent to participation is the assurance and offer of confidentiality to potential research participants (Homan, 1991). The assurance of confidentiality of the research participants and details on how the information gathered will be kept and published/shared were included in the information sheet. The consent form also specified how identities and information would be kept confidential. In the final document, the names of research participants were not used except for Ms. Gemma Bulos who agreed to have her name published and opinions attributed to her. The audio recordings, and any interview notes will be destroyed after the completion of the research project. Having clear understanding on consent, confidentiality, and 
ownership of research results can help mitigate risks such as misuse of data or any other potential harm to individual research participants.

To ensure the accuracy of information, transcripts of the interviews conducted with Ms. Gemma Bulos and the staff members were sent through e-mail. They were able to clarify and correct some points before I wrote the case study chapter. The first draft of the case study on ASDSW was also sent to Ms. Gemma Bulos, the Executive Director of ASDSW-Mr. Kevin Lee, and a staff member who was interviewed. Feedback was given by Mr. Kevin Lee, which was used in revising the draft. A copy of the final results will also be provided to ASDSW.

\subsection{Reflection on Research Process}

The role of the researcher and the personal bias that is brought into the research is a significant part of qualitative research. I acknowledge that my personal background affects the entire research process from conception to data collection to final analysis and write-up. My educational background as a graduate of the Development Studies Program of the Ateneo de Manila University, as well as my work experience in the field of microfinance, has contributed to my knowledge on social entrepreneurship. I have preconceived perceptions on what social entrepreneurship entails and the 'strengths' of the approach as a tool for development. These contributed to how I initially formulated the research objectives and research questions.

My connection to the Development Studies Program of the Ateneo de Manila University helped me in identifying and obtaining materials and sources of relevant information for the research. Finding an organization that was willing to participate in the research was not particularly difficult although it took around 6 weeks to finalize arrangements with ASDSW. This was mainly because communication with Ms. Gemma Bulos, who is not based in the Philippines, was only through e-mail. I initially met with 
Mr. Kevin Lee in Manila to discuss my plans for data collection and arrange the schedules for interviews and site visit. I also explained initial plans on how the information will be analysed. This meeting helped in establishing some of the expectations from my side as a researcher and ASDSW's side as a subject and participant of the research. A day before the Learning Exchange Workshop, I went to ASDSW's office and was introduced to the staff. I also had the chance to talk with some members of the staff, which helped me to feel more comfortable. I think that being of the same nationality and speaking the same language contributed to making the staff feel comfortable with talking to me as well. The interview with the members of the staff was also conducted in Tagalog so we were able to express ourselves clearly.

I initially planned on visiting the community at least twice so that I could first introduce myself to the community group before conducting an interview. However, since access to the community group was made possible through ASDSW, I had to fit my plans into their schedule. Although the community was located in Puerto Princesa city, it takes about 2 hours travel to reach it from the city centre. Public transportation was not readily available so it would have been difficult for me to go on my own. I only went to the community once, however the discussion with the community group still provided valuable insight on how they worked together as a group in implementing not only ASDSW's projects but also other development projects. I initially wanted to compare the views of ASDSW staff and the community group regarding the effects of the programme, however I felt that the presence of an ASDSW staff member had an effect on the responses from the group. They mostly gave positive comments on their relationship with ASDSW and the benefits of the project. The situation demonstrates how plans are not always followed when conducting research and one should be flexible while maintaining the soundness of the research. In my case, the group was asked to 
identify challenges or difficulties that they have encountered in project implementation, which gave some balance to the discussion. The group interview was also conducted in Tagalog. All the members of the group were able to answer at least one question since the questions did not necessarily require an answer from each member of the group.

Some ethicists have argued that researchers have an obligation to do good and actively seek to maximize the benefits that can be derived from the research, particularly for disadvantaged groups (M. Israel \& Hay, 2006). Although the ASDSW staff that accompanied me to the community mentioned that my research could potentially help entrepreneurs, I did not feel that the San Carlos PODS' group members were expecting anything from me in relation to the research. I felt that they saw me as a potential customer for their eco-tourism enterprise since they asked me to come back to try the activities that they offered. Nonetheless, I still tried to be mindful of possible consequences of the research on the community groups that ASDSW works with, not just the San Carlos PODS. In addition, many researchers view participation in qualitative research as a way of empowering marginalized groups by "giving voice" (Stein \& Mankowski, 2004). The interview gave the San Carlos PODS members an opportunity to share their experiences and accomplishments, which I felt they were very proud of. I believe that this also increased their confidence and encouraged them in continuing their community development efforts since they know that there are people who are interested in what they are doing.

Even if I am not certain whether the research will actually be beneficial to ASDSW, their partner communities, or other social enterprises, the research process has been a worthwhile experience that not only expanded my own knowledge through the interaction with research participants, but gave them the opportunity to reflect on their work and processes as well. 


\subsection{Conclusion}

This research employed qualitative methods for data collection and analysis. A case study approach was utilized and information was gathered through secondary data collection, semi-structured interviews, and observation. The secondary data from the training manuals and reports that I collected, as well as the information gathered from observing the Learning Workshop provided details on ASDSW. Meanwhile the interviews conducted with Ms. Gemma Bulos, the staff, and the San Carlos PODS members gave insight on their experiences in managing and implementing social entrepreneurship activities. I was able to get different perspectives on the programmes and activities of ASDSW since they had different roles in the organization.

One of the weaknesses associated with the case study approach is that a generalization cannot be made based on a single case (Flyvbjerg, 2006). This research focused on ASDSW and the experiences of its founder, staff members and one of their partner groups. The organization's situation and experiences and the views expressed by the participants may differ from other social enterprises and cannot be interpreted as definitive of the social entrepreneurship industry. Hence, it was very important to establish the common characteristics among social enterprises that can be gleaned from the literature, and to identify the similarities between ASDSW's activities and strategies with those of other Philippines social enterprises. The following chapter explores these issues by focusing on social entrepreneurship in the Philippines. 


\section{CHAPTER 4 \\ Philippine Development Context and Social Entrepreneurship in the Philippines}

\subsection{Introduction}

The Philippines has a vibrant development landscape composed of different actors that carry out initiatives dealing with pertinent social issues. While local government units (LGUs) are primarily responsible for the delivery of basic social services and the implementation of local development plans, the national government coordinates and executes nationwide programmes through various line agencies. The current Medium Term Philippine Development Plan (MTPDP) outlines the government's development strategy, including goals aimed at reducing poverty and inequality. Implementation of the latest MTPDP ended in 2010, and the newly elected administration will prepare a new plan for the next six years. Meanwhile, a review by civil society organizations (CSOs) of the previous administration's implementation of the MTPDP found that targets in the areas of poverty reduction, sustainable economy, and people empowerment and democratization have not been met (Caucus of Development NGO Networks, 2010). It has been the practice of CSOs in the country to monitor government activities for the purpose of accountability. In addition, a number of CSOs are engaged in development work and some also provide services to the poor. It is in this sphere of civil society that social entrepreneurship in the Philippines has taken root, adding to the dynamic development setting.

This chapter provides an overview of the emerging social entrepreneurship movement in the Philippines based on literature searches and secondary data analysis. It addresses the first research question, which is: How did social entrepreneurship emerge as a development approach in the Philippines? The first part will provide a brief overview of the Philippines' socio-economic and local development background. This 
will be followed by a discussion on the history of CSO involvement in development work, including the beginnings of social entrepreneurship ventures. Next, a discussion on the ways social entrepreneurship is being promoted and its significance for continuing development work in the Philippines will be provided. This will be followed by examples of social enterprises in the country. The chapter concludes with a discussion on the issues or challenges faced by social entrepreneurship ventures, which will be explored further in the case study chapters.

\subsection{Philippine Socio-Economic and Development Profile}

The Philippines (see Figure 4.2.1) is an archipelago located in the western Pacific Ocean and surrounded by bodies of water that separate it from other Southeast Asian countries (see Figure 4.2.2). According to the 2007 census, the population has reached around 88.5 million and is estimated to reach around 94 million in 2010 (National Statistical Coordination Board, 2007b).

Based on conventional development measures and approaches, the Philippines is viewed as lagging behind other Asian countries and is described by Balisacan and Hill (2003) as a 'development puzzle'. According to them, the Philippines had one of the most favourable conditions for economic development among the newly independent states but in the following decades the country did not experience similar growth with other Asian countries. As a result of this poor economic performance, social and living conditions also suffered (Balisacan \& Hill, 2003). The country's economic performance improved recently with the annual Gross Domestic Product (GDP) growth rate at $7.3 \%$ in 2010, which is the highest it has been since 1976 (National Statistical Coordination Board, 2011a). However, whether this growth will help in improving living standards and reducing poverty, remains to be seen. Many Filipinos are still seeking employment opportunities abroad. The Philippine Overseas Employment Administration (2009) 
reports that about 1.4 million workers were deployed in 2009. Meanwhile, there are around 2.8 million unemployed members of the labour force ${ }^{3}$ in the country (Bureau of Labor and Employment Statistics, 2010).

Figure 4.2.1

Philippine Map

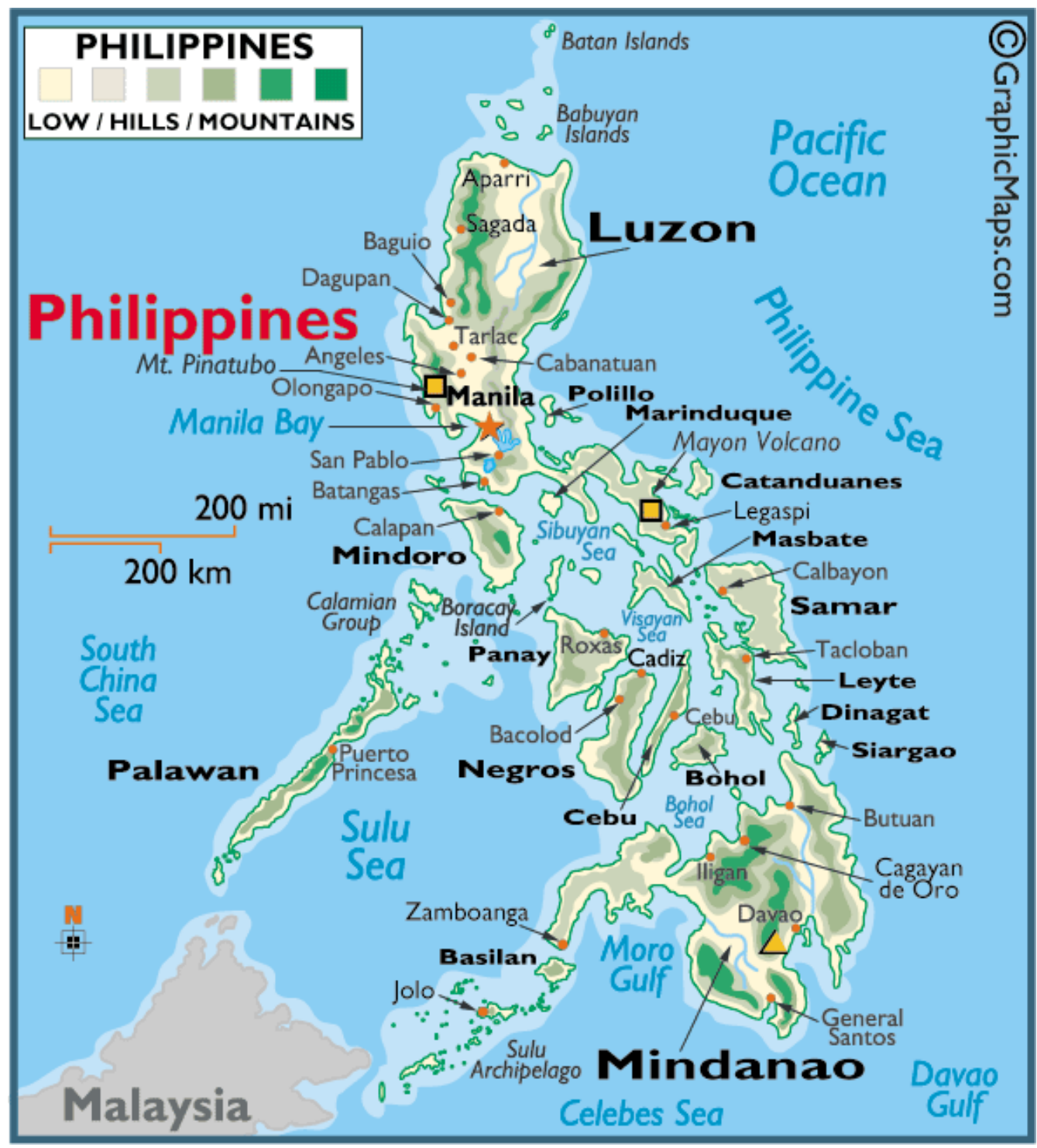

Source: (Graphic Maps, 2011)

3 The labour force is composed of population 15 years old and over, whether employed or unemployed, who contribute to the production of goods and services in the country 
Figure 4.2.2

Philippines Location Map

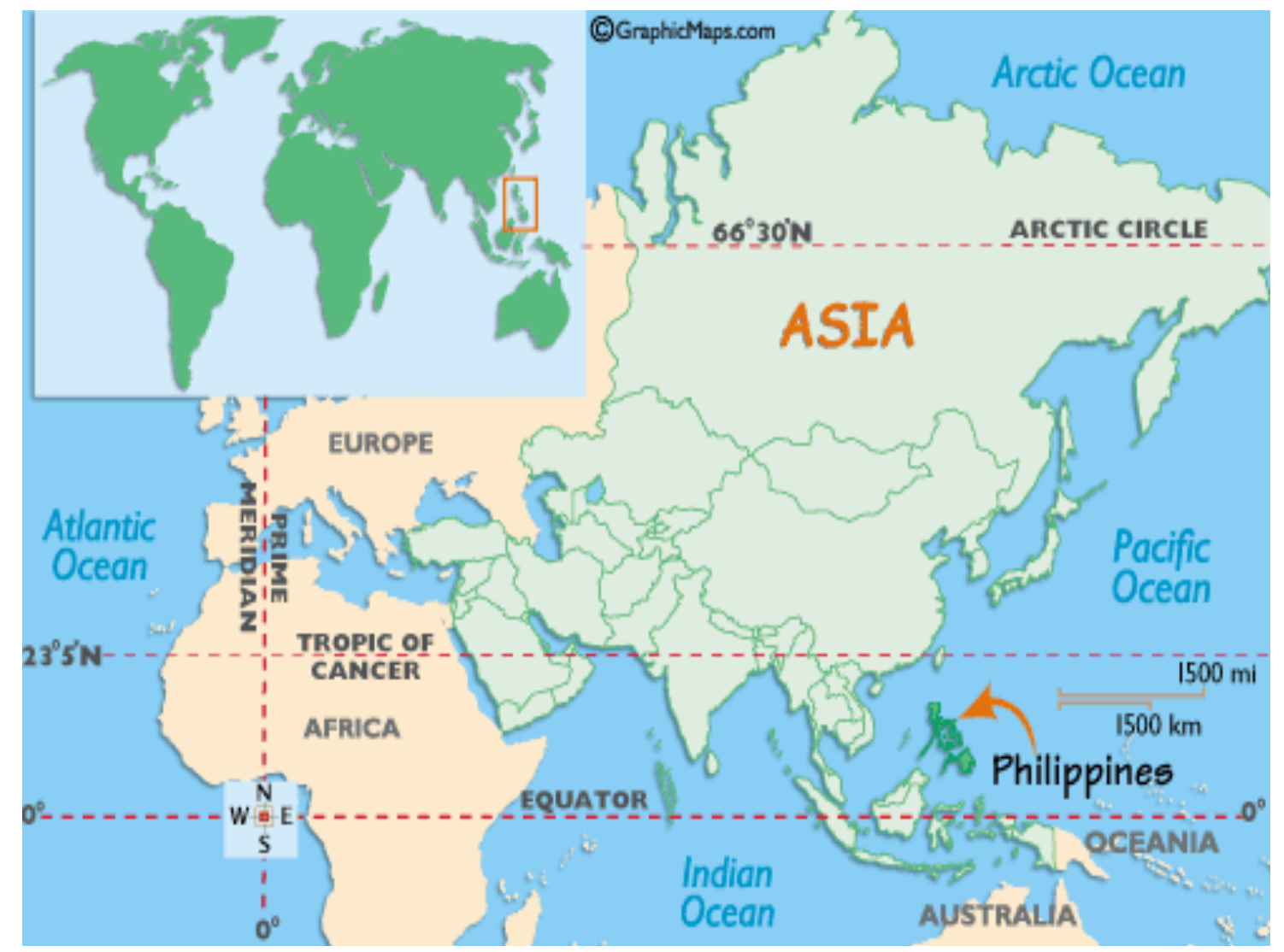

Source: (Graphic Maps, 2011)

According to the Philippines' 2010 Progress Report on the Millennium Development Goals, poverty reduction is among the areas in which the country is lagging behind (see National Economic and Development Authority, 2010). The latest poverty statistics show an increase in the magnitude of poor ${ }^{4}$ population from 22.2 million in 2006 to 23.1 in 2009 (see Table 4.2.1). Moreover there is a significant difference in the poverty incidence between regions, with the National Capital Region

\footnotetext{
${ }^{4}$ Based on Republic Act 8425, or the Social Reform and Poverty Alleviation Act of 1997, the poor refers to individuals and families whose income fall below the poverty threshold as defined by the government, and/or those that cannot afford in a sustained manner to provide their basic needs of food, health, education, housing and other amenities of life. (National Statistical Coordination Board, 2007a)
} 
having the lowest number of poor population (see Appendix 1). The approach used in measuring poverty is based on income, which is typical in development.

Table 4.2.1

Annual Per Capita Thresholds, Poverty Incidence and Magnitude of Poor

\begin{tabular}{|c|c|c|c|}
\hline \multirow{2}{*}{ Statistics } & \multicolumn{2}{|c|}{ Estimate } & \multirow{2}{*}{$\begin{array}{c}\text { Inc/Dec } \\
2006 \text { to } 2009\end{array}$} \\
\hline & 2006 & 2009 & \\
\hline $\begin{array}{l}\text { Annual Per Capita } \\
\text { Poverty Threshold } \\
\text { (PhP) }\end{array}$ & 13,348 & $16,841^{5}$ & 26.2 \\
\hline \multicolumn{4}{|c|}{ Poverty Incidence (\%) } \\
\hline Families & 21.1 & 20.9 & $(0.2)$ \\
\hline Population & 26.4 & 26.5 & 0.1 \\
\hline \multicolumn{4}{|c|}{ Magnitude of poor (in million) } \\
\hline Families & 3.67 & 3.86 & 5.0 \\
\hline Population & 22.17 & 23.14 & 4.4 \\
\hline
\end{tabular}

Source: (National Statistical Coordination Board, 2011b)

Development planning in the Philippines has mostly focused on mainstream development approaches such as economic growth, infrastructure development, and structural adjustment (see Balisacan, 2003). In 1986, the government under Corazon Aquino emphasized poverty alleviation, advocated equity through employment opportunities, and promoted rural and agriculture development (Balisacan, 2003). The Comprehensive Agrarian Reform Program (CARP) was the main social justice and equity program of the administration, and was an ambitious undertaking that planned to redistribute all agricultural lands within 10 years (Balisacan, 2003). However, the government struggled with the implementation of the CARP given the formidable task and limitations on the government's budget (Balisacan, 2003). It was also during Aquino's presidency that the Philippine Constitution and the Local Government Code

\footnotetext{
${ }^{5}$ Equivalent to around 506.05 NZD as of February 2011
} 
(LGC) were enacted. The 1987 Constitution is a significant milestone in instituting democracy in the country, while the LGC was meant to change the highly-centralized governance structure so that citizens can approach and possibly influence the government, making it more responsive to their needs (Iszatt, 2004).

Since the introduction of the LGC, the provision of basic services and facilities has been devolved to Local Government Units $^{6}$ (LGUs). This includes the following: agricultural support services; health and social welfare; sanitation and waste disposal; community-based forestry programs; roads, bridges and water systems; and other infrastructure facilities ("The Local Government Code of the Philippines," 1991). Funding for basic services and facilities will come from the LGUs' share in the proceeds of national taxes, which is referred to as the Internal Revenue Allotment (IRA). The IRA is generally based on the population and land area of the province, city or municipality. In addition to the IRA, the LGUs are granted the autonomy to raise their own revenues for the delivery of services and implementation of local development plans. LGUs should allocate $20 \%$ of their IRA for the implementation of development projects.

Succeeding administrations formulated strategies and socio-economic platforms to address development issues in the country. The government under Fidel Ramos (19921998) addressed human development through the Social Reform Agenda (SRA), which targeted the 20 poorest provinces and included interventions such as housing projects, employment opportunities and healthcare benefits (Halili, 2004). Joseph Estrada's Lingap Para sa Mahirap (Caring for the Poor) program targeted the 100 poorest families in each province and city, who will be provided with welfare services (Haggard \& Kaufman, 2008). Chapter 12 of The Medium Term Philippine Development Plan (MTPDP) 2004-2010 identifies the Macapagal-Arroyo administration's strategies for

\footnotetext{
${ }^{6}$ composed of the following political subdivisions: provinces; cities and municipalities; barangays
} 
poverty reduction. The flagship program for poverty reduction was the Kapit Bisig Laban sa Kahirapan (Joining Hands Against Poverty) or KALAHI program. Balisacan (2003) observed that the program lacked focus and is thus doubtful of what it can achieve. The targets for livelihood and job creation in particular, were quite ambitious. It was envisioned that 10 million jobs will be created and the unemployment rate will go down from $10.2 \%$ in 2003 to $8.9 \%$ in 2010 (see National Economic and Development Authority, 2004).

As part of the Macapagal-Arroyo administration's efforts in increasing employment opportunities, entrepreneurship was heavily promoted. A National SME (Small and Medium Enterprise) Agenda was launched, and in 2004 a Small and Medium Enterprise Development Council was formed. The council was tasked with formulating a SME Development Plan to increase the productivity of micro, small, and medium enterprises $\left(\mathrm{MSMEs}^{7}\right.$ ) and encourage the formation of new ones (see Small and Medium Enterprise Development Council, 2004). Government programmes to assist enterprises included financing support through grants and loans; managerial and technological training programmes; and product development assistance. According to the Department of Trade and Industry (DTI) (2009), MSMEs accounted for $99.6 \%$ of all business enterprises in the Philippines and generated a total of 3,595,641 jobs in 2009. The unemployment rate as of October 2010 is $7.1 \%$ (Bureau of Labor and Employment Statistics, 2010), which is lower than the projected target. This indicates that the enterprise promotion strategy contributed to increasing employment opportunities in the country.

\footnotetext{
7 Philippine SMEs are defined based on assets, excluding land and number of employees. In 2003 the SMED Council formulated the ff. categories: Microenterprises- assets worth PHP 3,000,000 or less with 1-9 employees; Small enterprises- assets worth PHP 3,000,001 to 15,000,000 with 10-99 employees; Medium enterprises- assets worth PHP 15,000,001 to 100,000,000 with 100-199 employees (Small and Medium Enterprise Development Council, 2004, p. 2)
} 
The availability of support programmes for enterprise development contributed to the adoption of income-generating activities as part of social development projects. Social enterprises in the Philippines, examples of which are given later on in the chapter, demonstrate how social entrepreneurship builds on this strategy by advocating entrepreneurial activity not only for job creation and economic development, but for social development as well.

The next section looks into the beginnings of social entrepreneurship in the Philippines. It was mentioned in the literature that social entrepreneurship emerged from the 'third sector' consisting of non-profit organizations and cooperatives. In the Philippines, these organizations are part of the broader civil society that also acts as agents of development.

\subsection{Civil Society Organizations and Social Development}

As mentioned, CSOs in the Philippines are very active and involved in development work. The pervasiveness of poverty, inequality, and calamity throughout the country, has brought about volunteerism among its citizenry (Constantino-David, 1998). The inefficient and ineffective response of the government to the problems besetting the country also prompted CSOs to not only become a check to government actions, but become service providers as well. CSOs are numerous, with developmentoriented NGOs estimated to be at 3,000 to 5,000 (ADB NGO and Civil Society Center, 2007). The beginnings of development NGOs has been linked to initiatives focused on rural and community development established after the Second World War to counter the growing communist movement (see Asian Development Bank, 1999; ConstantinoDavid, 1998). The Catholic Church and the private sector such as the Philippine Rural Reconstruction Movement (PRRM), which was established in 1952, mostly led these initiatives. Although earlier CSOs were established to counter communist activities, new 
organizations and social movements influenced by global perspectives of dependency theory and liberation theology were established by the 1960s (Constantino-David, 1998). Growing social unrest also contributed to the formation of organizations dedicated to community organizing ${ }^{8}$, particularly in urban areas (Asian Development Bank, 1999). The business sector likewise became involved in social issues through the creation of the Philippine Business for Social Progress (PBSP) in 1970.

When President Ferdinand Marcos declared martial law in 1972, political activists had to go underground and social movements were suppressed. However, there were still those who viewed NGO work as a way to be politically involved, and thus continued community-organizing initiatives (Asian Development Bank, 1999). Many of these were backed by the Catholic and Protestant churches, such as the Task Force Detainees of the Philippines, which dealt with human rights violations (ConstantinoDavid, 1998). The struggles brought about by the martial law period also strengthened some NGO associations and networks. Some of the networks formed during the time included the Association of Foundations, the National Association of Training Centers of Cooperatives (NATCCO), and the Philippine Partnership for the Development of Human Resources in Rural Areas (PhilDHRRA). While the dictatorship lost its popularity in international circles, civil society initiatives gained the support of the international NGO community (Constantino-David, 1998).

One of the most well known events in the Philippine's political history is the EDSA $^{9}$ Revolution of 1986 , wherein different groups and thousands of civilians poured onto the streets for non-violent demonstrations against the Marcos regime. It was spurred

\footnotetext{
8 - as opposed to community development, which was described by Constantino-David as activities involving "sanitation, livelihood, backyard gardens, beautification" (1998, p. 32). Community organizing on the other hand, dealt with "the structural determinants of poverty" (p. 33)

${ }^{9}$ EDSA stands for Epifanio De los Santos Avenue, the main thoroughfare where protests were held
} 
by several events, beginning with the 1983 assassination of Senator Benigno Aquino, Jr. upon his return to the Philippines after a three-year exile in the United States. Aquino was a popular leader who opposed the dictatorship and his assassination lead to the formation of more anti-dictatorship organizations that now openly challenged the Marcos regime (Constantino-David, 1998). In 1986, a snap presidential election took place wherein, Corazon Aquino, the widow of Senator Benigno Aquino, ran against Marcos for the presidency. The Commission on Elections (COMELEC) declared Marcos the winner but the National Movement for Free Elections' (NAMFREL) vote-count reflected Aquino as the winner. Reports of election fraud set into motion the defection of several military personnel and the mass mobilization of civil society, eventually resulting to Marcos' departure and the inauguration of Corazon Aquino as the President of the Philippines.

Many of the development NGOs and networks that participated in the movement were hopeful and continued to expand as the new government gave them formal recognition through various legislations (Constantino-David, 1998). In addition, funding support from international sources such as the Philippine-Australian Community Assistance Program, encouraged the growth of development NGOs (Asian Development Bank, 1999). With these developments came the need to build stronger partnerships and establish governing principles. So in 1990 , ten national NGO networks formed the Caucus of Development NGO Networks (CODE-NGO) and they ratified the Covenant on Philippine Development. The covenant "contained the consensually validated principles and responsibilities, goals, and commitments, as well as a code of conduct to govern development NGOs" (Constantino-David, 1998, p. 37). From a few scattered organizations and volunteers, NGOs are now important to many aspects of social development work (see Table 4.3.1) 
Table 4.3.1

Number of Base Organizations by Nature of Program

\begin{tabular}{|l|c|}
\hline \multicolumn{1}{|c|}{ Core Program } & Total Number of Organizations \\
\hline Agrarian Reform and Rural Dev't & 59 \\
\hline Arts and Cultural Heritage & 14 \\
\hline Cooperative Dev't & 80 \\
\hline Gender Dev't & 76 \\
\hline Health and Nutrition & 81 \\
\hline Education, Training, and Resource Dev't & 139 \\
\hline Community Dev't & 157 \\
\hline Enterprise Dev't/Livelihood & 131 \\
\hline Microcredit/Microfinance & 88 \\
\hline Peace and Dev't & 12 \\
\hline Labor Organizing & 3 \\
\hline Science and Technology & 3 \\
\hline Social Services & 58 \\
\hline Legal Services & 8 \\
\hline Sustainable Dev't and Environment & 70 \\
\hline Student and Volunteer Formation & 17 \\
\hline Urban Poor And Social Housing & 20 \\
\hline Advocacy on Child's Rights & 18 \\
\hline Advocacy on Human Rights & 5 \\
\hline
\end{tabular}

Source: (Caucus of Development NGO Networks, 2006)

The role of Philippine NGOs in addressing social issues through advocacy work, community organizing, and delivery of services has been significant throughout the years. However, development NGOs also face challenges that could affect their operations. Recently, the most pressing concern has been the limited availability of longterm funding sources. Typical sources of funding for Philippine NGOs include foreign donor grants, government agencies, churches, private donations, and internally generated funds such as membership dues. Among these, foreign funding from bilateral aid agencies and international NGOs account for the majority of NGO funds (Asian Development Bank, 1999). This dependence on foreign donor grants has become problematic for most NGOs. There has been notable decrease in ODA funding to NGOs, with grants amounting to $\$ 296.5$ million in 1990 decreasing to \$165.9 million in 1996 
(Aldaba, et al., 2000). This problem may not be resolved in the next couple of years as there has been a global decline in funding, with the aid programming of OECD countries becoming more conservative due to the recent economic crisis (see Organisation for Economic Co-operation and Development, 2009).

Constantino-David $(1995 ; 1998)$ notes that a related concern for most development NGOs is trying to professionalize their operations in order to respond to donor requirements. There is pressure to improve financial and management systems, which can be difficult for NGOs that have limited financial and human resources. NGO staff are compelled to spend time organizing their administrative affairs, thus reducing the time spent attending to their activities (Constantino-David, 1995). Moreover, most donors still prefer quantifiable outputs and getting results within definite timeframes. This can sometimes lead NGOs to bypass their own processes and push forward with activities so that they can show some results (Constantino-David, 1998). Development NGOs, especially those engaged in community organizing and those working with People's Organizations (POs), may find that they are compromising their flexibility in order to ensure donor funding (Constantino-David, 1995). This presents a challenging situation for NGOs since they risk losing legitimacy and weakening their relationships with community or grassroots partners (Aldaba, et al., 2000). At the extreme, NGOs would have to choose between stopping their operations due to lack of funding, or continuing on even if they lose the substance of their initiatives. Both situations pose an ethical dilemma for NGOs. This situation demonstrates how development initiatives are often constrained by organizational systems and procedures (Mosse, 2001). This could bring about what post-development writers describe as the de-politicizing effect of development. Instead of addressing the "processes that produce poverty in the first 
place", development professionals will often choose a technical solution that they can implement within budgets and timelines (Nustad, 2007, p. 37).

\subsection{Social Entrepreneurship in the Philippines}

As a response to these challenges, social entrepreneurship emerged in the Philippines as a strategy that could grant sustainability and autonomy to NGOs (Dacanay, 2006). As discussed in the literature review, social entrepreneurship ventures include earned-income activities that utilize any profit gained for fulfilling a social mission. It is an approach to social development that ensures sustainability of outcomes by ensuring the sustainability of operations (Hechanova-Alampay \& dela Cruz, 2009). In addition, social entrepreneurship is characterized by innovation and risk-taking. This goes well with the concept of having an internal resource base since new organizations or those that have relatively new and untested methodologies or activities might have more difficulty finding external funding. Donors sometimes look for a track record or require those applying for funding to align their activities with the donor agency's priorities. Therefore, social enterprises seek to have the flexibility to design and implement their own programmes and hopefully produce development alternatives.

There has been a worldwide growth in the number of organizations considered to be social enterprises (Keh, 2009). In the Philippines, the social enterprise has become a new type of CSO that is viewed as "an alternative means of achieving a more effective and more sustainable development that benefits not only a few but also the greatest number of people, especially those in the marginalized sector" (La Vina, 2009). There is limited documentation on social enterprises in the Philippines, making it difficult to determine the scale of the industry. One indication of the number of social enterprises in the country is the list of members on the website of the Philippine Social Enterprise 
Network or PhilSEN, which lists 37 members across the country ${ }^{10}$ (see Philippine Social Enterprise Network, 2010b). The next section looks into the ways social entrepreneurship is being promoted in the country, leading to the growth of the industry.

\subsubsection{Promoting Social Entrepreneurship in the Philippines}

The increasing popularity of social entrepreneurship as a development strategy in the Philippines can be seen not only through the number of organizations adopting it, but also by the other ways it is being supported and advanced. As mentioned in the literature review chapter, social entrepreneurship is an idea that seems to have garnered support from different groups including NGOs, people's organizations, government, businesses, and the academe - that can sometimes be in conflict with one another. In the Philippines, it seems to be the academe, particularly the Ateneo de Manila University, and civil society organizations that are actively supporting social entrepreneurship ventures. The following discussion focuses on recent developments aimed at promoting social entrepreneurship in the country.

The Ateneo de Manila University has recently been supporting and promoting social entrepreneurship through various initiatives, including integrating the subject in academic programmes. The university's graduate school of government in particular offers various training seminars and courses on social entrepreneurship. Since 2008, the Ateneo School of Government (ASoG) has been running the Social Entrepreneurship Training Program for Professionals. Now on its $6^{\text {th }}$ run $^{11}$, the training program gives an introduction to social entrepreneurship, and also provides participants the opportunity to develop their own social enterprise business plans, with assistance from experts in the

\footnotetext{
10 This list is not exhaustive and there are social enterprises in the country who are not members of PhilSEN

${ }^{11}$ At the time of writing, the $6^{\text {th }}$ instalment of the program runs from June 29 to October 3, 2010
} 
field (Ateneo School of Government, 2010). A parallel activity is the Beyond

Bottomlines: An Introduction to Social Entrepreneurship seminar-workshop, which has similar content to the training program for professionals but only runs for one day. The program for professionals on the other hand, usually runs for several weeks with participants attending lectures every Saturday (see Ateneo de Manila University, 2010a). In addition to these, the ASoG, together with different partners, offers specialized training programs on social entrepreneurship for various target audience (see Table

Table 4.4.1

ASoG's Social Entrepreneurship Programs

\begin{tabular}{||l|l|}
\hline \multicolumn{1}{|c|}{ Title } & \multicolumn{1}{|c|}{ Description } \\
\hline $\begin{array}{l}\text { Youth Leadership and Social } \\
\text { Entrepreneurship (YLSE) }\end{array}$ & $\begin{array}{l}\text { The Program promotes the spirit of social entrepreneurship } \\
\text { among the youth and their organizations in partnership with } \\
\text { other academic institutions, LGUs, non-profit organizations and } \\
\text { the private sector. }\end{array}$ \\
\hline $\begin{array}{l}\text { Future Leaders of Asia } \\
\text { Forum }\end{array}$ & $\begin{array}{l}\text { This forum primarily aims to introduce to young leaders the idea } \\
\text { of social entrepreneurship to make them more adept at various } \\
\text { innovative means of solving social problems. Most importantly, } \\
\text { it empowers the youth to become catalysts of change in their } \\
\text { own unique ways - to be change-makers themselves. }\end{array}$ \\
\hline $\begin{array}{l}\text { Greenwich-Youth Leaders } \\
\text { Engaged in Active } \\
\text { Development Program } \\
\text { (YLEAD) }\end{array}$ & $\begin{array}{l}\text { Aims to prepare and inspire a new generation of effective and } \\
\text { ethical Filipino youth leaders who will proactively work towards } \\
\text { addressing key social problems in the fields of education, health } \\
\text { and the environment, among others. Youth leaders chosen for } \\
\text { the Greenwich YLEAD Program undergo leadership training that } \\
\text { equips them with skills in developing and implementing projects } \\
\text { that offer innovative solutions to key problems in their } \\
\text { community. The participants are partnered with mentors and } \\
\text { advisers who help them ensure the success of their projects. }\end{array}$ \\
\hline $\begin{array}{l}\text { Leadership and Social } \\
\text { Entrepreneurship Training } \\
\text { Program for Migrants }\end{array}$ & $\begin{array}{l}\text { This is a year-long social entrepreneurship and leadership } \\
\text { program for Filipinos based overseas. The Program primarily } \\
\text { aims to develop their leadership skills and raise their awareness } \\
\text { on various entrepreneurial possibilities that they can engage in } \\
\text { and help them make a positive impact on their community. }\end{array}$ \\
\hline $\begin{array}{l}\text { Skills for Social } \\
\text { Entrepreneurs: Training } \\
\text { Caravan for University } \\
\text { In padents } \\
\text { British Council Manila }\end{array}$ & $\begin{array}{l}\text { This Program aims to inspire young people to become social } \\
\text { entrepreneurs and equip them with skills to find innovative } \\
\text { ways to help address local problems. It provides young people } \\
\text { with opportunities to help them make a difference in their } \\
\text { localities and empower them to take action and realize their } \\
\text { dreams. }\end{array}$ \\
\hline
\end{tabular}




\begin{tabular}{|l|l|}
\hline $\begin{array}{l}\text { Social Enterprise course for } \\
\text { trainers and teachers* } \\
\text { In partnership with the } \\
\text { British Council }\end{array}$ & $\begin{array}{l}\text { Offered in October 2009, a 10-day extensive course specifically } \\
\text { designed to provide participants a comprehensive } \\
\text { understanding of social entrepreneurship and the opportunity } \\
\text { to develop their own training programme or put this knowledge } \\
\text { into enhancing the social impact and strategies of their own } \\
\text { organizations. }\end{array}$ \\
\hline $\begin{array}{l}\text { Social Enterprise } \\
\text { Development: An } \\
\text { Introductory Course for NGO } \\
\text { Managers* }\end{array}$ & $\begin{array}{l}\text { Offered in February 2010, a five-day introductory course about } \\
\text { what social entrepreneurship is and its relevance to NGOs and } \\
\text { social change in the Philippines. The course will help } \\
\text { British Council }\end{array}$ \\
\hline $\begin{array}{l}\text { Online Social } \\
\text { Entrepreneurship Course for } \\
\text { Professionals }\end{array}$ & $\begin{array}{l}\text { manage social enterprises or wealth-creating organisations with } \\
\text { a social mission. }\end{array}$ \\
\hline $\begin{array}{l}\text { Beginning January 2010, this online program, will introduce the } \\
\text { emerging concept of Social Entrepreneurship as an innovative } \\
\text { solution to social problems using entrepreneurial skills through } \\
\text { lectures, presentations, video clips, readings, and case studies } \\
\text { of actual social enterprises in the Philippines and in other } \\
\text { countries. Furthermore, the program will also help participants } \\
\text { develop new and innovative social enterprise business plans. } \\
* \text { not regular programs }\end{array}$ \\
\hline
\end{tabular}

Source: (Ateneo de Manila University, 2009a, 2009b, 2010b; Ateneo School of Government, 2010)

In terms of integrating social entrepreneurship in the university's academic programmes, the most recent development is the introduction of a new masters programme that will be jointly offered by ASoG and the Institute for Social Entrepreneurship in Asia (ISEA), which is the Master in Public Management Major in Social Entrepreneurship (MPM-SE) (Institute for Social Entrepreneurship in Asia, 2010a). It is a "practitioner-oriented" course designed specifically for professionals who are interested in either integrating social entrepreneurship into their programmes; improving or mastering their skills on social enterprise management; or pursuing a career in social entrepreneurship (Institute for Social Entrepreneurship in Asia, 2010a). As for their undergraduate programmes, the Development Studies Program of the Ateneo de Manila University offers an elective class on Social Entrepreneurship ${ }^{12}$. Overall, these initiatives form the University's commitment to social entrepreneurship and some will

\footnotetext{
12 I attended the Social Entrepreneurship class during my $4^{\text {th }}$ year of undergraduate study at the Ateneo de Manila University.
} 
become part of the recently opened Ateneo Centre for Social Entrepreneurship. The centre is jointly managed by the Development Studies Program; the John Gokongwei School of Management; Ateneo School of Government; and Ateneo Graduate School of Business.

Since social entrepreneurship is still an emerging field of study, research and documentation of cases and best practices are also being encouraged. The ISEA, seems to be taking the lead for these initiatives. The institution seeks to be a resource centre for social entrepreneurs and social enterprises in Asia by developing a knowledge base and learning exchange network for practitioners (Institute for Social Entrepreneurship in Asia, 2010b). ISEA has several articles, case studies, and publications related to social entrepreneurship available on their website (http://isea-group.net/learning-hub.html). In 2009, ISEA and Oikocredit, a private institution that provides funding for the microfinance sector, jointly published a resource book on how to measure social enterprise performance. "Measuring Social Enterprise: A Resource Book on Social Enterprise Performance Measurement", presents two tools for performance measurement-Development Indexing (DI) and Social Return on Investment (SROI), which are already being used by other non-profit organizations (see Dacanay, 2010). The book features case studies that demonstrate how social enterprises can apply these tools to their organizations.

Similarly, a Social Enterprise Quality Index (SEQI) is being developed by the Philippine Social Enterprise Network (PhilSEN). The SEQI is a tool that can be used by the social enterprises that are members of PhilSEN, to check their performance vis-à-vis a criteria (see Ateneo de Manila University Development Studies Program and Philippine Social Enterprise Network, 2009). The criteria to be used is based on the triple bottom line framework-Doing well, doing good, doing right-that members of 
PhilSEN pursue. With the SEQI, PhilSEN hopes to set a common standard to which social enterprises can be held to account by their stakeholders, as well as come up with a guide for establishing best practices (Philippine Social Enterprise Network, 2009, forthcoming).

Apart from the SEQI, PhilSEN has several other initiatives that support social enterprises, particularly those who are members of the network. Having a national network for social enterprises is in itself a major step towards promoting social entrepreneurship. To strengthen relationships among members and facilitate knowledge sharing, PhilSEN applies the Community of Practice (CoP) approach (Philippine Social Enterprise Network, 2010a). Specifically, it "aims to develop replicable models of social enterprise interventions and strategies in value chain, provide opportunities for exchanges of experiences and lessons, and utilize experiences and lessons learned for effective lobby work in support of social enterprises" (Philippine Social Enterprise Network, 2010a). PhilSEN's programmes include membership development, advocacy and networking services, and business development services. PhilSEN encourages the pursuit of earned income activities or livelihood and enterprise development for both their members and the partner communities of members.

Lastly, financial support for 'budding' social entrepreneurs and social enterprises are available from different institutions that are dedicated to social entrepreneurship. For instance, Ashoka International, an organization that advocates social entrepreneurship, provides financial support through its Fellowship programme, wherein accepted fellows are given a living stipend for three years so that they can concentrate on fulfilling their ideas and establishing their institutions (Ashoka Philippines, 2010). The Philippine office is now in the process of selecting its first batch of Ashoka fellows. Similarly, the British Council in Manila has recently launched the "I am a Changemaker" social enterprise 
business plan competition, which awards seed capital to social enterprises that meet a certain criteria (British Council Philippines, 2010). In addition to the seed capital of 100,000 PHP (around 3,131 NZD), the winners also received a training on Social Enterprise Planning and Development from the Social Enterprise Development Partnership, Inc. (SEDPI), an organization that offers capacity building services for social enterprises (see Social Enterprise Development Partnership, 2010). On the other hand, Oikocredit, is now providing loans to social enterprises that work with grassroots groups for their livelihood and economic development, as well as to community-based enterprises and cooperatives (Ateneo de Manila University Development Studies Program and Philippine Social Enterprise Network, 2009). Meanwhile, support from the national government could be a challenge for Philippine social enterprises. One board member of a local social enterprise hopes that the government will support social entrepreneurship through policy, such as a bill for social entrepreneurship that will distinguish social enterprises from corporations and NGOs and will treat them differently in terms of registration and taxation (Pastores, 2010). This could prove to be a difficult and lengthy undertaking since 'hybrid organizations' are not yet legally defined ${ }^{13}$.

These initiatives by various institutions are helping to provide the conditions for social entrepreneurs and social enterprises in the Philippines to grow and potentially become successful in their endeavours. However, it seems that social entrepreneurship is emerging as an expert field with several training and academic programmes offering to provide skills and knowledge in social entrepreneurship. These seem similar to the skills required in operating a business and/or a development NGO. For instance, most of the training programmes offered by the Ateneo School of Government include business plan formulation and project management. This seems to encourage the emergence of social

\footnotetext{
13 Under the Corporation Code of the Philippines, NGOs and non-profit organizations are registered with the Securities and Exchange Commission as non-stock corporations.
} 
entrepreneurs as experts who have the key to addressing social problems. If this is the case, then social entrepreneurship becomes part of the development discourse that 'professionalize' underdevelopment through expert knowledges and fields (Escobar, 2007). The consequence of 'professionalization' is that development professionals dictate and prescribe solutions, thereby ignoring local knowledge and practice. Yet, the literature on social entrepreneurship suggests that social entrepreneurship practices involve working with communities and mobilizing local knowledge and resources. The next section looks into how social enterprises in the Philippines address different development issues and how they work with local communities.

\subsubsection{Social Enterprises in the Philippines}

The three examples discussed here were chosen based on their activities and organizational structure, to cover the range of social enterprises discussed in the literature review. These three cases demonstrate some of the diversity identified with social entrepreneurship ventures. They differ in terms of sustainability strategies and their level of participation in the market or profit-orientation. The information given here was sourced from the websites of these social enterprises and from existing case studies.

\subsubsection{Rags2Riches, Inc.}

For some social enterprises, sustainability also means 'economic empowerment' and 'self-reliance' of the groups that they are trying to assist (Dacanay, 2006). There is a desire to see these groups be able to manage and sustain development initiatives in their own communities (Dacanay, 2006). Rags2Riches, Inc. seems to share this sentiment, hence their commitment to "empower communities from marginalized sectors, improve the lives, and secure the future of families in these communities through building socially responsible 
and sustainable community-based enterprises" (Rags2Riches, 2010a). The company works with women, mostly mothers, from an urban poor community where rug-weaving was a common household enterprise (Que \& Adriano, 2009). These rugs were made from scraps of cloth that the women scavenged from the garbage dumps of Payatas, which is Metro Manila's main landfill. However, middlemen started to take-over the sourcing of these scraps of cloth, with some going to garment factories directly (Que \& Adriano, 2009). The women now had to buy raw materials instead of getting them for free. Moreover, another set of middlemen who marketed the rugs got most of the profits while the women only made 1.00 PHP per rug (around .03 cents NZD ${ }^{14}$ ) (Rags2Riches, 2010b).

Viewing the situation as a social injustice, a group of students and young professionals, together with a Jesuit brother, started thinking of ways to help the women of Payatas. The group came up with a project that would facilitate market access for the women, without going through middlemen (Rags2Riches, 2010b). In July 2007, Rags2Riches, Inc. was established. They started by selling the rugs in different bazaars, which became a success (Rags2Riches, 2010b). The women members now had access to the market and their income increased from 1.00 to 20.00-25.00 PHP (around 0.63 to 0.78 NZD), per rug (Que \& Adriano, 2009). Rags2Riches demonstrates innovation through the expansion of their product lines and the partnerships that brought about this expansion. From rugs, the company now produces high-end fashion accessories such as bags and purses, as well as home accessories through collaboration with Filipino fashion designers.

The company describes itself as a social business enterprise that makes profits but according to co-founder Reese Fernandez, they have different bottom

14 as of August 2010 (this exchange rate is used throughout the chapter) 
lines ("Filipino retailers pave the way for socially-responsible business," 2010). They came up with the 4Ps-People, Planet, Profit, and Positive Influence, to describe these bottom lines. The social orientation of the company is clear in their expression of commitment to the women and community that they work with. Empowering the women also means treating them as business partners and including them in the decision-making process, says Fernandez (Que \& Adriano, 2009). The company is now in the process of assisting the women in forming the Rags2Riches Payatas Cooperative, which will be independent from Rags2Riches, Inc. and fully owned by the women. According to Mark Ruiz (2010), co-founder and board member, it is a step that is necessary to the empowerment of the community (see Box 4.4.2.1).

Box 4.4.2.1

Rags2Riches Business Model

\section{rags? riches}

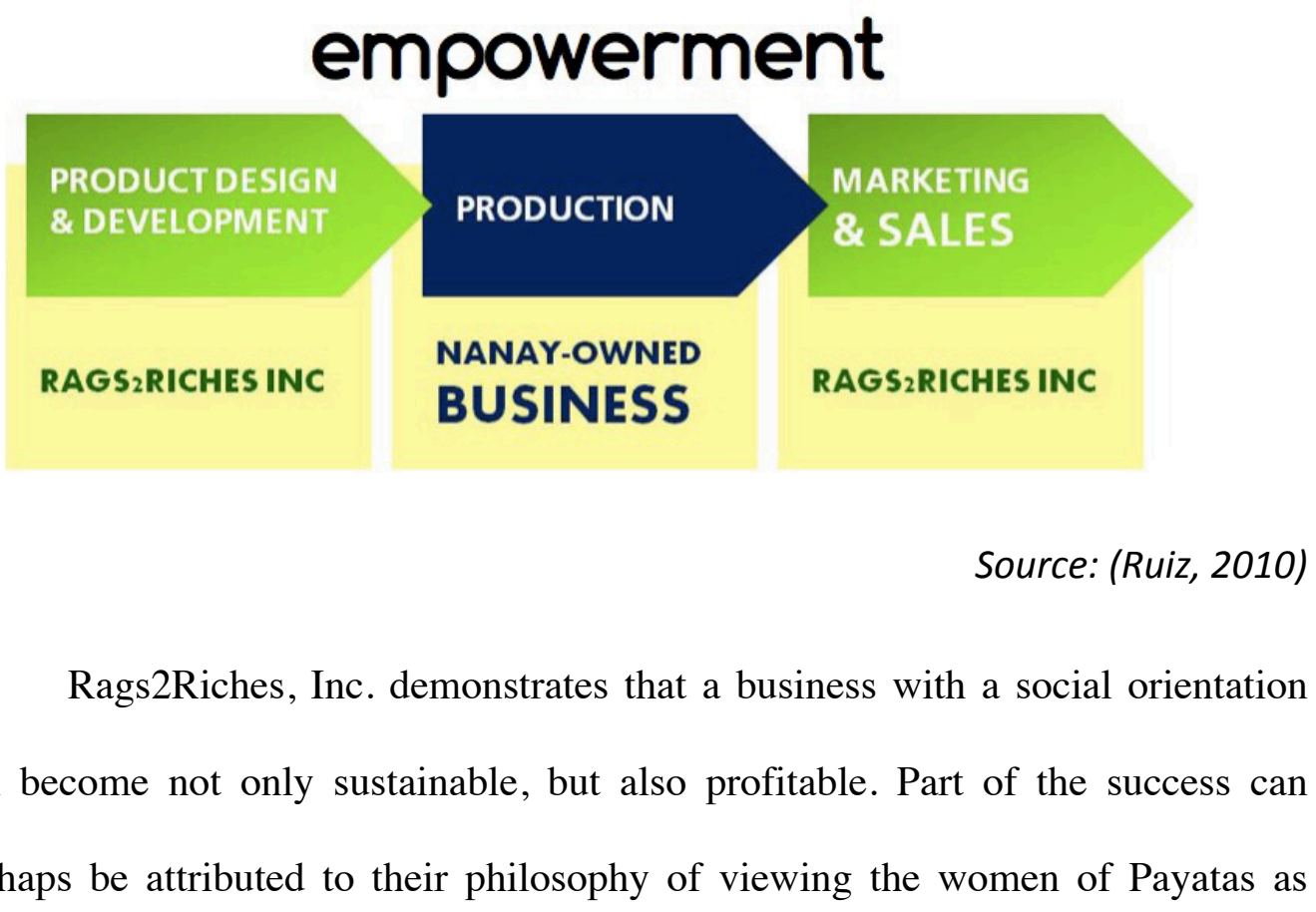


partners instead of beneficiaries, and seeing their potential. A large part of their activities involve teaching business principles to the women, an area that Rags2Riches finds challenging (Que \& Adriano, 2009). In addition, most of the strategies employed by Rags2Riches such as marketing and product development is standard business practice. The alternative being offered by their model is that the workers/weavers are also the owners. The board members believe that the women will be empowered by becoming business owners, which could certainly help in enlarging the economic opportunities for these women but it is unclear how this affects the broader community. As stated above, Rags2Riches is also concerned with improving the lives of families living in marginalized communities. However, there is no indication that they address the possible effects of the intervention on the relationship between the women that they work with directly and the rest of the community.

\subsubsection{Alternative Indigenous Development Foundation, Inc.}

The agriculture sector remains as a significant part of the Philippine's economy, particularly as a source of employment, accounting for $37 \%$ of the total labour force (Habito \& Briones, 2005). However, $70 \%$ of the poor in the country are based in rural areas and are dependent on agriculture-based activities for their income (David, 2003). For the Alternative Indigenous Development Foundation, Inc. (AIDFI), in order to overcome this situation of chronic poverty in rural areas, the marginalized sectors-landless farmers; farm workers; agrarian reform beneficiaries; settlers; indigenous communities; and small agricultural producers, should have access to and control of assets that are essential to their livelihood such as land, water, energy, and appropriate tools and technologies (Ombion, 
2009, forthcoming). With this in mind, AIDFI aims to empower these marginalized sectors to become self-reliant and self-governing rural communities.

The organization was formed in 1992, but it wasn't until 1997 that AIDFI made some progress with its activities. They decided to focus on the design and development of appropriate technologies for sustainable and organic agriculture (Alternative Indigenous Development Foundation, 2010a). The organization's flagship technology is their patented Hydraulic Ram Pump (see Figure 4.4.2.2), which was designed for use in areas located in the mountainous terrain of Negros Province (Wheldon \& Pepler, 2007). The hydraulic ram pump does not require electricity or fuel for it to run. Instead, it makes use of the energy from water flowing down, to pump a portion of that water to a greater height (Alternative Indigenous Development Foundation, 2010d). AIDFI was able to modify the technology and came up with a design that made use of locally available materials, and can be maintained by local communities with minimal tools (Wheldon \& Pepler, 2007).

AIDFI recognizes that technology alone would not be sustainable, hence they also engage in capacity development for rural communities (Ombion, 2009, forthcoming). They encourage the formation of community-based enterprises to increase the incomes of families and to develop self-reliant rural communities. For instance, in some areas where ram pumps have been installed, community members form water associations that maintain the ram pumps. The water associations can earn extra income by selling surplus water to nearby communities that do not have a ram pump installed yet (Wheldon \& Pepler, 2007). Thus far, there are 11 water associations out of the 200 communities nationwide that have AIDFI water systems (Ombion, 2009, forthcoming). The 
water associations can already be considered as social enterprises since they provide social benefits to the communities in a sustainable manner.

Figure 4.4.2.2

Hydraulic Ram Pump Diagram

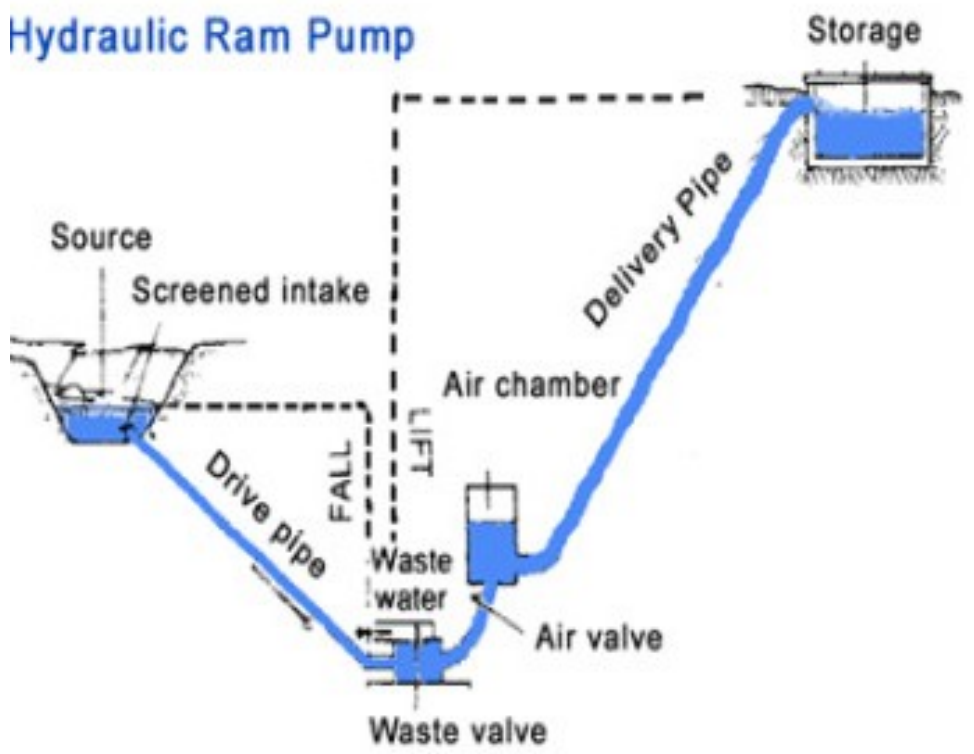

Source: (Now on the Spot, 2010)

While aiming for the sustainability of their partners' projects, AIDFI also aims to be a sustainable organization itself. Although it is registered as a nonprofit NGO, AIDFI has several entrepreneurial activities that earn income to support its operations. Since technology for the Hydraulic Ram Pump is patented, AIDFI is the only organization in the country that manufactures the system. They encourage other groups in the Philippines to become installers and they offer training and technical consultancy services for this purpose (see Alternative Indigenous Development Foundation, 2010b). For international parties that are interested in the technology, AIDFI offers technology transfer services, including how to manufacture the ram pumps (Alternative Indigenous Development Foundation, 2010b). The organization has also set-up and opened a Technopark 
that offers guided tours for academic institutions, local government units, farmers associations, and any groups or citizens that are interested in learning about AIDFI's technologies (Alternative Indigenous Development Foundation, 2010c). In addition to the proceeds from entrance fees, the Technopark also has a learning centre, which can be hired for trainings and conferences (Alternative Indigenous Development Foundation, 2010c).

In sum, AIDFI is an example of a social enterprise that is a non-profit organization but has some earned income activities that sustain its operations. The organization has a clear social mission, which is to empower rural communities through the promotion of appropriate technologies that can help improve livelihoods and uplift standards of living. In addition, the sustainability of community projects is ensured by utilizing local resources and skills, as well as introducing an entrepreneurial component. As their name suggests, AIDFI offers possibilities for truly locally-based development, in spite of the challenges present in the communities that they work with.

\subsubsection{Kooperatibang Likas ng Nueva Ecija (KOOL-NE)}

Like AIDFI, the Kooperatibang Likas ng Nueva Ecija (KOOL-NE) is rooted in the agricultural sector. It is a farmer-based multi-purpose cooperative in the province of Nueva Ecija, which is often called "The Rice Granary of the Philippines", with $60 \%$ of the province's land area dedicated to rice farming (Marin, Mercado, \& Nicolas, 2008). Rice production in the Philippines is relatively low as compared to other Southeast Asian countries, thus the country still imports rice to meet its consumption requirements. For now, the National Food Authority (NFA) limits the quantity of rice imports per year but this could change once quantitative restrictions are lifted and the Minimum Access Volume 
(MAV) of rice under World Trade Organization (WTO) rules is increased (Marin, et al., 2008). The implication for the 11.5 million rice farmers is that they would need to compete with the cheaper imports. In the midst of decreasing productivity and increasing costs of farm inputs, rice farmers in the Philippines are at risk of not being able to earn enough to sustain their basic needs.

In response to the situation, the Philippine Rural Reconstruction Movement (PRRM), initiated their Alternative Rural Finance (ARF) and Alternative Trading and Marketing (ATM) project for the farmers of Kalipunan ng mga Magbubukid para sa Likas-kayang Pananakahan sa Nueva Ecija (KALIKASAN-NE), also a multi-purpose cooperative (Marin, et al., 2008). This was part of PRRM's Alternative Rice Production Pattern (APP) program, which aims to increase the income of farmers based on the following strategies (Box 4.4.2.3).

\begin{tabular}{c||c|}
$\begin{array}{c}\text { Box 4.4.2.3 } \\
\begin{array}{c}\text { PRRM's Alternative } \\
\text { Rice Production } \\
\text { Program }\end{array}\end{array}$ & $\begin{array}{l}\text { Method of farming: Shift from intensive agro-chemical } \\
\text { use to low external input or organic rice production. }\end{array}$ \\
& $\begin{array}{l}\text { Mode of production financing: Shift from dependence } \\
\text { on usurious informal credit to mainly self-financing. }\end{array}$ \\
& $\begin{array}{l}\text { Marketing. Shift from reliance on traditional traders to } \\
\text { farmers' participation in a bulk marketing scheme. }\end{array}$ \\
\hline
\end{tabular}

Source: (Ciencia, 2009-2010, p. 14)

In 2002, KOOL-NE was jointly established by PRRM and KALIKASAN-NE to support the sustainable rice production and marketing initiatives of the farmermembers and help them raise their incomes (Roque, 2006). Based on the abovementioned strategies, KOOL-NE supports its farmer-members through: provision of low-cost farm inputs for the production of organic rice; assistance in 
the development and processing of value-adding products and rice by-products; marketing and selling of products; and microfinancing (see Ciencia; Marin, et al., 2008).

Since rice harvesting does not occur for the entire year, KOOL-NE has introduced the production of value-adding products and rice by-products to their members. Examples of these products are: rice coffee, rice wine, rice straw handicrafts, and carbonized rice hull (Ciencia, 2010). The farmer-members of KOOL-NE will be the household-based producers while KOOL-NE will oversee the product development and marketing (Ciencia, 2010). They plan to "form partnerships with local health food shops, supermarket chains, export organizations, and farmers' associations" for the marketing of these products (Ciencia, 2010). Hopefully, with this initiative, the farmers can still be productive and earn income after the harvesting season.

According to Shubert Ciencia, PRRM's Area Manager for Nueva Ecija, KOOL-NE is ran as a "corporative" (Roque, 2006). It means that their organizational structure is that of a cooperative but the management is similar to business corporations, with a team dedicated to the financing and marketing aspects (Marin, et al., 2008; Roque, 2006). Social entrepreneurship can sometimes be thought of as the application of business principles to social development initiatives, whether these involve earned-income activities or not (dela Cruz, 2009). In the case of KOOL-NE, it is a social enterprise that employs business principles and has earned-income activities. As characteristic of social enterprises, KOOL-NE aims to be a financially sustainable organization. Being a cooperative, KOOL-NE gets its capital from its members. Farmers who want to become members of KOOL-NE pay a membership fee of 100.oo PHP (3.13 
NZD) and raise 4,800 PHP (150.30 NZD) as share capital (Marin, et al., 2008). The cooperative then earns income by selling the organic rice produced by the farmer-members. According to the General Manager of the cooperative, the members are encouraged to see farming as a business enterprise so that they will understand the importance of being financially sustainable (Marin, et al., 2008).

Overall, KOOL-NE aims to increase the incomes of its rice farmermembers by providing the necessary support throughout the production cycle. Through the loans offered, farmers are able to purchase farm inputs for organic rice production without having to go to loan sharks or usurers. Since the cooperative also accepts harvested rice as repayment for the loan, farmers do not have to go through rice traders who sometimes buy their products at prices lower than what is prescribed by the NFA (Marin, et al., 2008). Again, the Alternative Rice Production Pattern is helping prevent income leakages for the farmers (Ciencia, 2009-2010). As a "corporative", KOOL-NE demonstrates how cooperatives are adapting business concepts such as marketing to advance not only the goals of the organization, but also the interests of its members.

\subsection{Conclusion}

This chapter gave an overview of the social entrepreneurship industry in the Philippines. In a country with prolific numbers of development practitioners and initiatives, social entrepreneurship is fast-becoming the social development approach of today. The method of achieving a social mission while being financially sustainable appeals to many NGOs who want to become less dependent on aid.

The growth in the number of social enterprises in the Philippines can perhaps be attributed to several factors. Employment opportunities in the country are limited, which 
lead to the government's support for entrepreneurship as a strategy for increasing livelihood activities. Assistance programmes for enterprises were mobilized, resulting in an increase in the number of MSMEs. Social enterprises, particularly the ones shown here are also concerned with expanding economic opportunities for their partner communities and likewise support entrepreneurial activities. Social entrepreneurship goes beyond the economic benefits by encouraging entrepreneurial activity as a way to address other development issues.

Social enterprises continue to grow in number since there are institutions that provide the necessary support. Training and capacity building services are available from academic and network institutions. Based on the types of training programmes being offered, it seems that the skills needed to for social entrepreneurship are similar to the skills required to operate a business and/or a non-profit organization. Financial support is also available from funding institutions for budding social entrepreneurs. Moreover, existing social enterprises can improve their operations through learning from each other and establishing standards or performance measures.

The shift towards social entrepreneurship practices marks a paradigm shift for development practitioners who traditionally viewed the market as incompatible with social objectives (Hechanova-Alampay \& dela Cruz, 2009). Social enterprises are not averse to market activities and are finding ways to utilize the market to advance social goals. The examples presented here demonstrate how engaging the market can be an advantage not only for the organization but for their partners or members as well. The level of market integration differs but all three social enterprises aim to sustain their operations and at the same time facilitate the economic empowerment of their partners/members (see Table 4.5). Social enterprises in the Philippines, including those presented here also have an environmental objective or a 'third bottomline'. 
Rags2Riches, Inc. is ensuring that their production process is ecologically safe; AIDFI is promoting appropriate and environment-friendly technologies; and KOOL-NE is advocating sustainable and organic agriculture.

Table 4.5

The Range of Social Entrepreneurship-Philippine Examples

\begin{tabular}{|c|c|c|}
\hline Place of Social Goods & Role of Commercial Exchange & Example \\
\hline $\begin{array}{l}\text { Enterprise goals are } \\
\text { exclusively social }\end{array}$ & No commercial exchange & NGOs \\
\hline $\begin{array}{l}\text { Enterprise goals are } \\
\text { exclusively social }\end{array}$ & $\begin{array}{l}\text { Some commercial exchange, } \\
\text { any profits directly to social } \\
\text { benefit (integrated) or in } \\
\text { support of enterprise } \\
\text { (complementary) }\end{array}$ & $\begin{array}{l}\text { Alternative Indigenous } \\
\text { Development Foundation Inc. }\end{array}$ \\
\hline $\begin{array}{l}\text { Enterprise goals are chiefly } \\
\text { social, but not exclusively }\end{array}$ & $\begin{array}{l}\text { Commercial exchange; profits } \\
\text { in part to benefit } \\
\text { entrepreneur } \\
\text { supporters }\end{array}$ & $\begin{array}{r}\text { KOOL-NE; } \\
\text { Rags2Riches, Inc. }\end{array}$ \\
\hline $\begin{array}{l}\text { Social goals are prominent } \\
\text { among other goals of the } \\
\text { enterprise }\end{array}$ & $\begin{array}{l}\text { Commercial exchange; profit- } \\
\text { making to entrepreneur and } \\
\text { others is strong objective }\end{array}$ & Rags2Riches, Inc. \\
\hline $\begin{array}{l}\text { Social goals are among the } \\
\text { goals of the enterprise, but } \\
\text { subordinate to others }\end{array}$ & $\begin{array}{l}\text { Commercial exchange; profit- } \\
\text { making to entrepreneur and } \\
\text { others is prominent or prime } \\
\text { objective }\end{array}$ & $\begin{array}{r}\text { 'Cause branding'; social } \\
\text { objectives undertaken by } \\
\text { corporations }\end{array}$ \\
\hline
\end{tabular}

Source: (adapted from Peredo \& McLean, 2006, p. 63)

Having multiple objectives seems to be one of the main challenges that social enterprises face. Balancing social and market goals can be difficult especially for the organizations that are assisting community-based enterprises (Hechanova-Alampay \& dela Cruz, 2009). Partner groups or communities do not necessarily have a business mindset. For instance, the board members of Rags2Riches, Inc. recognize that the women they work with still need to understand market factors such as demand, and how it affects them (Keh, 2009). The same is true for KOOL-NE in encouraging the farmers to be more entrepreneurial so that the cooperative can be sustainable. However, observations on social enterprises seem to focus more on how these organizations can assist communities in improving or gaining business acumen. There is little discussion 
on how market-based activities or business-oriented practices, which are being encouraged in social entrepreneurship, can affect existing community practices and relationships. One consequence that has been mentioned in the literature is that marketbased transactions tend to weaken the social capital on which communities depend on to meet their basic needs (Gold, 2003). Chapter 6 will explore this further by examining a social entrepreneurship type programme, particularly the activities involving business and market-oriented practices, and consider the impact of these activities on communities

Overall, in a country where poverty and social injustice is such that citizens prefer to leave and find hope elsewhere, the search for effective and sustainable development interventions has been a challenging endeavour. NGOs, particularly those working with peoples organizations and grassroots groups have been looking for approaches that are not tied to donor conditionalities. Social entrepreneurship provides an opportunity for development practitioners to become financially sustainable and be able to determine their own goals, processes, and activities. However, social entrepreneurship is also emerging as a field of expertise that promotes a certain type of individual - the social entrepreneur, or organization - a social enterprise, as having the solutions to successfully addressing development problems, rather than local communities. On the other hand, as demonstrated by the social enterprises presented here, communities and grassroots groups are not just passive beneficiaries but seem to be active partners in the pursuit of mutual development goals. Still, whether this participation is tantamount to communities being able to pursue their own selfdetermined goals cannot be easily ascertained. It seems that social enterprises rather than their community partners largely define goals and objectives. The next chapter will examine the activities of another Philippine social enterprise to determine whether social 
entrepreneurship practices contribute to alternative pathways that enable communities to pursue self-determined goals. 
CHAPTER 5

Exploring Alternative Ways: Community Initiative through Social

Entrepreneurship

Case Study on A Single Drop for Safe Water, Part 1

\subsection{Introduction}

The previous chapter showed that social enterprises in the Philippines have certain features in common. A primary feature that they share is ensuring the sustainability of their operations, usually by adopting income-generating activities. Although being able to finance projects and activities continuously is a key consideration, sustainability also entails strengthening the capability of communities to manage initiatives on their own. In their review of several social enterprises, HechanovaAlampay \& dela Cruz (2009, p. 122) found that these organizations "invested heavily in human resource development" and consider this to be one of the success factors for Philippine social enterprises. Activities such as business and leadership training that are meant to empower communities are integrated in the organizations' programmes (see Hechanova-Alampay \& dela Cruz, 2009). Ideally, communities will become self-reliant and able to make decisions regarding their own development.

The significance of empowerment and community participation is emphasized in alternative and grassroots development approaches (Mayo \& Craig, 1995). However, as mentioned in the literature review chapter, many of 'alternative development' principles have been adopted by mainstream development practices. But it does not mean that community-based ideals such as empowerment and participation are not valid or valuable objectives. From a post-structural perspective, community empowerment requires challenging the dominant discourses of power so that alternative voices can be heard (Ife, 2002). Likewise, post-development practice advocates shifting the power to define standards, goals, and means, from 'development experts' to members of local 
communities so that alternative pathways will be revealed. On the other hand, social entrepreneurship does not explicitly deal with discourses of power, but social enterprises, at least in the Philippines, are concerned with empowering members of the community by providing economic opportunities and acknowledging that local skills and knowledge are valuable to achieving desired goals.

This chapter further examines social entrepreneurship practice and its potential to open genuine alternative pathways by looking into the operations of A Single Drop for Safe Water (ASDSW), a non-profit organization that provides assistance to, and builds the capacity of community-based organizations to implement water and sanitation projects. As a social entrepreneurship organization, ASDSW believes that sustainability can be best achieved by 'giving a hand-up not a hand-out', which means strengthening local communities who have better knowledge of their environment and resources, and are therefore most capable of implementing their own projects. The organization is committed to "providing communities ownership of not just the project but of the process" (K. Lee, personal communication, October 8, 2010). The chapter is structured as follows: the next section is mainly a description of ASDSW-its history, organizational structure, and services, which will be followed by a review of activities in the first module of ASDSW's PODS programme to determine the opportunities and challenges in community initiatives, and how these can contribute to finding alternative ways.

\subsection{A Single Drop for Safe Water, Philippines}

\subsubsection{History}

According to Ashoka, "Social entrepreneurs often seem to be possessed by their ideas, committing their lives to changing the direction of their field" (Ashoka, 2010). 
This description fits ASDSW's founder-Gemma Bulos, a Filipino-American who was a professional singer and pre-school teacher living in New York City at the time of the September 11 attacks. Her pre-school class was located across the World Trade Centre but due to personal reasons, Gemma was not in New York City that particular day (G. Bulos, interview, June 1, 2010). Upon her return, she found that people became united through the grief and sadness brought about by the events of that day. This became Gemma's inspiration for pursuing a mission of uniting people through music. She wrote a song called "We Rise" and decided to start the Million Voice Choir, a movement that would mobilize people around the world and unite them through a celebration of their connectedness.

Social entrepreneurs are also described as risk-takers or not limited by available resources when pursuing a social mission (see Dees, 1998). Gemma seems to have this characteristic as well. She decided to travel the world with little money to spend in order to build the choir. In 2003, her song was declared as a Human World Anthem by the United Nations. The same year, Gemma met someone at the Water for Life Conference who helped her establish a non-profit organization-A Single Drop U.S., which allowed her to receive donations in support of raising awareness on global water issues through the Million Voice Choir (G. Bulos, interview, June 1, 2010). On the $21^{\text {st }}$ of September 2004, which was the International Day for Peace and Global Ceasefire Day, people from over a hundred cities in sixty countries sang "We Rise" together.

Fulfilling this mission was a great achievement for Gemma, but she wanted to do something more concrete, such as community water projects (G. Bulos, interview, June 1, 2010). In 2005, she went to the Centre for Affordable Water and Sanitation Technologies in Canada to undergo training on building Bio-Sand filters, a technology that she decided to bring to the Philippines. Gemma met with several organizations in the 
Philippines and invited them to participate in trainings on the Bio-Sand Filter, which A Single Drop, U.S. would sponsor. In January of 2006, she met Kevin Lee or Kiwi, a former Peace Corps volunteer who served in the mountain village of Ambaguio in Northern Luzon (A Single Drop, 2010). Kiwi has a mechanical engineering background and he designed a community water system project in Ambaguio (A Single Drop, 2010). Together with representatives from CAWST, they organized six trainings in the provinces of Palawan, Samar, and Masbate (G. Bulos, interview, June 1, 2010). In the same year, A Single Drop for Safe Water, Philippines was registered as a non-profit organization in Puerto Princesa City, Palawan after they received a grant worth 50,000 CAD from the Canadian Embassy.

One of the critiques directed at social entrepreneurship is its emphasis on the individual experiences and achievements of social entrepreneurs (see Nicholls \& Cho, 2006). Indeed, organizations such as Ashoka and the Schwab Foundation provide support to individuals who meet the criteria to be considered as social entrepreneurs. Recently, Gemma was recognized as one of Schwab Foundation's Regional Social Entrepreneurs of the Year for Asia at the World Economic Forum's Annual Meeting 2010 (see Gee, 2010). Innovation is one of Schwab Foundation's key criteria for selecting social entrepreneurs, which means: "The candidate has brought about social change by transforming traditional practice. Such transformation can have been achieved through: an innovative product or service; the development of a different approach; or a more determined or rigorous application of known technologies, ideas and approaches" (Schwab Foundation for Social Entrepreneurship, 2010a). According to the Foundation, “ASDSW's key innovation is teaching communities to create and run their own clean water systems through the People Offering Deliverable Services (PODS) model" (2010b). 
Although it was Gemma's vision and personal journey that turned into the establishment of ASDSW, it should be emphasized that the development of the organization's programmes and activities is the collaborative work of Gemma, Kiwi, the staff, their partner organizations and partner communities. The organization's history involves the development of its programme and staff (see Box 5.2.1).

Box 5.2.1

ASDSW Organizational Development Timeline

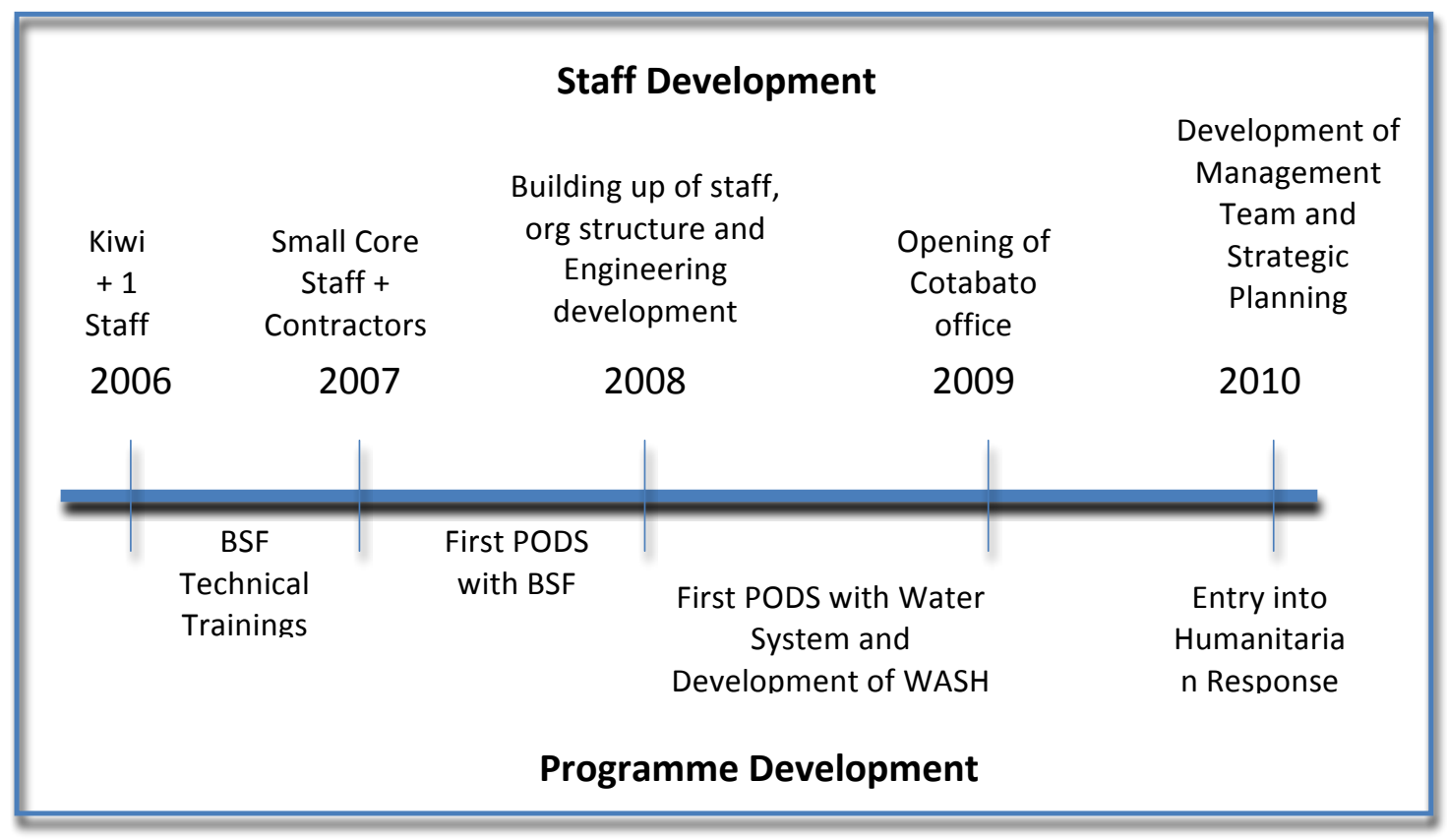

Source: (K. Lee, personal communication, October 8, 2010)

\subsubsection{Organizational Structure and Funding}

ASDSW, Philippines is an autonomous international office of A Single Drop, U.S. - the non-profit organization that Gemma started in 2003. Gemma acts as the Executive Director of A Single Drop, U.S. and Founding Director of ASDSW, Philippines $^{15}$ (A Single Drop, 2010). There is a set of Board Members for both

15 In December 2010, it was announced that A Single Drop, U.S. has been dissolved as an organization and consequently, Gemma Bulos has resigned from the Board of Trustees of ASDSW, which remains as a separate legal entity (Bulos, 2010) 
organizations. ASDSW has a separate staff headed by Kevin Lee as Executive Director. In 2009, ASDSW opened a Satellite Office in Cotabato City in Mindanao in addition to their main office in Puerto Princesa City (A Single Drop for Safe Water, 2009b). Both offices are headed by the Executive Director and are composed of administrative and field personnel. Most of ASDSW's field personnel are trainers or facilitators since their core programme involves capacity building and knowledge transfer. ASDSW's website (http://www.asdforsafewater.org/) lists 15 personnel, excluding the Founding and Executive Directors.

Figure 5.2.2

ASDSW Organizational Structure

A Single Drop For SafeWater Organizational

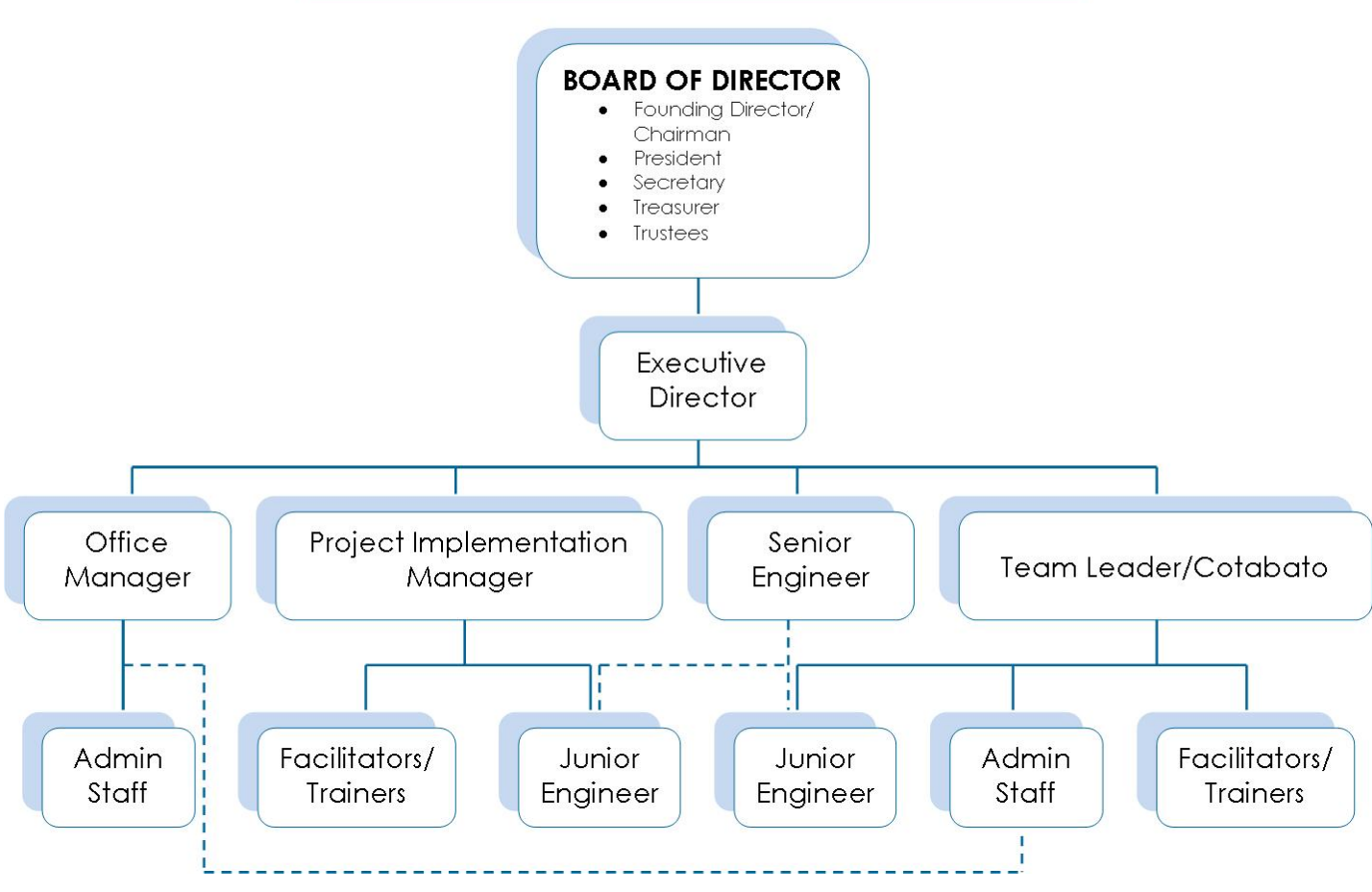

Source: (M. Obligar, personal communication, September 8, 2010)

The organization earns income through training, consulting or management fees, which they use to finance the office's expenses including staff salary (K. Lee, personal communication, October 8, 2010). They specialize in water, sanitation, and hygiene (WASH) programmes and offer their services to other local and international 
organizations, LGUs, and communities. ASDSW earns 95\% of its revenue and in 2009, their annual budget totalled 85,000 USD (Schwab Foundation for Social Entrepreneurship, 2010b). They receive donations in the form of supplies, while the conduct of trainings, including those conducted at the community level, is a service that donors pay for (K. Lee, personal communication, October 8, 2010). The community, LGU and other NGOs also provide counterpart funding for project implementation (ASDSW Staff, interview, May 26, 2010).

\subsubsection{Services}

ASDSW aims to strengthen the capacity of local governments, NGOs, and community groups to plan and implement community-driven water and sanitation programmes by providing training and consultation on organizational development; appropriate technologies; and WASH education.

\subsubsection{PODS Training}

The People Offering Deliverable Services or PODS model is a sustainable approach to implementing community-based WASH projects, which involves forming or strengthening community organizations that will take the lead in planning and managing the projects. The process aims to empower communities by providing them the opportunity to take ownership of the projects and building their capacity (A Single Drop for Safe Water, 2010b). The local PODS are intended to be independent and sustainable organizations that provide services to the community and follow either a cooperative or micro-business model (A Single Drop for Safe Water, 2010b). The main purpose is to provide WASH services and this entails paying for manpower and setting aside funds for maintenance as well as expansion of services (K. Lee, personal communication, 
October 8, 2010). Therefore "there is an income-generating component but the focus is on affordable sustainability and not high profitability" (K. Lee, personal communication, October 8, 2010).

ASDSW has developed a four-week organizational development training programme $^{16}$ for the formation of local PODS, which covers the following topics: Strategic Planning; Business Planning, Financial Management and Bookkeeping; and Installing Continuity of Project (see Appendix 2). The PODS model is currently applied to water systems and Bio-Sand Filter (BSF) projects but the BSF PODS is a more business-oriented model wherein profit will be a main incentive for a smaller group (K. Lee, personal communication, October 8, 2010). The PODS training programme is a significant part of the organization's drive towards community-led projects and it would be further examined later on in this chapter and in the next one.

\subsubsection{WASH Technologies}

ASDSW advocates the use of community-based technologies that are: "simple, durable and easy to maintain; affordable that it uses local resources and infuses local economy; can be manufactured locally and replicated easily; and does not have negative environmental impact" (A Single Drop for Safe Water, 2010d). However, ASDSW rarely conducts stand-alone technical trainings since training for water systems and the BSF or Bio-Sand Filter are usually done together with organizational development training, depending on project type.

16 At the time of writing, ASDSW is in the process of updating their PODS training modules. Some information provided here may change. 
An essential technology training that ASDSW offers is water testing using a Portable Microbiology Lab. The kit can be used by any person with minimum training to conduct and interpret microbiological tests in the field without expensive equipment or electricity (A Single Drop for Safe Water, 2010d). The Portable Microbiology Lab can be used to test a community's water sources for bacteria such as E. Coli. Meanwhile, the BSF is a technology that can be used by households in de-contaminating their water. According to CAWST (2010), the BSF has been proven to remove up to $98.5 \%$ of bacteria and up to $99.9 \%$ of protozoa from contaminated water. It was designed by Dr. David Manz and is an adaptation of the conventional slow sand filtration process (A Single Drop for Safe Water, 2010d). Unlike the traditional slow sand filtration, the BSF does not require water to flow through it all times (A Single Drop for Safe Water, 2010d). The BSF is also smaller and the materials needed for construction can be commonly found in any locality so it is relatively simple and inexpensive to construct.

ASDSW also provides training on community water systems should local PODS choose to install a new water system or rehabilitate an existing one. Examples of community water systems that ASDSW supports are: Wells-direct drilling to access groundwater sources; Spring development_-gravity-fed systems to capture and pipe water to communities; Pumps - installation and repair of own pumps, which can also be offered as an income-generating service to surrounding communities (A Single Drop for Safe Water, 2010d).

In addition to these, ASDSW also supports the installation of water storage equipments such as Ferro-cement tanks and the construction of sanitation technologies such as pit latrines (A Single Drop for Safe Water, 2010d). 


\subsubsection{WASH Planning}

ASDSW, together with the Local Government Support Program in the Autonomous Region in Muslim Mindanao (LGSPA) developed a seminar series on

WASH Planning to assist local governments and community leaders in evaluating their water, sanitation, and hygiene needs and designing an Action Plan that would address these needs (A Single Drop for Safe Water, 2010e). Whereas the PODS training is conducted directly at the community level, the WASH Planning seminar seems to be focused on the municipal level and is geared towards The Governance Approach to WASH Defined

\section{Box 5.2.3}

The Governance Approach to WaSH is an empowering process of engagement that would increase the supply and quality of WaSH services by increasing the demand for it, enhancing the abilities of suppliers to provide it and presenting opportunities for both duty holders (government) and claim makers (citizens and communities) to systematically work together, thereby creating, strengthening and transforming governance relationships.

Source: (LGSPA, 2009, p. 11) the formation of a Regional organization composed of Municipal WASH Task Forces (MWTFs), Water Sanitation Associations (WSAs), and NGOs (A Single Drop for Safe Water, 2009a). The WASH Planning process is a 'governance approach to WASH' (see Box 5.2.3) that builds partnerships between LGUs and community organizations. ASDSW actively seeks working with local governments since LGUs are mandated to provide WASH services and ASDSW aims to raise the priority of WASH in local development plans (K. Lee, personal communication, October 8, 2010).

Community participation in the process is pursued through the WSAs, which are "community-based organizations formed primarily to operate, manage and maintain water, sanitation and hygiene services in a particular area" (LGSPA, 2009, p. 31). In this sense, the WSAs are similar to local PODS organizations but 
WSAs are also expected to: "represent and speak for the WASH concerns of the community, and elevate these concerns to the local government for appropriate action" (LGSPA, 2009, p. 31). The first step in the process is the formation of the WSAs and MWTFs. These groups are meant to work together in each subsequent step of the planning process, which includes: Conducting an Inventory of WASH Resources and Needs; Formulating the WASH Plan; WASH Initiatives Implementation; and Planning and Implementing an Information, Education, Communication (IEC) Campaign for WASH (see LGSPA, 2009). Throughout the process, the broader community is convened twice: once for the Community Focal Group Discussion as a final step in the WASH Inventory, and a second time for presenting and validating the Municipal WASH Plan. The rest of the community is invited to participate in the installation of the WASH system by contributing labour or the WSA can assign particular tasks to community members.

According to Executive Director Kevin Lee (personal communication, October 8, 2010), this process, particularly the formation of MWTFs and WSAs, is now gaining the most recognition among the organization's programmes. $\mathrm{He}$ added that ASDSW was recently hired by an LGU to assist them in their WASH Planning and now there are investors competing for the LGU's projects, which he believes "changes the development landscape to go from Supply Driven to Demand Driven [and] would completely shift the balance of power within the development industry and vastly improve the success of development efforts" (K. Lee, personal communication, October 8, 2010).

\subsubsection{Humanitarian Response}


ASDSW has recently added Emergency Relief to their operations, seeing as the Philippines is one of the most disaster prone countries in South East Asia, with typhoons, floods, earthquakes and volcanic eruptions affecting the country. In the event of disasters, international NGOs or UN agencies usually take the lead in humanitarian response and local NGOs are tapped as implementers (A Single Drop for Safe Water, 2010a). However, local NGOs have limited capacity in the area of emergency relief and "the relationship between local NGOs and international NGOs/UN agencies is typified as a 'humanitarian contractorship', with the international organizations directing areas and actions for the emergency relief" (A Single Drop for Safe Water, 2010a). In response, ASDSW will be spearheading a Humanitarian Response Consortium (HRC), which aims to strengthen the capacity of local NGOs to implement emergency relief operations through coordination and complementation of skills and resources. The HRC will be composed of NGOs in different geographic locations and with varying areas of specialization to ensure that emergency response is comprehensive and appropriate to the local situation (A Single Drop for Safe Water, 2010a). As a group, the HRC will respond to emergency situations in coordination with the government, other local and international NGOs and affected communities (A Single Drop for Safe Water, 2010a).

\subsubsection{Areas of Operations}

ASDSW has countrywide operations, with projects in 14 provinces and one city in the National Capital Region (see Figure 5.2.4). Area selection is mostly donor-driven since donors pay ASDSW for training services. Although there are instances when the donors would ask ASDSW to select a community "based on need" (ASDSW Staff, interview, May 26, 2010). ASDSW is venturing into working with communities who 
approach them and they will assist the communities in mobilizing the necessary funds (G. Bulos, interview, June 1, 2010).

Figure 5.2.4

ASDSW Program Sites

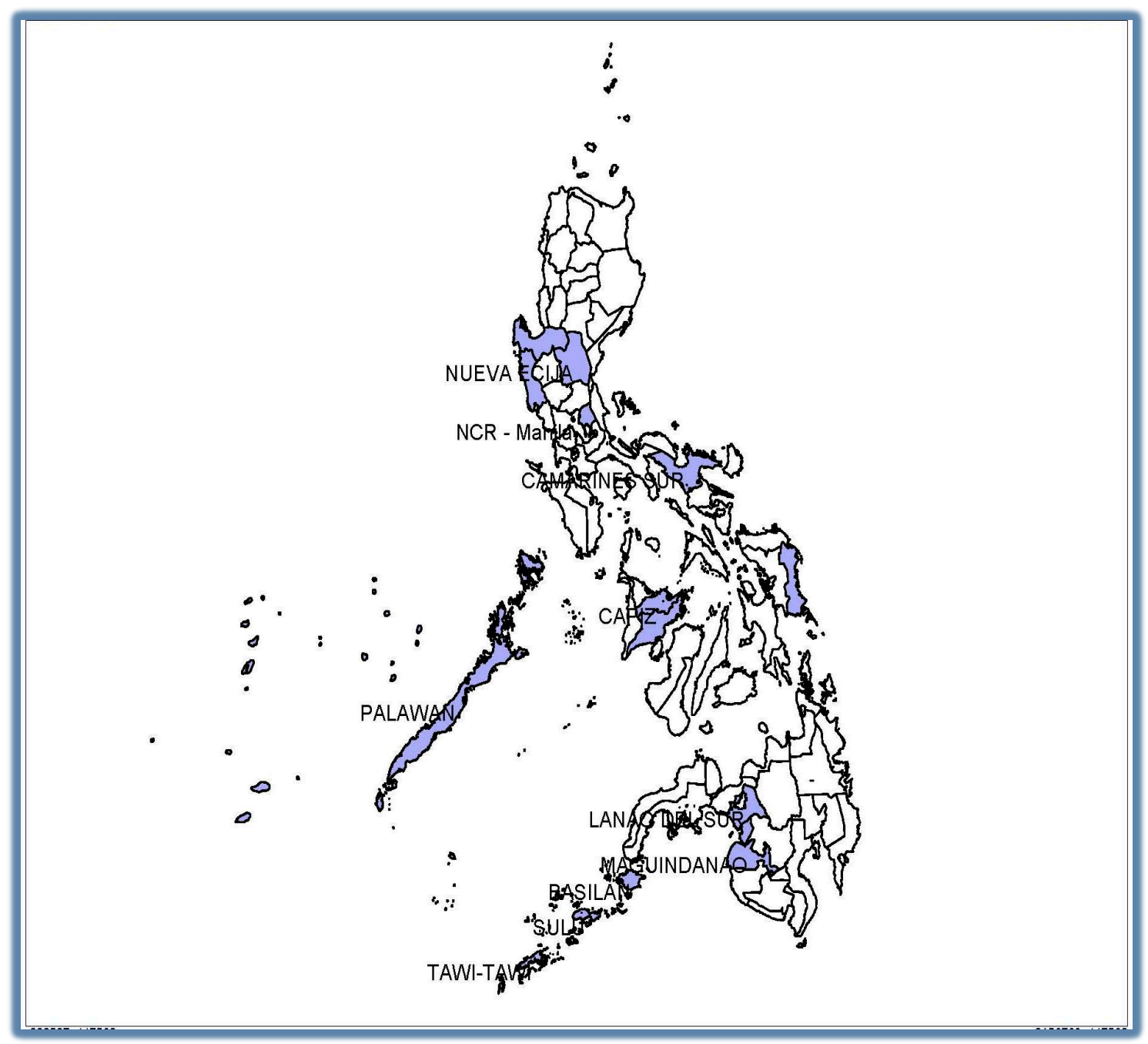

The following table (Table 5.2.4) shows the types of services implemented in these areas. Note that ASDSW's various training services are sometimes implemented in conjunction with one another. 
Table 5.2.4

Types of Services per Area

\begin{tabular}{|c|c|c|c|c|}
\hline Province & Municipality & Technology & PODS & $\begin{array}{l}\text { WASH } \\
\text { Planning }\end{array}$ \\
\hline $\begin{array}{l}\text { ARMM } \\
\text { Provinces }\end{array}$ & 31 municipalities & $\begin{array}{l}\text { MWTF Training, NGO Training, } \\
62 \text { WSA }\end{array}$ & No & Yes \\
\hline \multirow[t]{2}{*}{ Camarines Sur } & Buhi, Iraya & Water System & Yes & No \\
\hline & Buhi & MWTF Training & $n / a$ & Yes \\
\hline Capiz & Province Wide & Water Quality Monitoring & $n / a$ & $n / a$ \\
\hline \multirow[t]{2}{*}{ Eastern Samar } & $\begin{array}{l}\text { Borongan - } 4 \\
\text { barangays }\end{array}$ & Water System & Yes & No \\
\hline & All & Water Quality Monitoring & $\mathrm{n} / \mathrm{a}$ & $n / a$ \\
\hline Iloilo & Iloilo City & BSF & Yes & No \\
\hline \multirow[t]{3}{*}{ Lanao Del Sur } & Pualas & BSF & Yes & No \\
\hline & Maragong & BSF & Yes & No \\
\hline & Calanogas & BSF & Yes & No \\
\hline \multirow[t]{6}{*}{ Maguindanao } & $\begin{array}{l}\text { Datu Abdullah } \\
\text { Sangki }\end{array}$ & BSF & Yes & No \\
\hline & Sultan Kudurat & BSF & Yes & No \\
\hline & North Kabuntalan & Hand Pumps & No & Yes \\
\hline & All & Humanitarian Response & $\mathrm{n} / \mathrm{a}$ & $\mathrm{n} / \mathrm{a}$ \\
\hline & Datu Piang & $\begin{array}{l}\text { IDP Camp Water Treatment } \\
\text { Station }\end{array}$ & $n / a$ & Yes \\
\hline & Guindalongan & BSF Pilot Project & $n / a$ & $n / a$ \\
\hline NCR & Caloocan & BSF & Yes & No \\
\hline Nueva Ecija & Guimba & Water System & Yes & No \\
\hline \multirow[t]{4}{*}{ Palawan } & Puerto Princesa City & BSF & Yes & No \\
\hline & Espanola & BSF & Yes & No \\
\hline & Batarazza & BSF & Yes & No \\
\hline & Batarazza & Water System & Yes & Yes \\
\hline \multirow[t]{3}{*}{ Pangasinan } & $\begin{array}{l}\text { Sual - Bgy. Sioasio } \\
\text { East/ Sioasio West }\end{array}$ & Water System & Yes & Yes \\
\hline & Sual - Poblacian & BSF/Latrines/Water System & Yes & Yes \\
\hline & Sual-Baybay Norte & water system & Yes & Yes \\
\hline Rizal & San Mateo & BSF & Yes & No \\
\hline Zambales & Iba & Water System & Yes & No \\
\hline
\end{tabular}

Source: (A Single Drop for Safe Water, 2010c)

\subsection{Promoting community initiatives: opportunities and challenges}

Social entrepreneurship is touted as 'innovative' and 'an alternative means' to efficiently address social concerns. For post-development writers, 'alternatives' emanate 
from local organizations and grassroots movements that deal with local struggles by relying on their own knowledge and capacities (see Escobar, 1992; Esteva \& Prakash, 1997; Latouche, 1993). By supporting self-reliant communities, do social entrepreneurship practices broaden the possibility for finding 'ways of knowing and doing' that are significantly different from the prevailing development system? The following examines the methods employed by ASDSW in their PODS Training Programme to determine the opportunities for, as well as challenges to, the broadening of local alternatives through social entrepreneurship.

Among ASDSW's services, the PODS Training Programme seems to support community members in expressing and pursuing their own aspirations for their community's future. Although the WASH Planning also tries to promote community participation and empowerment, the entire process does not leave much space for deviation since it follows a specific method to reach a desired outcome. Moreover, it is meant to be part of the existing development planning process of LGUs, which have specific timeframes. This does not mean that the WASH Planning is not useful or effective, but it might not be the appropriate mechanism for alternative possibilities to thrive. While the PODS Training Programme also leans towards being formulaic, it still presents opportunities for communities to apply their own resources and abilities to pursue self-determined goals. As mentioned, the PODS Training Programme promotes social entrepreneurship at the local level through the formation of community-based organizations that will operate a sustainable water service. Like the social enterprises discussed in the previous chapter, ASDSW is concerned with empowering communities so that they can manage development initiatives on their own. The PODS training provides them the opportunity to take ownership of the projects by building their 
capacity. It should be noted that the specific activities within the PODS training might differ from the capacity-building activities of other social enterprises.

\subsubsection{Selecting Participants}

The PODS training is designed to include the participation of community members in determining WASH-related issues within the community and in implementing a project that addresses the identified issues. To identify participants for the training, a team of ASDSW trainers will conduct a Pre-Setup activity held through a Barangay Assembly ${ }^{17}$ meeting. During this activity they will give an orientation about ASDSW and the PODS training, and community members will be invited to participate in the training. The recommended number of participants is 20-25. Based on the experience of the trainers, there would be volunteers during the pre-setup but most of the time they would not meet the minimum number of participants (ASDSW staff, interview, May 26, 2010). In that case, the Barangay captain or Purok ${ }^{18}$ leaders would try to find more participants. However, as the training progresses there would be several drop-outs (ASDSW staff, interview, May 26, 2010). To ensure full participation in the training, ASDSW staff have suggested during the recently conducted Learning Exchange workshop, that a criteria for participant selection be formulated. Recommendations for the criteria included certain characteristics such as commitment and reliability. The participation of representatives or leaders from sectoral groups and existing community organizations was also suggested.

Selective participation is one of the difficulties in trying to engender community participation, with development practitioners failing to identify "less obvious partners"

\footnotetext{
17 The Barangay Assembly is composed of actual Barangay residents, aged 15 and above. Meetings are held upon the call of the Barangay Captain, or at least 4 members of the Barangay, or upon written petition of at least $5 \%$ of the assembly members ("The Local Government Code of the Philippines," 1991)

18 'zone'- a political subdivision of a Barangay
} 
beyond the "most visible and vocal, wealthier, more articulated and educated groups" (Botes \& van Rensburg, 2000, p. 45). Although it was emphasized during ASDSW's workshop that participation of individuals that hold positions of authority in the community should not prevent other community members from participating in the training, it is unavoidable that only certain members of the community will join the training. At the outset, complete attendance during a Barangay Assembly meeting is unlikely. There is a chance that only those who are already active in community affairs will be present in the meeting. Moreover, since participation in the training is on a voluntary-basis, much depends on individual personalities and it is probable that those who are less vocal or confident will not readily participate. The community leaders are asked to find more volunteers, which may lead to potential bias for individuals that either have a close relationship with them or are their political allies. There is a danger that the project may be used to further the personal or political interests of the community's elites.

In some cases, ASDSW works with an existing community organization and provides the training to its members. This has advantages for ASDSW since the community organization may already possess relevant skills and competencies. Most community organizations also have experience in working on community development projects and working with the other community members. However, the possibility that these groups may not necessarily share the broader community's views should not be overlooked. Participatory approaches have been criticised for viewing the 'community' as homogeneous and for de-emphasizing power relationships between individuals or groups (Williams, 2004). ASDSW acknowledges that there are socio-political differences between communities and that there may be conflicting groups within each community, which is why they immerse their trainers and facilitators in the community, 
to gain better understanding of community dynamics. In case of conflicts between groups or individuals involved in the PODS training, trainers or facilitators are advised to allot time for resolving the conflict before proceeding with the training (ASDSW Staff, personal communication, July 9, 2010). Still, there is no guarantee that these conflicts will not arise in the future, especially if these are related to existing power relations. Moreover, Ilan Kapoor (2002, p. 109) warns, "the very exercise of seeking a consensus risks using coercion and simplifying diversity". In ASDSW's case, it would be difficult to balance the focus on achieving the outcome of the training - a functioning community organization, with an earnest attempt to address concerns and differences between individuals and groups within the organization and the broader community.

\subsubsection{Formulating Community 'Dream'/Vision}

The PODS training begins with a module on Strategic Planning, which focuses on guiding the group/organization in mapping out a vision statement, project goals and activities. There is an emphasis on changing the participants' views, attitudes, and behaviour regarding their role in the community's development (see A Single Drop for Safe Water, 2009d). The main objective is "for the participants to actively decide and

draw a clear picture of where they want to go" (A Single Drop for Safe Water, 2009d, emphasis in original). The first part of the module involves visioning activities. Participants are shown a picture called 'The Two Faces of Development' (see Box 5.3.2), which represents 'urban and rural development' (A Single Drop for Safe Water, 2009d). They are asked to give opinions and to debate on whether 'the two faces' show their own ideas of development. 
Box 5.3.2

ASDSW's The Two Faces of Development

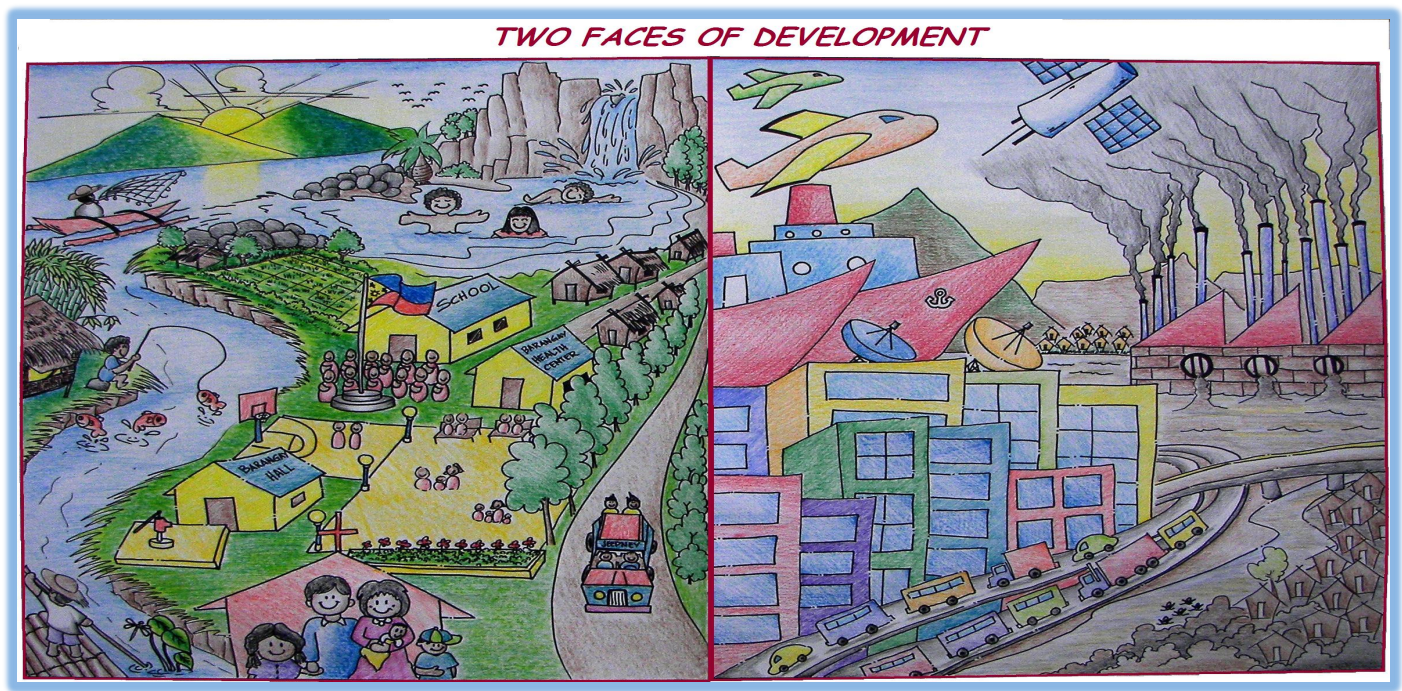

Source: (A Single Drop for Safe Water, 2009d)

The facilitator is instructed to acknowledge all the generated opinions and to guide the discussion towards the next exercise, which prompts participants to express their personal aspirations in the areas of Family, Friends, Work, and Community Service (see A Single Drop for Safe Water, 2009d). Participants will then be divided into smaller groups with 4 to 5 members each, depending on the total number of participants (see A Single Drop for Safe Water, 2009d). The training manual does not specify if the participants are divided according to a certain criteria and it seems that this is the facilitator's discretion. The groups are asked to discuss each of their member's dreams and to come up with a group dream, which will be presented to the entire group. During the presentations, participants are asked to comment on the differences between each group's dream maps but a basic rule of "no criticism or making fun of others' dreams" is stated (A Single Drop for Safe Water, 2009d). Afterwards, the entire group is instructed to draw a collective dream map that incorporates the individual dreams. A vision statement that describes their long-term objectives for the community's development is also formulated based on the dream map. 
The set of activities described above presents an opportunity for articulating desired ends that are not limited by traditional development goals. At the beginning, participants are encouraged to visualize what they want to happen in their community and to come up with 'their own version of development'. They are asked if there are 'other ways' than those shown in the picture. The challenge here is in the use of the word 'development', which has attached meanings, and the circumstances in which this exercise is being conducted. Although the facilitators will only guide the discussion without giving suggestions, their presence could also affect the responses of the participants. As with Participatory Rural Appraisal (PRA), the presence of outsiders and the public nature of the training can restrict the behaviour of participants (Kapoor, 2002). Since the participants are aware of ASDSW's work and they know that the purpose of the training involves the implementation of a WASH project, they might be inclined to come up with ideas that are closely related to the nature of ASDSW's work. The 'scanning of individual aspirations and possibilities' exercise on the other hand, could motivate the participants to come up with unconventional ideas. These may or may not be related to development goals since participants are asked to reflect on what they want to accomplish in areas of their lives that are not usually explicit concerns of development interventions - family, friends and community service.

In these activities attention is given to individual ideas and desires since ASDSW believes that when people are personally engaged or see that their own goals can be achieved, they will be more willing to participate in community efforts (see A Single Drop for Safe Water, 2009d). However, the ultimate intention is to produce a collective dream map so the facilitator is instructed to "synthesize by emphasizing on similarity of each or the individual's aspirations" (A Single Drop for Safe Water, 2009d). It is arguable that having a shared vision could instigate action, but again it should not be 
neglected that seeking unity and agreement might leave some voices unheard. The process of breaking into smaller groups may give the chance for less vocal individuals to express their ideas but at the same time, even in a smaller group, there could be more dominant personalities especially since the composition of each group is not clear. Trying to incorporate everyone's dreams into the collective dream map can be a difficult task, which may be the reason for emphasizing the similarities in the given aspirations. But if some aspirations could not be included, the participants should not be made to feel like these are not valid. Beyond acknowledging the 'other dreams', it could also be beneficial to say that the participants could still pursue these as separate or different projects if they are unrelated to the intended project.

Since not everyone in the community is a participant in the PODS training, a "Dream-Matching" activity is conducted to give other members of the community the opportunity to comment on the vision and objectives that were identified during the training. In this activity, the participants either go on community rounds or call for a Barangay Assembly meeting to discuss with other members of the community what they did during the training and show their collective dream map (A Single Drop for Safe Water, 2009d). A commitment ceremony is also conducted wherein the participants will formally present the dream map and vision statement and afterwards the other members of the community are asked to pledge their commitment by signing the vision statement (A Single Drop for Safe Water, 2009d). The 'Dream-Matching' activity does not seem to involve changing or modifying the output of the training but rather "is a way to find out the extent of community's acceptance of the project" (A Single Drop for Safe Water, 2009d). If there are individuals who do not agree or have different ideas, their opinions may not have any influence on the end-result. The commitment ceremony is conducted 
in a public setting and in the presence of facilitators and/or donors, which as previously mentioned, could have an effect on the behaviour of the community

\subsubsection{Setting Project Goals}

The Strategic Planning module also includes activities on community resource mapping and organizational capacity diagnosis, to assist the participants in determining goals. Participants are again divided into 3 groups: women, Barangay officials, and sectoral or elders (A Single Drop for Safe Water, 2009d). Each group is asked to either draw a new map or work on an existing map of the community to show available resources. Resources are defined as either human resources-individuals or organizations that have potential to contribute to their vision; natural resources; or manmade resources such as facilities (A Single Drop for Safe Water, 2009d). Each group will then present their output and other participants will be asked to comment, with the facilitator guiding the discussion. This step is meant to allow for a deeper analysis of the resource map by discussing specific features of each resource such as relevance to the community, quality, and accessibility (A Single Drop for Safe Water, 2009d). In addition to the community resource map, the participants are also asked to identify organizational strengths and opportunities that could help them in achieving their vision statement.

This process follows an asset-based approach similar to the one employed by Gibson-Graham (2005) in the action research project in Jagna municipality. An assets map was also formulated in Jagna to bring the focus on the resources within the community that they can work with instead of what they needed or lacked (Cahill, 2008). But beyond the physical and natural resources, the project team also tried to emphasize that the social assets found in the community such as skills and capacities of the residents contribute significantly to their wellbeing (Gibson-Graham, 2005). Identifying the 
community's strengths served to strengthen a view of community members as already having the power to spur local economic development (Cahill, 2008). Similarly, ASDSW aims to highlight the strengths and opportunities that can be found within the community, as well as among the participants themselves. This can change the participants' view of themselves as not being able to do something about their situation into one that sees "the reality that we have the power to choose a positive response to those circumstances" (A Single Drop for Safe Water, 2009d). Moreover, ASDSW encourages the use of 'proactive language' instead of 'reactive language' as a starting point towards changing the belief of community members that they are 'victims' whose situation depends on outside forces (A Single Drop for Safe Water, 2009d). This process is a good approach towards empowering community members but other actors such as LGUs, other NGOs and ASDSW itself, should also be aware of the language that they use in their programmes and when working with communities. Terms such as 'poor' or 'poverty alleviation' could still encourage dependence "because the idea of "poverty alleviation' looks at the question of poverty in terms of meeting a social liability rather than nourishing a social asset" (Rahman, 1995, p. 30).

Once the group has achieved appreciation and understanding of the community's resources and their strengths as a group, they will begin identifying specific goals and objectives that could lead to the fulfilment of their vision statement. Participants have to rank the resources and organizational capacities that they have previously identified, based on utilization or which needs immediate attention (A Single Drop for Safe Water, 2009d). For each priority resource, they will formulate specific goals or what it is that they want to change about that resource. At this point of the training, the participants will be asked to focus on water resources and WASH issues. Although the participants were able to formulate their own vision statement and they can still identify other goals, it is 
expected that they will have to focus on WASH-related goals. The rest of the modules (which will be discussed in the next chapter) are designed to train participants on various skills related to project implementation and enterprise operations.

This demonstrates another limitation of bottom-up approaches to development. According to Nustad (2007, p. 37), "a development process is initiated with a specific goal in mind, and, although developers portray themselves as 'facilitators', they still know where the process ought to be heading". For instance, looking into the participatory planning process employed by the Kribhco Indo-British Farming Project (KRIBP), David Mosse (2001) found that villagers often articulated their needs based on the goals of the existing project. He further asserts that 'peoples planning', and the knowledge it produces such as needs and plans, have the following characteristics: "it is conditioned by project deliverables; it closely matches and supports programme priorities; and it involves bargaining and negotiation between villagers and project staff but ultimately is a collaborative product" (Mosse, 2001, p. 23). In the case of ASDSW, it is clear that they have an expertise and their services are specific to water and sanitation. They do not claim otherwise. But they do aim to give the communities 'ownership of the entire process'. The assumption is that ownership can be achieved by involving (some) community members in the step-by-step process of planning and implementing a WASH project. Yet, the community may not have been the one to decide that they need or want a WASH-related project if they were 'selected' by a donor. In addition, the idea for the PODS and the training modules and activities were designed by ASDSW. The community was not initially involved in that process. Although the training participants are given the opportunity to formulate their own vision and goals, the outcomes and methods were already determined, since these are part of ASDSW's broader aims. 


\subsubsection{Making way for alternative possibilities}

The previous discussion identified some concerns regarding the PODS programme but it does not mean that ASDSW is ineffective or that the programme does not result into capable community organizations and improved water and sanitation conditions in communities. In some cases (see Table 5.3.4), particularly for water systems, the community organizations that were formed are able to manage the projects after ASDSW's intervention, which indicates a sense of ownership.

In its current form however, the PODS programme tends to be formulaic since communities are presented with a particular way to address a concern-through organizational development and the resulting PODS organization. The overall social thrust is also pre-determined. It is understandable that most social entrepreneurship organizations, like traditional NGOs, deal with specific development concerns. Moreover, traditional development goals such as what is being tackled by ASDSW are not always destructive or inappropriate, and as some authors point out (see De Vries, 2007; Pieterse, 1998), communities may very well aspire and struggle for those goals. However, from a post-development perspective, the problem is that development professionals tend to see themselves as having the solution that would help communities to achieve those goals. And no matter how noble their intentions may be, local knowledge and voices get lost in the process. Again, the question is "how could the development apparatus, be used to cultivate subjects of diverse developments and diverse modernities?" (Escobar, 2007, p. 25). In the same way, how could ASDSW's expertise on water and sanitation and their PODS Training Programme be utilized to advance the knowledge and capacities of the communities that they work with towards determining and striving for community aspirations? 
Table 5.3.4

PODS Project Status

\begin{tabular}{l|l|l}
\multicolumn{1}{c|}{ Municipality } & \multicolumn{1}{c|}{ Technology } & \multicolumn{1}{c}{ Status } \\
\hline Buhi, Iraya & Water System & Operational \\
\hline Borongan - 4 barangays & Water System & Operational \\
\hline Iloilo City & BSF & Non-functional \\
\hline Pualas & BSF & Non-Functional \\
\hline Maragong & BSF & Non-Functional \\
\hline Calanogas & BSF & Non-Functional \\
\hline Datu Abdullah Sangki & BSF & Operational \\
\hline Sultan Kudurat & BSF & Dormant \\
\hline Caloocan & BSF & Non-functional \\
\hline Guimba & Water System & Construction on-going \\
\hline Puerto Princesa City & BSF & Dormant \\
\hline Espanola & BSF & Operational \\
\hline Batarazza & BSF & Operational \\
\hline Batarazza & Water System & Construction on-going \\
\hline Sual - Bgy. Sioasio East/ & Water System & Operational \\
\hline Sioasio West & & \\
\hline Sual - Poblacian & BSF/Latrines/Water & Operational \\
\hline Sual - Baybay Norte & System & \\
\hline San Mateo & Water system & Construction on-going \\
\hline Iba & BSF & Non-functional \\
\hline & Water System & Operational \\
\hline
\end{tabular}

Source: (A Single Drop for Safe Water, 2010c)

Access to safe water is a goal that most communities probably aspire for, and they are likely to support projects related to this. However, the government or development agencies typically provide projects related to this, which leaves the impression that local communities cannot pursue this goal on their own due to 'lack of' funding or expertise. In a way, ASDSW is challenging this notion by assisting communities to develop and operate their own water projects. But their operations are still largely dependent on funders who will hire them and pay costs of working with a community. As mentioned, ASDSW is trying to overcome this situation by mobilizing the funds for communities who seek their assistance. This is a positive step since 
communities would probably be more inclined to take ownership of a project that they decided they needed or wanted instead of one that was chosen by external donors.

There are already existing opportunities in the way that ASDSW works with communities that could facilitate less dependence on external funders. For instance, communities already provide counterpart funding in the form of labour and they provide food during training sessions. They can also provide lodging for the facilitators. All of these can contribute to a sense of ownership on the part of the community. In terms of funding for the actual project that they would implement, the community could also try to mobilize funding from within the community. A good example of how this could be done is again, the Jagna Community Partnering Project (see Cahill, 2008; GibsonGraham, 2005). The community groups in Jagna were not given any funding for their microenterprises but they were still able to start production by using local resources and investing their time and labour even without pay (Cahill, 2008). They also accessed funding through the remittances of Overseas Filipino Workers (OFWs) whose families lived in Jagna. In addition, through the diverse economy approach, they were able to identify groups and networks within their own community that had access to resources and could therefore be tapped for their economic development (Cahill, 2008).

In a similar way, ASDSW's resource mapping exercise could be expanded to help communities identify local sources of funding. They could also try to identify activities in the community that the residents previously organized without external assistance, to show that they have the capability and even the finances to accomplish different projects. Hopefully, by focusing on local assets and capacities, the communities will be able to realize that they can support their desired project without depending on external donors. This could also open opportunities for ASDSW to work with more communities but it would require further flexibility on their part. Currently, the resource 
mapping exercise is incorporated into the PODS training as part of a planning exercise. But if ASDSW wants to assist communities in finding local sources of funding through this kind of process, they might need to facilitate it before the actual PODS training, which means they would have to cover the costs of sending facilitators to the communities. In addition, the whole project will likely take more time since mobilizing local funding is not instantaneous. Both the community and ASDSW would have to be patient and receptive to unplanned outcomes.

ASDSW could also try to make the PODS training less formulaic by consulting the community on how they want to proceed instead of just following a fixed design. This could contribute to the sense of ownership of the entire process since the community will be making decisions regarding the whole approach. For instance, it might be worth knowing whether the community agrees that the most appropriate vehicle for project implementation is an organization with a cooperative or micro-business structure. It is possible that they prefer or have other ideas for different arrangements. Whether community members would like to form these type of organizations or not, they should at least be given the chance to decide even if the PODS training is supposed to be an organizational development training. Meanwhile, the visioning and goal setting activities are a good starting point whether or not the community decides to form an organization. The creation of a community dream map in particular, can motivate participants since they are given the freedom to articulate their own dreams even if these do not necessarily correspond with the project to be implemented. And based on the following example, unconventional aspirations can also emerge (see Box 5.3.4). 
Box 5.3.4

Community Vision-Sitio San Carlos, Barangay Bacungan

"Isang Maunlad na Barangay na may Pagkakaisa, Maayos na Imprastraktura at Edukasyong Pang- Elementarya, may Angkop na Turismo at Nananatiling Mayaman at Protektadong Kalikasan."

\section{A Prosperous Community that has Unity, Sound Infrastructure, Elementary Education, Appropriate Tourism and an Environment that will continue to be abundant and protected.}

Source: (A Single Drop for Safe Water, 2009c)

The community vision of San Carlos shows aspirations that are not related to a WASH project. As mentioned above, the facilitators could emphasize that the community can still pursue the aspirations they have identified as separate projects or activities. In the same way, during the goal-setting activity, it may not be necessary to focus on WASH-related goals only. Both facilitators and participants could be more open to the possibility that the gains from this particular undertaking, whether new skills or attitude, can be useful not just for the intended project but for future initiatives as well.

Although the rest of the training modules have already been designed, ASDSW can try to exercise flexibility and give the communities the chance to adapt the activities based on existing practices, knowledge or skills, which they can incorporate into the programme. A meaningful exchange of ideas and expertise, can lead to the emergence of new ways that are determined not just by ASDSW but by the community as well. Based on several case studies of South Asian NGOs, John Hailey (2001) found that personal, informal interaction, and relationships based on friendship and trust were much more significant to the success of the NGOs programmes than formal participatory tools and techniques. One of the NGOs, the Bangladesh Rural Advancement Committee (BRAC), admits that engaging in dialogue with communities requires a great deal of time, but 
listening and learning is crucial to their work, which is rooted on community-based values (Hailey, 2001). ASDSW can consider this approach in order to fulfil the potential of the PODS as a programme supportive of local decision-making and ownership.

\subsection{Conclusion}

According to its Executive Director, ASDSW's key advantage is that they are "a

Box 5.4

Why PODS?

needs-based technology expert that meets the needs of the situation, which involves figuring out how to solve the issue. There is no package deal that solves all" (K. Lee, personal communication, October 8, 2010). This statement indicates a degree of flexibility and open-endedness as opposed to having pre-determined means and ends, which is characteristic of most development initiatives. If that is the case, then ASDSW's work could contribute to practices that promote different ways of pursuing priorities. In addition, ASDSW aims to provide 'ownership of the process, not just the project' to communities, which indicates their support for local self-determination.

A closer look into their community-based initiative shows that there are several difficulties to actualizing this principle. Firstly, the PODS programme is an organizational development training that is geared towards a group of people and not the entire community. Despite attempts at involving the broader community, it should not be 
overlooked that ownership may be limited to a group within the community. Moreover, it seems that ASDSW's approach to providing ownership is by facilitating a process wherein the participants to the PODS training will undertake the planning, implementation, and management of a WASH project. This approach is not necessarily inappropriate or ineffective, and in fact, ASDSW has experienced relative success with the PODS programme (see Table 5.3.4). However, from a post-development perspective, the process of having community members go through a series of training modules that were pre-designed can limit the potential to devise their own methods.

Despite these challenges, there are also opportunities to utilize the PODS programme for communities to determine their own futures and strive for aspirations in their own ways. The philosophy behind the PODS shows possible starting points (see Box 5.4). First, there is an opportunity for community members to articulate their dream for the community and to set goals in order to achieve that dream. Given ASDSW's technical expertise in the area of water and sanitation, it is likely that community aspirations will lean towards development goals that are aligned with the organization's programmes. It is significant to a community's self-determination that they identify priorities instead of external agents deciding for them on what goals are important. In addition, the conduct of a resource mapping exercise to identify assets found within the community can help empower community members. It is an opportunity for them to gain a positive outlook and realize that they have the resources and capacity to achieve their dream. In order to realize these opportunities within the PODS programme, both ASDSW and the communities may need to be more patient and flexible. Ultimately, the possibility of finding alternative pathways within initiatives such as the PODS programme will depend on the willingness and creativity of those working together to see beyond what is planned. 
CHAPTER 6

Social Entrepreneurship: Furthering the Influence of Market and Business Practices?

Case Study on A Single Drop for Safe Water, Part 2

\subsection{Introduction}

The previous chapter showed that, while social entrepreneurship methods that seek to promote community-based initiatives, such as ASDSW's PODS Programme, still fall within the sphere of 'traditional' development, there are also opportunities for promoting 'alternatives' that are locally-determined. The search for, and advocacy of locally defined 'alternatives to development' can be linked with post-development's criticism of development as a process that emphasizes and propagates Western ideals of economic wealth and technological advancement as determinants of progress. Thus, as Latouche (1993) suggested, true 'alternatives' can be found in communities wherein social relationships and activities are much more significant to sustaining welfare than purely economic activities. However, if 'alternatives' are those knowledge and practices that are removed from 'market rationalities', perhaps social entrepreneurship cannot be interpreted as contributing to diverse 'alternative pathways'. Social entrepreneurship, which has also been considered as an application of business techniques and principles in solving social problems (see Haugh, 2006b), clearly has an economic component. Could it be just a new phase in the expansion of neo-liberal principles and a co-option of social movements by businesses?

The cases of social entrepreneurship that have been discussed here show that NGOs, whose operations have been different from those of private enterprises are now acting more business-like with the adoption of a 'profit-motive'. In addition, it seems that this entrepreneurial mindset is also being advocated at the community-level. For instance, Rags2Riches, Inc. conducted a training on finance and managerial accounting 
for their community partners to enhance their business skills (see Ruiz, 2010). One motivation for providing this type of training is the belief that providing communities with business skills will not only broaden their livelihood opportunities but also empower them. While in ASDSW's PODS Programme, teaching community organizations how to operate a micro-business is related to the goal of sustainability. In this case, entrepreneurial skills are applied not only to marketing commodities but in the provision of a social service as well. This chapter will explore the role of business practices in social entrepreneurship endeavours within a community setting, using ASDSW's PODS programme as an example. The question of whether the marketoriented strategies being employed are assisting community members to achieve social objectives or are weakening traditional and local practices will be considered. First, the effects of privatizing water services and charging user fees will be analysed. This will be followed by a discussion on whether the income earned from the social enterprise is being used for other community development initiatives. Lastly, the impact of the business-related training on local practices will be explored.

\subsection{Effects of Market and Business Practices in Communities}

\subsubsection{Water Services: Privatization and User Fees}

The PODS Programme is a strategy for bringing water services to communities that may not have these services in place. Water supply in the Philippines is provided by both public and private institutions, which include LGUs, Rural Water and Sanitation Associations (RWSAs), Barangay Water and Sanitation Associations (BWSAs), water districts, private firms, cooperatives, and small-scale independent providers (SSIPs) (D. C. Israel, 2009). Water systems in the country are classified into three types (See Box 6.2.1). Facilities that are directly managed by provincial, city, or municipal LGUs were 
set-up through their engineering and local development planning departments. At the Barangay level, community-based organizations can register as RWSAs or BWSAs to manage communal water systems, with support from LGUs or NGOs (D. C. Israel, 2009). The governance structure of water associations is similar to those of cooperatives except members of a cooperative contribute equity for investments in

Box 6.2.1

Philippine Water System Classification infrastructure and they are entitled to dividends (The International Bank for Reconstruction and Development, 2005). Water districts are governmentowned and controlled corporations (GOCCs), which can be established by a LGU with consent from the Local Water Utilities Administration (LWUA) who provides technical support and financing (The

Level I - stand-alone water
points (hand pumps, shallow
wells, rainwater collectors)
Level II - piped water with
communal water points (bore
well, spring system)
Level III - piped water supply
with private water point
(household connections)

Level I - stand-alone water points (hand pumps, shallow

Level II - piped water with communal water points (bore well, spring system)

Level III - piped water supply (household connections)

International Bank for Reconstruction and Development, 2005). In Metro Manila, two large concessionaires, the Manila Water Company, Inc. (MWCI) and Maynilad Water Services, Inc. (MWSI), have been supplying water since 1997 after private sector participation was initiated (A. Robinson, 2003). There are only four other privately operated water systems outside of Metro Manila (A. Robinson, 2003). SSIPs are composed of various water operators such as real estate developers, homeowners' associations, local entrepreneurs, mobile water truckers and haulers, and peddlers (The International Bank for Reconstruction and Development, 2005).

Efforts at expanding private sector participation beyond Metro Manila have met little success, thus public suppliers provide water services to the majority of the population. It is argued that privatization of public services, which is part of the neoliberal approach to reform, will improve the efficiency of service delivery and also 
improve access of the poor to affordable services (Prasad, 2006). On the other hand, privatization can also lead to the exclusion of the poor from basic services if they can no longer afford the fees that private companies levy. In his study of the privatization of water services and its possible effect on the poor, Naren Prasad (2006) finds that reconciling the profit maximizing behaviour of private firms with a concern for delivering services to the poor, remains a challenge.

The water supply providers in the country charge different rates and have varying tariff structures with no standard method for setting tariff rates (see Table 6.2.1.1).

Table 6.2.1.1

Tariff Rates of Philippine WSPs (2005 Data) ${ }^{19}$

\begin{tabular}{|c|c|c|c|}
\hline Type of WSP & Tariff Rate & Tariff Structure & Other Fees \\
\hline $\begin{array}{l}\mathrm{MWCl} \text { and } \\
\mathrm{MWSI}^{20}\end{array}$ & $\begin{array}{l}\text { Lifeline rates of USD } \\
0.15-0.25 \text { per cubic } \\
\text { metre }\end{array}$ & $\begin{array}{l}\text { Increasing blocks } \\
\text { with an initial lifeline } \\
\text { block of } 10 \text { cubic } \\
\text { metres }\end{array}$ & $\begin{array}{l}\text { - Connection fee of USD } \\
40.00-60.00 \text { for new } \\
\text { customers } \\
\text { - } \quad \text { Sewerage charges at } \\
50 \% \text { of the household } \\
\text { water bill } \\
\text { - } 10 \% \text { environmental } \\
\text { surcharge }\end{array}$ \\
\hline Water District & $\begin{array}{l}\text { Minimum charge of } \\
\text { USD } 3.85-4.30 \text { for } 10 \\
\text { cubic metres or less } \\
\text { monthly consumption }\end{array}$ & Increasing block rates & $\begin{array}{l}\text { - Connection fee of USD } \\
100.00 \text { to be paid up- } \\
\text { front }\end{array}$ \\
\hline LGU & Varies & $\begin{array}{l}\text { Increasing block } \\
\text { rates, decreasing } \\
\text { block rates or flat } \\
\text { rates }\end{array}$ & $\begin{array}{l}\text { Usually charges } \\
\text { connection fees }\end{array}$ \\
\hline BWSA or RWSA & $\begin{array}{l}\text { None or PHP } 5.00-10.00 \\
\text { monthly for level } 1 \text { or } 2 \\
\text { systems }\end{array}$ & Flat rate & \\
\hline SSIPS & $\begin{array}{l}\text { Varies. Ranges from } \\
\text { USD } 0.27 \text { per cubic } \\
\text { metre for a community- }\end{array}$ & & Connection fees \\
\hline
\end{tabular}

19 Exchange rate of USD $1.00=$ PHP 55.80

20 The Metropolitan Waterworks and Sewerage System (MWSS) Regulatory Office has approved tariff increases for the two concessionaires to cover inflation and foreign exchange fluctuations from the period 1997-2002 (The International Bank for Reconstruction and Development, 2005). The MWSS Regulatory Office is responsible for reviewing and monitoring water and sewerage rates in the areas covered by the concessionaires. 


\begin{tabular}{||l|l|l|l|}
\hline Type of WSP & \multicolumn{1}{|c|}{ Tariff Rate } & Tariff Structure & Other Fees \\
\hline & owned water facility to & & \\
& USD 3.36 per cubic & & \\
& metre for water bought & & \\
from a water tanker & & \\
\hline
\end{tabular}

Source: (The International Bank for Reconstruction and Development,

2005, pp. 122-123)

The PODS formed through ASDSW's programme that will manage a community water system (WS-PODS) are also community-based organizations with governance structures similar to RWSAs, BWSAs, and cooperatives. They are not private enterprises although they should be able to cover operation and maintenance costs on their own through user fees. The RWSAs and BWSAs are legally allowed to charge user fees ${ }^{21}$, but more often than not, they depend on financial support from local governments and allocation from congressional funds for capital outlay and operation and maintenance costs (The International Bank for Reconstruction and Development, 2005). Setting of user fees for the WS-PODS would depend on the members and they are advised on how to determine the amount during the training. The key considerations reflect standard business practice, such as taking into account the costs of providing the service, looking into current market demands and existing competition, and whether potential customers will be willing to pay the price based on value (see A Single Drop for Safe Water, 2009d). As mentioned in the previous chapter, the WS-PODS is not meant to be a highly profitable business and not intended to augment the members' incomes. The goal is to have members of the community operate and manage a water system instead of having business operators supplying water to the community at higher costs (ASDSW staff, interview, May 26, 2010).

\footnotetext{
21 "The BWSA may impose such minimal charges as may be necessary for the maintenance and normal repairs of said facility" ("An Act Providing for the Construction of Water Wells, Rainwater Collectors, Development of Springs and Rehabilitation of Existing Water Wells in all Barangays in the Philippines," 1989, Section 3)
} 
Even if the fees levied by community organizations such as the PODS are minimal, it can still affect low-income households, particularly those who depend on LGU subsidized services. Level II water systems can be a more accessible and safer source of water but if a household cannot afford to pay for the service, they might choose to get water from an open or free source. As such, they will also be excluded from the potential benefits of the project, such as reduced risk from diseases. In addition, this could magnify the existing inequalities between members of the community. If the community views the service as bringing about a significant improvement in their quality of life, those who cannot avail of the service can feel deprived and even embarrassed which can also give rise to social exclusion. The ability to participate in community life is valuable in itself (Sen, 2000). Particularly in small communities outside of Metro Manila, most residents still value belonging to a community and social acceptance.

In reality, providing water services entail costs such as for the construction or infrastructure and for its operation and maintenance. In their evaluation of Water Supply and Sanitation projects, the ADB (2002) stressed the importance of cost-recovery for water suppliers in order to ensure long-term service provision. There would also be repercussions if such services were not available, as identified in Table 6.2.1.2. One could not fault ASDSW in promoting measures that would ensure the sustainability of service provision. However, if ASDSW believes that water is an equalizer, then an awareness of the possible effects of the programme on the state of inequality within communities is likewise important. 
Table 6.2.1.2

Water Problems in Developing Countries

\begin{tabular}{|c|c|c|}
\hline Aspect & Immediate Problem & Consequences \\
\hline \multirow[t]{3}{*}{ Water supply } & Distant sources & $\begin{array}{l}\text { - Much expenditure of } \\
\text { time and energy } \\
\text { (especially by women) } \\
\text { - } \quad \text { Low levels of water } \\
\text { consumption, resulting } \\
\text { in water-related disease }\end{array}$ \\
\hline & $\begin{array}{l}\text { Unreliable sources (drought- } \\
\text { prone, or poorly engineered } \\
\text { or managed) }\end{array}$ & $\begin{array}{l}\text { Time spent queuing or } \\
\text { seeking alternative sources }\end{array}$ \\
\hline & $\begin{array}{l}\text { Poor quality (faecally } \\
\text { contaminated) sources }\end{array}$ & Waterborne disease \\
\hline Wastewater disposal & $\begin{array}{l}\text { Engineered facilities for } \\
\text { treatment or safe disposal } \\
\text { rarely exist }\end{array}$ & $\begin{array}{l}\text { Indiscriminate disposal leads } \\
\text { to environmental } \\
\text { contamination, insect } \\
\text { habitat creation, and/or } \\
\text { unsafe re-use downstream }\end{array}$ \\
\hline
\end{tabular}

Source: (Carter, Tyrrel, \& Howsam, 1999, p. 292)

The above concerns can also be identified in the PODS for the production and marketing of Bio-Sand Filters (BSF-PODS). ASDSW is currently re-designing the BSFPODS to be more business-oriented with profit as a main incentive for members. In this case, the organization is not offering a service but selling a product to members of the community or nearby communities. The selling price for one unit of BSF is also determined by the PODS members and would depend on the cost of production, i.e. manpower, materials, other overhead expenses (see A Single Drop for Safe Water, 2009d). For example, the members of a PODS in San Carlos community in Puerto Princesa City, have priced one unit of Bio-Sand Filter at 1,700 PHP (around 50.24 $\mathrm{NZD}^{22}$ ) for sale within San Carlos and 2,000 PHP (around 59.11 NZD) for sale outside, accounting for transportation costs. This price is relatively steep considering that 1,700 PHP can buy around 55 kilograms of rice ${ }^{23}$. In this case, the BSF is not necessarily a

22 Exchange Rate of 1 NZD = 33.84 PHP as of November 2010

$231 \mathrm{~kg}$ of regular milled rice $=30.56$ PHP in October 2010 (Bureau of Agricultural Statistics, 2010) 
basic need because households can use other methods of purifying water such as boiling and solar pasteurization. The effectiveness of using a BSF in preventing water-borne diseases as compared with other water purification methods is debatable. However, it is a new commodity being introduced to the community. Illich (1997) warns that 'underdevelopment as a state of mind' occurs when needs (in this case, safe drinking water) become a desire for a product (BSF) that cannot be obtained by all. Again, it is possible that some members of the community will not be able to afford the product, which would not only result in their exclusion but could further lead them to see themselves as poor.

The PODS members in San Carlos are finding it difficult to sell the Bio-Sand Filters in their community despite their belief in the benefits of the product and how it could help members of their community. In order to cope with the challenge of marketing the product, the group has devised several strategies. In addition to having sales agents who advocate the use of the Bio-Sand Filter to the community, the group also offers discounts and payment by instalment (San Carlos PODS Members, interview, June 3, 2010). They have also advised households to share a Bio-Sand Filter so that they can also share the cost of purchasing one (San Carlos PODS Members, interview, June 3, 2010). These strategies may work but could result into some households feeling the pressure to purchase a BSF for the sake of fitting in with the rest of the community. One possible way of making the product available and accessible to a majority of the community is for the local government to purchase a certain number of units for communal use. Another would be for the PODS members to teach other members of the community how to build a BSF, particularly those who may not have the money to purchase one, but are willing to do the labour and find the materials they would need. However, this could possibly conflict with their entrepreneurial endeavour since they 
could lose customers and even gain competitors. This situation demonstrates one of the challenges in integrating entrepreneurship practices in social initiatives.

ASDSW emphasizes that they are a non-profit organization and not a NGO because NGOs and the government traditionally have an adversarial relationship in the Philippines, while ASDSW seeks working together with local governments (K.Lee, personal communication, October 8, 2010). Although LGUs are legally mandated to provide basic services, there are difficulties in service delivery particularly at the Barangay level due to limited financial capabilities vis-à-vis multiple priorities, "with some failing to spend on important basic services such as health and education" (Layug, Pantig, Bolong, \& Lavado, 2010). Working with other development organizations, as well as community members and community-based organizations is a way for local governments to cope with the demands of providing various services. However, this does not mean that local governments should not be made accountable if there are significant issues in the delivery of services. These initiatives should not be taken as a replacement for services that LGUs are required to provide. There have been cases where there has been a withdrawal of government services due to the entry or private service providers. For example, Ka-Ho Mok (1997, p. 260) describes how the Chinese government has "reduced its involvement in the provision of social welfare services, [particularly educational services], shifting responsibilities to the non-state sector and even to the market". The rise in social enterprises might give way to a similar situation.

\subsubsection{Using Profit for Social Objectives}

Part of what makes social entrepreneurship appealing to development practitioners is the idea of having an income that would directly support their activities. The previous chapters have discussed how NGOs employ different strategies to earn profits while pursuing more traditional social development objectives, whereas 
organizations such as ASDSW are promoting social entrepreneurship at a community level. The promotion of community-based enterprises is not an unconventional development strategy in the Philippines. The Caucus of Development NGO Networks have 131 member organizations whose primary programme involves enterprise development or livelihood (see Table 4.3.1). Meanwhile, the government under former President Gloria Arroyo initiated a National SME Development Agenda and formulated the SME Development Plan 2004-2010, which outlined the strategies to encourage the growth of micro, small, and medium enterprises (MSMEs) (see Small and Medium Enterprise Development Council, 2004). The objectives of programmes that support MSMEs are usually related to economic purposes such as increasing local employment opportunities and adding to household incomes. On the other hand, social enterprises are intended to bring about social benefits to the wider community as well.

Ideally, communities should be the ones to determine how the profits earned will be utilized or what goals they want to pursue. During the PODS training, the module on Business Planning starts with an introduction to entrepreneurship and the members of the organization are encouraged to appreciate the role of local enterprises in meeting social development goals so that they can apply their understanding to their own enterprise. Particular focus is given to how business enterprises can also be social enterprises by not focusing on the profit motivation alone but also considering the impact it can have on the welfare of other people (A Single Drop for Safe Water, 2009d). In this case, the type of enterprise that the community organization will establish has already been determined, i.e. water system or BSF production and the expected outcome that should the benefit the wider community is improved water and sanitation conditions. And as discussed above, the income to be earned from the social enterprises should be reinvested in order to 
maintain or expand the enterprises. Hence, the local PODS are somewhat limited to the water and sanitation project that ASDSW introduced.

Between the two types of PODS - water system and BSF, the organizations that are selling BSFs may have the potential to use profits earned for other endeavours. To some extent, the PODS in San Carlos community is able to do this. The PODS operates under an existing community organization, the Bacungan Coastal Development Residents Association (BCDRAI), which manages several community development projects. Before the PODS, one of their first projects was on the rehabilitation of mangroves in their area, which they did together with the Department of Environment and Natural Resources (DENR) (San Carlos PODS Members, interview, June 3, 2010). The residents of San Carlos value their coastal resources and persevere in protecting these since they rely mostly on fishing as their source of livelihood (San Carlos PODS Members, interview, June 3, 2010). From the mangroves rehabilitation, they saw the potential to start an eco-tourism project and were given the opportunity to do so with the support of ABS-CBN Foundation, Inc., a non-profit organization and the city government of Puerto Princes (San Carlos PODS Members, interview, June 3, 2010). San Carlos is now one of Puerto Princesa's eco-tourism destinations and offers a tour of the mangroves and a river cruise on a floating restaurant.

According to the PODS members, the earnings from the sale of BSFs were mostly used to pay sales agents and the individuals in charge of installing the filters (interview, June 3, 2010). Any amount left is placed in the association's funds, which is utilized for their other projects as well. For example, they would purchase chairs or kitchen utensils for the floating restaurant (San Carlos PODS Members, interview, June 3, 2010). Although, the money from the PODS might be used for another enterprise, it was the members themselves who decided on this. They regard the eco-tourism project 
as contributing significantly to the development of their community since it provided employment opportunities for residents, while also endorsing local produce and cuisine (San Carlos PODS Members, interview, June 3, 2010). Moreover, it is an important part of the community's continuing efforts to protect their coastal resources. In this case, the income from the PODS is still being used for an initiative that can benefit the entire community rather than personal gain.

According to ASDSW's project status report (see Table 5.3.4), the San Carlos PODS is currently dormant, which may be due to the difficulties they have encountered in selling the BSFs. In spite of this, the members of the organization seem to get by on their own decision-making as demonstrated by their initiative to devise marketing strategies for the BSF, as well as to somewhat combine the income from their community enterprises. This also shows how community members have the ability to modify development projects for their own purpose, which in the case of the San Carlos community is to pursue initiatives that have economic, social, and environmental benefits. However, this is a specific example and a conclusion on whether social entrepreneurship in general provides communities with the opportunity to pursue selfdetermined objectives using the income earned from enterprises, cannot be made. Other PODS organizations may only utilize the income earned from their water system or BSF projects to support those projects and not for other activities. The social entrepreneurship organizations that were discussed in Chapter 4 promote community enterprises as well, but again, the purpose of these seem to be limited to economic benefits and/or the social objectives determined by the organizations and not the communities. For instance, Rags2Riches, Inc. aims to empower the women of Payatas to become business owners but whether these women will utilize their profits to venture into other initiatives that can benefit their community is uncertain. The same goes for AIDFI who encourages the 
formation of community-based enterprises in rural areas but these are linked to their appropriate technologies programme and it seems that the income from these enterprises are not necessarily being used by the community members for social development initiatives. Further study is needed to gain an understanding on whether social enterprises at the community level are different from other microenterprises.

\subsubsection{Business skills training}

The PODS training includes modules on Business Planning and Financial Management, which aim to strengthen the organization's capacity to operate an enterprise. They are expected to write up a business plan with the following parts: Production Plan (for Bio-Sand Filter), Marketing Plan, Financial Management Plan and Organizational Plan (A Single Drop for Safe Water, 2009d). The group's output will be used for running their enterprise. The Financial Management and Bookkeeping module of the training aims to provide the participants with the necessary skills that would assist them in monitoring their business operations, making decisions, and being transparent with their operations to the rest of the community. The focus is on the principles of financial management that would assist them once they are operating their own microenterprise. Accounting processes such as maintaining a Chart of Accounts and preparing Financial Statements are discussed. Lastly, the group is taught how to analyse the financial status of their enterprise using financial viability ratios such as liquidity ratio, debt equity ratio, return on equity, return on capital, and return on investment (A Single Drop for Safe Water, 2009d). At the end of the training, it is expected that organization will be able to establish their Policies, System and Procedures (PSP).

Teaching professional business skills to community members and microentrepreneurs seem to be part of most social entrepreneurship organizations' capacity building efforts. These type of assistance are sometimes referred to as 'enterprise 
development' or 'business development services', which are "non-financial services that include training; giving technical and managerial assistance; developing, adapting, and promoting new technology; assessing markets and giving marketing support; providing physical infrastructure; and advocating policy" (Dawson, Kapila, \& Mead, 2002, p. 1). The expected benefit is that the business operations of these groups will become more efficient and produce better results in areas such as production and marketing. In addition, the newly acquired skills and better understanding of business principles would help these groups in forming partnerships with bigger businesses, which could open opportunities for expanding their own enterprises (see for examples Sandoval, 2009; Senajon \& Hechanova-Alampay, 2009). However, there seems to be a corresponding expectation that these groups will have to further 'professionalize' their operations and meet business standards by establishing formal mechanisms for quality control and accounting. "An important component of professionalization is improving the efficiency of operations through documentation of systems and procedures" (Hechanova-Alampay \& dela Cruz, 2009, p. 122). This is demonstrated in the PODS, as the organization is expected to establish PSP that will "systematize financial records and institutionalize financial management controls" (A Single Drop for Safe Water, 2009d).

Pascal Dey (2006) argues that the rhetoric of social entrepreneurship normalizes business practices, while non-business or 'traditional, voluntary and social' practices are deemed inferior. This echoes arguments made by post-development writers on the way so-called development professions and expertise are naturalized, thus eliminating local voices and knowledge. There is a risk that local or community practices will be disregarded or deemed unsatisfactory once programmes such as the PODS, introduce business concepts and provide training on business skills to communities. It is possible that community-based enterprises have their own record-keeping methods that may or 
may not conform to standard accounting practices. For instance, in the Philippines, a common practice among sari-sari store $^{24}$ owners is to keep a listahan or a card for each customer that lists the items taken and records the credit balance of the customer (Chen, 1997). These stores mostly operate on credit, which depends on other social relationships and traditions such as $s u k i^{25}$ system and palabra de honor ${ }^{26}$. The system works based on mutual trust as opposed to formal policies. However, it cannot be assumed that formal business practices will automatically eliminate local practices. As mentioned, communities have the ability to modify or adapt activities and projects. The works of Curry (2003, 2005a) and Bebbington (1993, 2000) discussed how economic/modern/business practices and indigenous/traditional/social practices can coexist.

The San Carlos community can also be an example of how social and economic practices can be intertwined. According to the group, it is the strong Bayanihan spirit in their community that enables them to work well and manage projects effectively (San Carlos PODS Members, interview, June 3, 2010). Bayanihan is a Filipino term derived from the word bayan, which can mean 'nation, town, or community' and "denotes team spirit, an atmosphere of unselfish cooperation, and a sharing of labour and spirit for the common good" (Steinberg, 2000, p. 24). In the case of San Carlos, the PODS members believe that their community demonstrates Bayanihan in every endeavour. The group considers this trait as an asset of their community that encourages organizations and donors to work with them for development projects (San Carlos PODS Members,

\footnotetext{
${ }^{24}$ A sari-sari store is an informal retailer of various goods and a primary source of consumer items for Philippine households. "Typically the store is operated from a portion of the owner's house dedicated to that purpose" (Chen, 1997, p. 88)

25 Suki relationships develop when two people (customer and supplier) agree to regular commercial exchange. Filipinos will regularly buy from specific suppliers who will give them in return, reduced prices, good quality, and credit (Dolan, 1991)

26 Translated as 'word of honour'. In the context of sari-sari stores, a customer's credit limit is highly dependent on his palabra de honor (Chen, 1997)
} 
interview, June 3, 2010). In their study of Marine Protected Areas, tourism, and community solidarity, Oracion, Miller, \& Christie (2005, p. 396) stressed the importance of Bayanihan in modern Filipino culture, particularly for "the process of local governance and self-determination". However, they warned that "commoditization, commercialization, and business contracts introduced by tourism" could endanger social structures such as Bayanihan (Oracion, et al., 2005, p. 397). In the case of San Carlos, it seems as though the introduction of enterprises, including eco-tourism, has strengthened community solidarity rather than undermining it. These enterprises have become an avenue for the residents to further demonstrate their Bayanihan spirit. Moreover, the PODS members are confident that they will be able to implement projects on their own because of the unity in their community.

\subsection{Conclusion}

The PODS programme shows how social entrepreneurship initiatives have aspects that reflect both post-development and market-based ideas (See Figure 6.3). Most social entrepreneurship organizations in the Philippines are concerned with economic empowerment of marginalized sectors or communities and they aim to provide these groups with the means to support local development by encouraging the formation of community enterprises. However, there is little information available to determine whether the income generated from these enterprises are used by communities to pursue local priorities. In the case of ASDSW, the local PODS are intended to be social enterprises that can contribute to the welfare of the community through the service or product offered, while earning income. The 'social' outcome has already been determined and the PODS organizations are expected to use any income earned to maintain the service or to save for future expansion. Thus, social enterprises do not 
necessarily contribute to enlarging the opportunity for communities to undertake their own self-identified projects.

Figure 6.3

Social Entrepreneurship Spectrum-PODS

\section{Social Entrepreneurship}

Promotes self-reliance

Builds communities' capacity

Mobilizes community strengths
Financial sustainability

Profit motivation

Business principles

\section{PODS Programme}

Utilizes local resources

Fosters local expertise

Culturally specific

Supports local leadership
User fees

Income generation

Builds business skills

The promotion of community enterprises also means that community members are introduced to market concepts and trained on different business skills. The local PODS for instance, are expected to see the value of fair payment for sustaining service delivery. However, the introduction of user fees for services that LGUs are required to provide can lead to the exclusion of low-income members of the community. Providing training on business skills and promoting business practices on the other hand, can lead to the weakening of social or local practices. According to Hechanova-Alampay \& dela Cruz (2009, p. 125), one of the challenges to the development of social enterprises in the Philippines is reconciling the world of community enterprises with that of traditional business practitioners: "community stakeholders have to make the transition into market 
practices when engage in earned income activities [while] those who come from the business standpoint must learn to deal with community dynamics". However, it seems that much more is expected from communities than the traditional business practitioners since communities are the ones who should undergo training on business skills and are expected to professionalize their operations. Instead of business practitioners adjusting or accepting the ways that communities transact or deal with one another, the communities are expected to conform to business methods.

The previous chapter discussed how ASDSW's PODS Programme tends to be formulaic, and in order to expand the community's decision making and for the programme to contribute to alternative possibilities, flexibility on the part of both ASDSW and the community groups is needed. In terms of the business and financial management training of the programme, ASDSW can try to incorporate the community's own methods of record-keeping, accounting, and reporting, if any. They can also consult the community regarding what practices work for them or which need improvement. This can lead to adoption of business practices while still maintaining social relations that can also contribute to success of enterprises such as commercial exchange based on trust and community cooperation.

The potential of social entrepreneurship as an alternative approach that combines social and economic objectives seems to be realized more at the level of NGOs or nonprofits rather than at the community or grassroots level. Traditional development organizations are experiencing relative success in their ventures to earn income that will support their social missions. However, the programmes and objectives are still largely defined by the development organizations instead of the communities or groups that they work with. The objectives of promoting community enterprises seem to be limited to livelihood and economic development with little indication that communities are 
becoming more self-reliant and are able to support their own socially relevant projects. Meanwhile, the influence of market and business practices is expanding at a local scale to communities and may affect existing social relations.

Social entrepreneurship tries to reconcile having a profit motive with achieving social objectives, leading to its malleability as a concept. The positive aspect of this is that social entrepreneurship can be an approach that allows diverse ways of addressing social concerns to emerge. On the other hand, there is also a risk that it will continue to be associated with business and will be used to expand neo-liberal development strategies. Practitioners need to be careful on how they use the concept, for it to be truly innovative, unconventional, and alternative. 


\section{CHAPTER 7 \\ Conclusion and Recommendations}

\subsection{Introduction}

The central aim of this research has been to analyse, from a post-development perspective, how social entrepreneurship differs from conventional development approaches. The literature review from this study demonstrates that the ideas found in both social entrepreneurship and post-development inform each other, which in turn can contribute to the broadening of alternative possibilities or ways that are unlike mainstream development practice. Post-development has been criticised for arguing against the idea of development but not being able to provide concrete practical alternatives. However, more recent research undertakings on post-development show that there is room to apply post-development ideas into development practice, informing even mainstream development. Socially embedded enterprises, diverse economies, and informal communities are a few examples of what could be 'alternatives to development' (see Curry, 2005a; Gibson-Graham, 2005; Latouche, 1993). There is emphasis on grassroots or community-based movements, local decision-making, and local knowledge and skills for the pursuit of self-determined goals. Meanwhile, the literature on social entrepreneurship activities show similar ideas such as highlighting opportunities and possibilities rather than needs or lack, prioritizing local initiative and ownership, and pursuing social and economic goals simultaneously.

However, there is very little literature relating social entrepreneurship to the broader development field, perhaps due to the lack of consensus on the definition of the term. The entrepreneurship component has been examined more, giving the impression that social entrepreneurship is just another market-based development strategy. This research has provided a much-needed critical examination of social entrepreneurship that 
is grounded in development theory, particularly post-development theory, while having empirical relevance for social entrepreneurs and development practitioners, to assist them in understanding and assessing social entrepreneurship as an approach to social development.

This thesis examined social entrepreneurship practices through a case study on A Single Drop for Safe Water (ASDSW), a non-profit organization in the Philippines that considers itself to be a social enterprise while also promoting social entrepreneurship to its partner communities. This chapter outlines the significant findings of the research. It highlights how social entrepreneurship is caught in the tension between possible 'alternatives to development', and mainstream approaches that adopt market-based principles. The chapter concludes with recommendations for further research.

\subsection{Significant Findings}

\subsubsection{Social Entrepreneurship: an emerging movement in the Philippines}

The first research question asks how social entrepreneurship emerged as a development approach in the Philippines. The research found that social entrepreneurship is a growing social movement in the Philippines that is deemed to be an alternative strategy for addressing issues such as poverty and inequality. The Philippines already has a strong volunteer sector with the number of development related NGOs estimated at 3,000 to 5,000 (ADB NGO and Civil Society Center, 2007). These NGOs are engaged in various aspects of social development work including agrarian reform, community development, human rights, and many others. Their role in addressing social issues particularly through community organizing and empowerment has been significant throughout the years (Constantino-David, 1995). Despite the relative success of development NGOs, some authors have suggested that their operations can be affected by lack of long-term funding (see Aldaba, et al., 2000; Constantino-David, 1998). This 
prompted many non-profit NGOs to venture into income-earning activities in order to have a stable source of funding that would support their activities (Dacanay, 2006). Development practitioners are traditionally wary of market related activities and Constantino-David (1998, p. 46) notes that "development workers are not entrepreneurs, in skill or in orientation". However, the organizations now described as social enterprises, are finding ways to utilize the market to achieve social goals. Thus, as Hechanova-Alampay and dela Cruz (2009) observes, social entrepreneurship has brought about a paradigm shift among traditional development practitioners.

A review of case studies on Philippine social enterprises revealed that these organizations are indeed engaging in market-based activities to varying degrees, with the key consideration being sustainability of operations. Another considerable similarity among social enterprises is that the concept of sustainability is conveyed to partner groups or communities and self-reliance is often promoted by adding an entrepreneurial aspect to projects. Dacanay (2006) uses the term economic empowerment in reference to a group or community's ability to manage resources and market systems to eventually be able to undertake and sustain development initiatives in their own communities. Several factors contribute to the increase in enterprises or income-generating activities as part of development projects. One would be the lack of employment opportunities in the country. In October 2003 , the unemployment rate in the country was $10.2 \%$ (National Statistical Coordination Board). The government promoted entrepreneurship as a strategy to increase livelihood opportunities. During her first term as President, Gloria Macapagal-Arroyo launched the National SME (Small and Medium Enterprises) Agenda as a priority programme for economic development in the country. In 2004, a Small and Medium Enterprise Development Council was formed with the Department of Trade and Industry as the lead agency. The council formulated a SME Development Plan for the 
years 2004-2010 that outlined specific strategies and programmes that would help increase the productivity of SMEs including, enhancement of financing support programmes; provision of managerial and technological capacity building; and strengthening of industries engaged in the international market (see Small and Medium Enterprise Development Council, 2004). The Department of Trade and Industry (2009), reports that in 2009 MSMEs accounted for $99.6 \%$ of all business enterprises in the Philippines and generated a total of $3,595,641$ jobs. Hence, these interventions encouraged the establishment of enterprises. Social entrepreneurship extends the strategy by advocating entrepreneurial activity not only for economic development, but for social development as well.

The social entrepreneurship industry in the Philippines continues to grow and there are institutions that provide support specific to social entrepreneurs. Academic institutions such as the Ateneo de Manila University are offering training programmes for those who are interested in starting their own social enterprise. In addition, the Philippine Social Enterprise Network (PhilSEN) also provides capacity building assistance to their member organizations, as well as the partner communities of these members. Although little information is available on what kind of resources or how much capital, if any, is needed to establish a social enterprise, there are organizations that provide financial support through grants or loans to aspiring social entrepreneurs. Despite the numerous assistance available, one board member of a social enterprise noted that government support for social entrepreneurs is also needed, particularly in terms of policy on registration and taxation (see Pastores, 2010). The hybrid status of social enterprises is a challenge if they are to be treated differently from NGOs or nonprofits and corporations. Another difficulty is managing or balancing the social and economic goals of the organization, especially when working with communities 
(Hechanova-Alampay \& dela Cruz, 2009). Community groups or community-based organizations do not necessarily have a market-oriented outlook, while the social entrepreneurship organizations need to understand community dynamics and practices. This points to the argument that there is an inherent conflict between having a profit motive and non-profit motive. There is a perception that market-based transactions would diminish the existing social capital on which communities depend to meet their basic needs (Gold, 2003). Still, social entrepreneurship attempts to reconcile this conflict and presents itself as an alternative to both non-profits and for-profits. Viewed as innovative, social enterprises have now become a permanent part of the Philippines' development landscape.

\subsubsection{Social Entrepreneurship: a malleable concept}

This research suggests that social entrepreneurship can contribute to the broadening of genuine alternatives to neo-liberal development practice but has a malleable nature that is influenced by both development and business practices. Answering the second research question of how social entrepreneurship contributes to alternative pathways that are different from prevailing development approaches, the case study on A Single Drop for Safe Water (ASDSW) shows that social entrepreneurship initiatives have aspects that encourage local self-determination of priorities and goals, but they also have market-oriented elements influenced by profit motives.

ASDSW is a non-profit organization that provides technological and organizational development training and consultation services to local governments, community-based organizations, and both local and international organizations for the implementation of water, sanitation, and hygiene (WASH) projects. As with most social enterprises, ASDSW is concerned with the sustainability of their operations and thus earn income through consultation and training fees to support their activities. The case 
study focused on one of their programmes - the People Offering Deliverable Services (PODS) programme, which is a training programme for organizational development. The PODS is mainly targeted at either existing community-based organizations or community members that will form an organization. After the training programme, they are expected to provide a WASH service to their respective communities, either by managing a communal water system or by constructing and selling Bio-Sand water filters. Both these projects have an entrepreneurial component to ensure sustainability. The rationale for the PODS (A Single Drop for Safe Water, 2010b) demonstrates the attempt to combine principles that on the one hand reflect post-development/alternative ideas: decision-making in the hands of the community, ensures community ownership and self-reliance, fosters local expertise, utilizes local resources, supports local knowledge; culturally respectful and specific; and on the other hand are based on market ideology: provides livelihood; infuses local economy; builds vocation and business skills. An in-depth examination of the PODS programme revealed that there are several challenges to truly reconciling these elements.

First, ASDSW claims to provide "ownership of the process, not just the project" (K. Lee, personal communication, October 8,2010 ) to the communities. There is an assumption that 'ownership of the process' will be achieved by engaging some members of the community in a step-by-step training programme that allows them to plan, implement, and manage a water project. However, donors mostly choose the communities that ASDSW works with so the decision to undertake a WASH project is not made by community members. Moreover, the PODS programme and the training modules were designed by ASDSW and the community members were not initially involved in that process. Even the end projects of the PODS programme are predetermined. Although there is an opportunity for community members to articulate goals 
and to create plans of their own, these are tied to an existing initiative. Thus, the formulaic characteristic of the PODS programme limits the possibility for community members to truly determine their own priorities and create solutions. This is an example where organizational systems and procedures restrict programme delivery so "there is a tendency for project works to cluster around a fixed set of standard interventions, limiting the potential creativity of participatory problem-solving" (Mosse, 2001, p. 24).

Secondly, the application of market-based principles for social services such as water and sanitation do not always have purely positive effects on communities. For instance, the community-based organizations either charge user fees for the water system or sell the filters at a price that will generate profits in order to sustain their operations. Some members of the community, particularly low-income households, may not be able to afford the service or product and will thus be excluded from the potential benefits. This can exacerbate the existing inequalities within the community and also bring about social exclusion. Another way in which these communities are affected, particularly those who participate in the PODS training, is that they need to adjust their attitudes and practices to business standards. Since community members are expected to manage a social enterprise, the PODS training includes modules on writing business plans and establishing accounting systems.

As mentioned, social entrepreneurship tries to unite the business or for-profit sector with the non-profit sector that is dependent on cooperative and voluntary practices. With the PODS, the way to achieve this is for communities to adopt businesslike procedures and be more 'professional'. Hence, the participation of community members in the training affects community practices, despite including local knowledge and expertise in project planning and implementation. Even development processes that employ participatory approaches and emphasize local knowledge can 
influence community practices. In his analysis of participatory planning, David Mosse (2001) found that local participants' made project plans that reflected development agencies' priorities, using the 'planning knowledge' that they gained instead of being guided by 'indigenous knowledge'.

Lastly, one of the key features of social entrepreneurship is that the income or profit generated is meant to support social objectives and eventually help communities in undertaking development initiatives on their own and thereby fit post-development type approaches. However, in the case of the PODS, the profits earned are intended to be reinvested in the existing project for maintenance or expansion purposes in a more market-driven model. Between the two types of projects, the Bio-sand filter production presents a slight opportunity for utilizing the income earned for other purposes since the community organization can decide to use the profits for activities other than the original project. For instance, a community-based organization that ASDSW works with-the Bacungan Coastal Development Residents Association (BCDRAI), places any profit that they earn from the Bio-sand filter enterprise into their funds, which they use for other projects as well. However, given that this is a particular situation, the conclusion that social entrepreneurship programmes such as the PODS enlarge opportunities for communities to undertake self-identified projects, cannot be made.

Despite these challenges, there is definite space to improve or enhance social entrepreneurship practices, the PODS programme in particular, based on postdevelopment ideas. Another side to the malleability of social entrepreneurship, is that it can be viewed as being open to change and possibilities, hence it can contribute to "thinking and practices that are generative, experimental, uncertain, hopeful", which Gibson-Graham (2005, p. 6) believe to be the essence of post-development discourse. For the PODS programme, the main consideration is to make it more adaptable and less 
formulaic throughout the process. ASDSW can try to accommodate communities who are interested in implementing a WASH project and who approach ASDSW directly rather than having been chosen by external donors. This way, the community can truly own the project since it is something that they identified themselves. ASDSW can assist these communities in finding local sources of funding for projects by expanding or modifying their existing resource mapping exercise. This exercise can also help communities to realize that they have the resources to undertake projects on their own. The community-based organization or community members can also collaborate with ASDSW staff to determine whether they want to go through all the activities in the PODS training programme or if they can choose or modify the activities and come up with the most appropriate way for them. Local knowledge, skills, and practices can also be incorporated into the programme, particularly those that can be used in managing an enterprise. It is possible that some communities have local ways of doing business, based on existing community economies, which could be more effective for them, rather than just adopting standardized 'professional' business methods.

On a final note, it cannot be overlooked that communities or local peoples and places have the ability to influence the direction of most development intervention. As in the case of BCDRAI, they were able to decide on how to use their resources in a way that was not necessarily advocated or advised by ASDSW. And although the PODS programme was designed by ASDSW with specific objectives and outputs in mind, both ASDSW and the community-based organizations should be open to possible ways in which the knowledge acquired, lessons learned, or skills gained from this undertaking can be beneficial for other initiatives. For example, in his study of Papua New Guineans engaged in smallholder oil palm production, George Curry (2003) found that, contrary to what was expected, the smallholder settlers did not transform into an indigenous 
entrepreneurial class' that favoured cash transactions over cultural practices. Rather, traditional exchange practices remained important, while cash transactions were more important in the land settlement schemes than in their home areas (Curry, 2003). If communities can steer social entrepreneurship opportunities in ways that are locally significant then social entrepreneurship may eventually become significant for broadening alternative pathways. One limitation of this research, which is due to time constraints, is that it did not look into the possible 'unintended' effects of the PODS programme on the community.

\subsection{Future Research}

To build on this research, further investigation coming from the perspective of communities is needed to determine how community members understand and view social entrepreneurship in general, and how it differs from other development initiatives they have encountered. A starting point could be examining how communities utilize income from social enterprises and whether business practices are adapted and combined with local practices (see Curry, 2005a; Prayukvong, 2005). The unintended effects of projects and programmes on the communities can also be explored.

Research on social entrepreneurship in general is starting to grow and as Mair and Marti (2006, pp. 42-43) note, the topic "provides a fascinating playground for research, drawing from different perspectives and literature". While this thesis used a post-development perspective, other theories of development can also be valuable in trying to understand social entrepreneurship, particularly the 'social' component, which as many authors point out, is not clearly defined (Cho, 2006; Nicholls \& Cho, 2006; Peredo \& McLean, 2006). Moreover, given that social entrepreneurship is relevant to development practice, research on social entrepreneurship in the context of developing countries would also be important. Most case studies on social entrepreneurship focus on 
Europe (see Borzaga \& Defourny, 2001; J. Thompson \& Doherty, 2006) and more recently, Defourny and Nyssens (2010) looked into how the concept of social entrepreneurship has evolved in the context of several European countries and in the United States. While this study focused on the case of the Philippines, looking into social entrepreneurship in other developing countries would also be valuable. It would be worth knowing how social entrepreneurship is conceptualized and practiced in different contexts and whether these can inform each other.

\subsection{Conclusion}

This research gives a critical assessment of social entrepreneurship practices grounded in post-development theory, which has not been explored in current social entrepreneurship literature. The primary aim of the research was to establish how social entrepreneurship differs from conventional development approaches, particularly those based on neo-liberal principles. It also attempted to determine whether social entrepreneurship practices contribute to the broadening of alternative pathways as shown by post-development ideas. Essentially, this research is an innovative undertaking that contributes to both social entrepreneurship and post-development literatures.

The research found that social entrepreneurship is an emerging approach to social development in the Philippines that appeals to many organizations since it presents an opportunity to earn income while addressing social problems. On the ground, social entrepreneurship is likewise encouraged as a way to empower communities or marginalized groups by encouraging them to manage and support their own development initiatives using local resources and expertise. There are aspects of social entrepreneurship that build on post-development ideals, which can contribute to alternative pathways. 
The research suggests that social entrepreneurship can be interpreted as a concept that is malleable. It is neither alternative nor mainstream but has the potential to be both and it is open to change. Social entrepreneurship will differ from place to place and from project to project but it provides new opportunities to break donor dependence. If done conscientiously, it can contribute to new alternative locally derived futures. On the one hand, we can be hopeful that social entrepreneurship will be recognized as an approach that opens possibilities for creative and diverse ways of independently addressing social development issues. However, there is also a risk that social entrepreneurship will be used to promote neo-liberal development strategies. Indeed, some social entrepreneurs admit to using the title, 'social entrepreneur' as a strategy for resource generation (Nicholls, 2010). Practitioners need to be careful in the way that they represent social entrepreneurship through their activities so that it will not be dismissed as just another buzzword or the new face of neo-liberalism. Meanwhile, those who are interested in researching social entrepreneurship should also consider looking into social entrepreneurship from perspectives other than business. 


\section{REFERENCES}

A Single Drop. (2010). Staff \& Board Retrieved August 18, 2010, from http://www .asingledrop.org/node/222

A Single Drop for Safe Water. (2009a, October 22). 35,000 People Impacted in the Autonomous Region of Muslim Mindanao Retrieved August 23, 2010, from http://asdforsafewater.blogspot.com/2010/06/35000-people-impacted-inautonomous.html

A Single Drop for Safe Water. (2009b, October 14). ASDSW Opens A Satellite Office in Cotabato City Retrieved August 20, 2010, from

http://asdforsafewater.blogspot.com/2010/06/asdsw-opens-satellite-office-in.html

A Single Drop for Safe Water (2009c, August 4). [Memo RE: BSF PODS Training for Sitio San Carlos, Bacungan, Puerto Princesa City, Palawan].

A Single Drop for Safe Water. (2009d). PODS Training Modules. A Single Drop for Safe Water, Philippines. Puerto Princesa City.

A Single Drop for Safe Water. (2010a). Intent of Humanitarian Response Consortium. A Single Drop for Safe Water, Philippines. Puerto Princesa City.

A Single Drop for Safe Water. (2010b). PODS Micro-Enterprise Retrieved August 20, 2010, from http://www .asdforsafewater.org/

A Single Drop for Safe Water. (2010c). Project Status. A Single Drop for Safe Water, Philippines. Puerto Princesa City.

A Single Drop for Safe Water. (2010d). Technology Solutions Retrieved September 8, 2010, 2010, from http://www.asdforsafewater.org/

A Single Drop for Safe Water. (2010e). WASH Planning Retrieved August 23, 2010, from www.asdforsafewater.org

ADB NGO and Civil Society Center. (2007). Overview of NGOs and Civil Societies: Philippines Civil Society Briefs: Asian Development Bank.

Aldaba, F., Antezana, P., Valderrama, M., \& Fowler, A. (2000). NGO Strategies Beyond Aid: Perspectives from Central and South America and the Philippines. Third World Quarterly, 21(4), 669-683.

Alternative Indigenous Development Foundation, Inc. (2010a, July 21). History of AID Foundation Retrieved August 2, 2010, from http://aidfi.org/default.aspx

Alternative Indigenous Development Foundation, Inc. (2010b). Technology Transfer Offer Retrieved August 4, 2010, from http://aidfi.org/default.aspx

Alternative Indigenous Development Foundation, Inc. (2010c). The Technopark Retrieved August 5, 2010, from http://aidfi.org/Technopark.aspx 
Alternative Indigenous Development Foundation, Inc. (2010d). Water Technologies Retrieved August 2, 2010, from http://aidfi.org/WaterTechnologies.aspx

An Act Providing for the Construction of Water Wells, Rainwater Collectors, Development of Springs and Rehabilitation of Existing Water Wells in all Barangays in the Philippines, R.A. 6716, Repblic of the Philippines (1989).

Anderson, R. B., Horig, B., \& Peredo, A. M. (2006). Communities in the Global Economy: Where Social and Indigenous Entrepreneurship Meet. In C. Steyaert \& D. Hjorth (Eds.), Entrepreneurship as Social Change A Third Movements in Entrepreneruship Book (pp. 56-78). Cheltenham and Northampton: Edward Elgar Publishing.

Arquiza, Y. (2009). Ecotouring Puerto Princesa: Bacungan River. The Green Dream Retrieved January 8, 2011, from http://lagalog.com/2009/04/ecotouring-puertoprincesa-bacungan.html

Ashoka. (2010). What is a Social Entrepreneur? Retrieved August 20, 2010, from http://www.ashoka.org/social_entrepreneur

Ashoka Philippines. (2010). Suport Social Entrepreneurs Retrieved April 17, 2010, from http://philippines.ashoka.org/support

Asian Development Bank. (1999). A Study of NGOs in Asia: Philippines. Manila: Asian Development Bank.

Asian Development Bank. (2002). Impact Evaluation Study on Water Supply and Sanitation Projects in Selected Developing Member Countries. Manila: Asian Development Bank.

Ateneo de Manila University. (2009a, November 10). Enroll now in the 1st Ateneo School of Government Online Social Entrepreneurship Course for Professionals Retrieved March 28, 2010, from http://www $\cdot$ admu $. e d u . p h / i n d e x . p h p ? p=120 \&$ type $=2 \&$ aid $=7574$

Ateneo de Manila University. (2009b, October 1). Social Enterprise course for trainers and teachers, Oct. 19-30 Retrieved March 28, 2010, from http://www.admu.edu.ph/index.php?p=120\&type=2\&aid=7403

Ateneo de Manila University. (2010a, May 25). 6th Social Entrepreneurship Training Program for Professionals, June 19-Oct. 3 Retrieved August 12, 2010, from http://www $\cdot$ admu $. e d u . p h / i n d e x \cdot p h p ? p=120 \&$ type $=2 \&$ aid $=8432$

Ateneo de Manila University. (2010b, January 16). ASoG and British Council offers Social Enterprise Development course for NGO managers Retrieved March 28, 2010, from http://www $\cdot$ admu $. e d u . p h / i n d e x \cdot p h p ? p=120 \&$ type $=2 \&$ aid $=7817$

Ateneo de Manila University Development Studies Program and Philippine Social Enterprise Network. (2009). Souvenir Program. Negosyo Para sa Iba, Negosyong Kakaiba, Negosyo Ka Nga Ba? . Quezon City, Philippines. 
Ateneo School of Government. (2010). Social Entrepreneurship Programs/Projects Retrieved March 28, 2010, from http://www.asg.ateneo.edu/focus_socentrep_projects.php

Austin, J., Stevenson, H., \& Wei-Skillern, J. (2006). Social and Commercial Entrepreneurship: Same, Different, or Both? Entrepreneurship: Theory and Practice(January), 1-22.

Austin, J. E. (2006). Three Avenues for Social Entrepreneurship. In J. Mair, J. Robinson \& K. Hockerts (Eds.), Social Entrepreneurship (pp. 22-33). New York: Palgrave MacMillan.

Balisacan, A. M. (2003). Poverty and Inequality. In A. M. Balisacan \& H. Hill (Eds.), The Philippine Economy, Development, Policies, and Challenges (pp. 311-341): Oxford Scholarship Online.

Balisacan, A. M., \& Hill, H. (2003). An Introduction to Key Issues. In A. M. Balisacan \& H. Hill (Eds.), The Philippine Economy, Development, Policies, and Challenges (pp. 3-44): Oxford Scholarship Online.

Barefoot College. (2010a). About Us Retrieved May 5, 2010, from http://www.barefootcollege.org/default.asp

Barefoot College. (2010b). Approach Retrieved May 5, 2010, from http://www.barefootcollege.org/barefoot_professional_approach.asp

Barefoot College. (2010c). Global Impact Retrieved May 5, 2010, from http://www.barefootimpact.in/

Barefoot College. (2010d). History Retrieved May 5, 2010, from http://www.barefootcollege.org/abo_history.asp

Bebbington, A. (1993). Modernization from Below: An Alternative Indigenous Development? Economic Geography, 69(3), 274-292.

Bebbington, A. (2000). Reencountering Developement: Livelihood Transitions and Place Transformations in the Andes. Annals of the Association of American Geographers, 90(3), 495-520.

Borzaga, C., \& Defourny, J. (Eds.). (2001). The Emergence of Social Enterprise: Taylor and Francis Group.

Botes, L., \& van Rensburg, D. (2000). Community Participation in Development: Nine Plagues and Twelve Commandments. Community Development Journal, 35(1), 41-58.

British Council Philippines. (2010). I Am A Changemaker Retrieved August 14, 2010, from http://www.britishcouncil.org/philippines-common-know-our-projectscurrent-projects-i-am-a-changemaker.htm 
Bulos, G. (2010, December). Important News from A Single Drop Founder Retrieved January 28, 2011, from http://asd2.sitejunction.org/single-drop-safewater/welcome

Bureau of Agricultural Statistics. (2010). Updates on Palay, Rice \& Corn Prices October 2010 (Vol. 2). Quezon City: Bureau of Agricultural Statistics.

Bureau of Labor and Employment Statistics. (2010). Current Labor Statistics Retrieved January 15, 2011, from http://www.bles.dole.gov.ph/Current\%20Labor\%20Statistics/HTML/data\%20hig hlights.html

Cahill, A. (2008). Power over, power to, power with: Shifting perceptions of power for local economic development in the Philippines. Asia Pacific Viewpoint, 49(3), 294-304.

Carnegie, M. (2008). Development Prospects in Eastern Indonesia: Learning from Oelua's Diverse Economy. Asia Pacific Viewpoint, 49(3), 354-369.

Carter, R. C., Tyrrel, S. F., \& Howsam, P. (1999). The Impact and Sustainability of Community Water Supply and Sanitation Programmes in Developing Countries. Water and Environment Journal, 13(4), 292-296.

Caucus of Development NGO Networks. (2006). Quick Stats Database. Retrieved July 22, 2010, from CODE-NGO http://code-ngo.org/codedb/codestats.php

Caucus of Development NGO Networks. (2010). Civil Society Assessment of the 20042010 Medium Term Philippine Development Plan (MTPDP). Manila: Caucus of Development NGO Networks (CODE-NGO).

Centre for Affordable Water and Sanitation Technology. (2010). Biosand Filter Retrieved September 8, 2010, from http://www.cawst.org/en/themes/biosandfilter

Chen, K. J. (1997). The Sari-Sari store: Informal Retailing in the Philippines. Journal of Small Business Management, 35(4), 88-91.

Cho, A. H. (2006). Politics, Values and Social Entrepreneurship. In J. Mair, J. Robinson \& K. Hockerts (Eds.), Social Entrepreneurship (pp. 34-56). New York: Palgrave MacMillan.

Ciencia, S. L. (2009-2010). Tracking the Government's Rice Program Implementation: The Case of Guimba. R1 Rice Self-Sufficiency Bulletin, 12-15.

Ciencia, S. L. (2010). Value Adding Rice and Increasing the Incomes of Small Farmers Retrieved August 7, 2010, from http://www.bidnetwork.org/page/23000/en

Constantino-David, K. (1995). Community Organizing in the Philippines: The Experience of Development NGOs. In G. Craig \& M. Mayo (Eds.), Community Empowerment: A Reader in Participation and Development (pp. 154-167). London: Zed Books. 
Constantino-David, K. (1998). From the Present Looking Back: A History of Philippine NGOs. In S. G. Silliman \& N. G. Noble (Eds.), Organizing for Democracy: NGOs, civil society, and the Philippine State (pp. 26-48). Honolulu: University of Hawai'i Press.

Contreras, M. E. (2004). Introduction. In M. E. Contreras (Ed.), Corporate Social Responsibility in the Promotion of Social Development: EXPERIENCES FROM ASIA AND LATIN AMERICA (pp. ix-xvi). Washington, DC: Inter-American Development Bank.

Corbridge, S. (1998). "Beneath the Pavement only Soil": The Poverty of 'PostDevelopment'. Journal of Development Studies, 34(6), 138-148.

Creswell, J. W. (2003). Research Design: Qualitative, Quantitative, and Mixed Methods Approaches (2nd ed.). Thousand Oaks, London and New Delhi: SAGE Publications.

Curry, G. N. (2003). Moving Beyond Post-Development: Facilitating Indigenous Alternatives for "Development". Economic Geography, 79(4), 405-423.

Curry, G. N. (2005a). Doing "Business" in Papua New Guinea: The Social Embeddedness of Small Business Enterprise. Journal of Small Business and Entrepreneurship, 18(2), 231-246.

Curry, G. N. (2005b). RELUCTANT SUBJECTS OR PASSIVE RESISTANCE? A commentary on J.K. Gibson-Graham's "Surplus possibilities: Postdevelopment and community economies". Singapore Journal of Tropical Geography, 26(2), $127-131$

Dacanay, M. L. M. (2006). Social Entrepreneurship: An Asian Perspective. Paper presented at the 2nd International Social Entrepreneurship Research Conference, New York.

Dacanay, M. L. M. (2010). Measuring Social Enterprise: Introduction Retrieved April 25, 2010, from http://www.oikocredit.org/rm/ph/news/marie-lisa-m-dacanay

David, C. C. (2003). Agriculture. In A. M. Balisacan \& H. HIll (Eds.), The Philippine Economy: Development, Policies, and Challenges (pp. 175-218). New York: Oxford University Press.

Dawson, J., Kapila, S., \& Mead, D. (2002). Introduction. In S. Kapila \& D. Mead (Eds.), Building Businesses with Small Producers: Successful Business Development Services in Africa, Asia, and Latin America. London: ITDG Publishing and the International Development Research Centre.

De Vries, P. (2007). Don't Compromise Your Desire for Development! A Lacanian/ Deleuzian rethinking of the anti-politics machine. Third World Quarterly, 28(1), 25-43.

Dees, J. G. (1998). The Meaning of "Social Entrepreneurship". Stanford University: Draft Report for the Kauffman Center for Entrepreneurial Leadership. 
Defourny, J. (2001). Introduction: From third sector to social enterprise. In C. Borzaga \& J. Defourny (Eds.), The Emergence of Social Enterprise (pp. 1-24). London, New York: Routledge.

Defourny, J., \& Nyssens, M. (2010). Conceptions of Social Enterprise and Social Entrepreneurship in Europe and the United States: Convergences and Divergences. Journal of Social Entrepreneurship, 1(1), 32-53.

dela Cruz, L. J. R. (2009). Making Sense of "Social Entrepreneurship" Retrieved August 18, 2010, from http://socialentrep.ateneodevstudies.net/article1.html

Department of Trade and Industry. (2009). MSME Statistics Retrieved February 15, 2011, from http://www.dti.gov.ph/dti/index.php?p=321

Dewalt, K. M., \& Dewalt, B. R. (2002). Participant Observation: A Guide for Fieldworkers. Walnut Creek: AltaMira Press.

Dey, P. (2006). The rhetoric of social entrepreneurship: paralogy and new language games in academic discourse. In C. Steyaert \& D. Hjorth (Eds.), Entrepreneurship as Social Change A Third Movements in Entrepreneurship Book (pp. 121-142). Cheltenham and Northampton: Edward Elgar.

Dolan, R. E. (Ed.). (1991). Philippines: A Country Study. Washington: GPO for the Library of Congress.

Escobar, A. (1992). Reflections on 'development': grassroots approaches and alternative politics in the Third World. Futures, 24(5), 411-435.

Escobar, A. (1997). The Making and Unmaking of the Third World Through Development. In M. Rahnema \& V. Bawtree (Eds.), The Post-Development Reader (pp. 85-93). New Jersey: Zed Books.

Escobar, A. (2000). Beyond the Search for a Paradigm? Post-development and Beyond. Development, 43(4), 11-14.

Escobar, A. (2007). Post-development as Concept and Social Practice. In A. Ziai (Ed.), Exploring Post-development Theory and Practice, Problems and Perspectives (pp. 18-31). London and New York: Routledge.

Esteva, G. (1992). Development. In W. Sachs (Ed.), The Development Dictionary: A Guide to Knowledge as Power (pp. 6-25). London: Zed Books.

Esteva, G., \& Prakash, M. S. (1997). From Global Thinking to Local Thinking. In M. Rahnema \& V. Bawtree (Eds.), The Post-development Reader (pp. 277-289). New Jersey: Zed Books.

Filipino retailers pave the way for socially-responsible business. (2010, August 2). The Philippine Star.

Flyvbjerg, B. (2006). Five Misunderstandings About Case-Study Research. Qualitative Inquiry, 12(2), 219-245. 
Fowler, A. (2000). NGDOs as a Moment in History: Beyond Aid to Social Entrepreneurship or Civic Innovation? Third World Quarterly, 21(4), 637-654.

Garratt, D. (2005). The Foundations of Experimental/Empirical Research Methods- Key Concepts. In B. Somekh \& C. Lewin (Eds.), Research Methods in the Social Sciences. London, Thousand Oaks, New Delhi: SAGE Publications.

Gee, V. (2010). Asia "Social Entrepreneurs Of The Year" Awarded At World Economic Forum's Annual Meeting Of The New Champions 2010 (Press Release) Retrieved October 7, 2010, from http://www.schwabfound.org/sf/index.htm

Gibson-Graham, J. K. (2005). Surplus Possibilities: Post-development and Community Economies. Singapore Journal of Tropical Geography, 26(1), 4-26.

Gillham, B. (2000). Case Study Research Methods. London: Continuum.

Gold, L. (2003). Small Enterprises at the Service of the Poor: The economy of sharing network. International Journal of Entrepreneurial Behaviour \& Research, 9(5), 166-184.

Grameen Communications. (1998a, April 15, 2010). A Short History of Grameen Bank Retrieved May 4, 2010, from http://www.grameeninfo.org/index.php?option=com_content\&task=view\&id=19\&Itemid=114

Grameen Communications. (1998b, April 15, 2010). Credit Delivery System Retrieved May 4, 2010, from http://www.grameeninfo.org/index.php?option=com_content\&task=view\&id=24\&Itemid=127

Grameen Communications. (1998c, April 15, 2010). General Questions on Grameen Bank FAQ Retrieved May 4, 2010, from http://www.grameeninfo.org/index.php?option=com_easyfaq\&task=cat\&catid=80\&Itemid=524\#faq 3

Grameen Communications. (1998d, April 15, 2010). Grameen Bank at a Glance, March 2010 Retrieved May 4, 2010, from http://www grameeninfo.org/index.php?option=com_content\&task=view\&id=26\&Itemid=175

Grameen Communications. (1998e, April 18, 2010). Introduction Retrieved May 4, 2010, from http://www .grameeninfo.org/index.php?option=com_content $\&$ task=view $\& i d=16 \& I t e m i d=112$

Graphic Maps (Cartographer). (2011). Philippines. Retrieved from http://www.worldatlas.com/webimage/countrys/asia/ph.htm

Grenier, P. (2006). Social Entrepreneurship: Agency in a Globalizing World. In A. Nicholls (Ed.), Social Entrepreneurship: New Models of Sustainable Social Change (pp. 119-143). New York: Oxford.

Habito, C. F., \& Briones, R. M. (2005). Philippine Agriculture over the Years: Performance, Policies and Pitfalls. Paper presented at the Policies to Strengthen Productivity in the Philippines, Makati, Philippines. 
Haggard, S., \& Kaufman, R. R. (2008). Development, Democracy, and Welfare States: Latin America, East Asia, and Eastern Europe. New Jersey: Princeton University Press.

Hailey, J. (2001). Beyond the Formulaic: Process and Practice in South Asian NGOs. In B. Cooke \& U. Kothari (Eds.), Participation: the New Tyranny? (pp. 88-101). London: Zed Books.

Halili, M. C. (2004). Philippine History. Manila: Rex Book Store.

Haugh, H. (2006a). A Research Agenda for Social Entrepreneurship? Journal of Social Enterprise, 1(1), 13-28.

Haugh, H. (2006b). Social Enterprise: Beyond Economic Outcomes and Individual Returns In J. Mair, J. Robinson \& K. Hockerts (Eds.), Social Entrepreneurship (pp. 180-205). New York: Palgrave Macmillan.

Hechanova-Alampay, M. R. M., \& dela Cruz, L. J. R. (2009). Lessons and Challenges for Filipino Social Enterprises. In M. R. M. Hechanova-Alampay (Ed.), For the People, With the People: Developing Social Enterprises in the Philippines (pp. 111-130). Quezon City: Ateneo de Manila University Press.

Hesse-Biber, S. N., \& Leavy, P. (2006). The Practice of Qualitative Research. Thousand Oaks: Sage Publications.

Homan, R. (1991). The Ethics of Social Research. London and New York: Longman.

Ife, J. (2002). Community Development: community-based alternatives in an age of globalisation (2nd ed.). Frenchs Forest, N.S.W.: Pearson Education.

Illich, I. (1997). Development as Planned Poverty. In M. Rahnema \& V. Bawtree (Eds.), The Post-development Reader (pp. 94-103). New Jersey: Zed Books.

Institute for Social Entrepreneurship in Asia. (2010a). ASoG and ISEA Launch Joint Masteral Program Retrieved April 25, 2010, from http://iseagroup.net/initiativese0se.html?target $=\mathrm{OA}==$

Institute for Social Entrepreneurship in Asia. (2010b). Vision, Mission, Objectives Retrieved April 25, 2010, from http://isea-group.net/vision-mission.html

Israel, D. C. (2009). Local Service Delivery of Potable Water in the Philippines: National Review and Case Analysis Discussion Paper Series No. 2009-38. Makati City: Philippine Institute for Development Studies.

Israel, M., \& Hay, I. (2006). Research Ethics for Social Scientists. London: Sage Publications.

Iszatt, N. T. (2004). Legislating for Citizens' Participation in the Philippines. In H. Antlo“v (Ed.), Citizen participation in local governance : experiences from Thailand, Indonesia and the Phillipines. Manila: Institute for Popular Democracy. 
Kapoor, I. (2002). The devil's in the theory: A critical assessment of Robert Chambers' work on participatory development. Third World Quarterly, 23(1), 101-117.

Keh, H. S. (2009). Introduction. In M. R. M. Hechanova-Alampay (Ed.), For the People, With the People: Developing Social Enterprises in the Philippines (pp. 1-9). Quezon City: Ateneo de Manila University Press.

Kiely, R. (1999). The Last Refuge of the Noble Savage? A Critical Assessment of Postdevelopment Theory. European Journal of Development Research, 11(1), 30-55.

La Vina, A. G. M. (2009). Foreword. In M. R. M. Hechanova-Alampay (Ed.), For the People, With the People: Developing Social Enterprises in the Philippines (pp. vii-ix). Quezon City: Ateneo de Manila University Press.

Latouche, S. (1993). In the Wake of the Affluent Society: an Exploration of Postdevelopment. London and New Jersey: Zed Books.

Latouche, S. (1997). Paradoxical Growth. In M. Rahnema \& V. Bawtree (Eds.), The Post-Development Reader (pp. 135-142). New Jersey: Zed Books.

Layug, A. S., Pantig, I. D. M. T., Bolong, L. E., \& Lavado, R. F. (2010). Do Barangays Really Matter in Local Services Delivery? Some Issues and Policy Options Discussion Paper Series No. 2010-03. Makati City: Philippine Institute for Development Studies.

LGSPA. (2009). WaSH Field Guide: A Governance Approach to the Delivery of Water, Sanitation and Hygiene Services. Davao City, Philippines: Local Governance Support Program in ARMM (LGSPA).

Lie, J. H. S. (2008). Post-development Theory and the Discourse-Agency Conundrum. Social Analysis, 52(3), 118-137.

Lorenzo-Molo, M. C. F. (2008). Why Corporate Social Responsibility (CSR) Remains a Myth: The Case of the Philippines. Asian Business \& Management, 8(2), 149168.

Mair, J., \& Marti, I. (2006). Social Entrepreneurship Research: A Source of Explanation, Prediction and Delight. Journal of World Business, 42, 36-44.

Mair, J., \& Noboa, E. (2006). Social Entrepreneurship: How Intentions to Create a Social Venture are Framed. In J. Mair, J. Robinson \& K. Hockerts (Eds.), Social Entrepreneurship (pp. 121-135). New York: Palgrave MacMillan.

Mair, J., \& Seelos, C. (2005). Social Entrepreneurship: Creating New Business Models to Serve the Poor. Business Horizons, 48, 241-246.

Marin, G. R. R., Mercado, R. D., \& Nicolas, G. M. (2008). Making Microfinance Work for Agriculture. Quezon City: John J. Caroll Institute on Church and Social Issues (JJCICSI), with funding assistance from the Interchurch Organization for Development Cooperation (ICCO) and Peace and Equity Foundation (PEF). 
Martin, R. L., \& Osberg, S. (2007). Social Entrepreneurship: The Case for Definition Stanford Social Innovation review (Spring 2007 ed.): Stanford Graduate School of Business.

Matthews, S. (2004). Post-development theory and the question of alternatives: a view from Africa. Third World Quarterly, 25(2), 373-384.

Mayo, M., \& Craig, G. (1995). Community Participation and Empowerment: The Human Face of Structural Adjustment or Tools for Democratic Transformation? In G. Craig \& M. Mayo (Eds.), Community Empowerment: A Reader in Participation and Developmet (pp. 1-11). London: Zed Books.

Mayoux, L. (2006). Quantitative, Qualitative or Participatory? Which Method, for What and When In V. Desai \& R. B. Potter (Eds.), Doing Development Research. London: Sage Publications.

McGregor, A. (2007). Development, Foreign Aid and Post-development in Timor-Leste. Third World Quarterly, 28(1), 155-170.

McGregor, A. (2009). New Possibilities? Shifts in Post-Development Theory and Practice. Geography Compass, 3, 1-15.

McIntyre, L. J. (2005). Need to Know: Social Science Research Methods. New York: McGraw-Hill.

Mok, K. (1997). Retreat of the State: Marketization of Education in the Pearl River Delta. Comparative Education Review, 41(3), 260-276.

Mosse, D. (2001). 'People's Kowledge', Participation, and Patronage: Operations and Representations in Rural Development. In B. Cooke \& U. Kothari (Eds.), Participation: the New Tyranny? (pp. 16-35). London: Zed Books.

N'Dione, E. S., de Leener, P., Perier, J. P., Ndiaye, M., \& Jacolin, P. (1997). Reinventing the Present: The Chodak Experience in Senegal. In M. Rahnema \& V. Bawtree (Eds.), The Post-development Reader (pp. 364-376). New Jersey: Zed Books.

National Economic and Development Authority. (2004). Medium-Term Philippine Development Plan 2004-2010. Manila.

National Economic and Development Authority. (2010). 2010 Philippines MDGs Progress Report. Mandaluyong City: National Economic and Development Authority.

National Statistical Coordination Board. Labor and Employment Statistics Retrieved January 15, 2011, from http://nscb.gov.ph/secstat/d_labor.asp

National Statistical Coordination Board. (2007a, June 5). FAQs on the Official Poverty Statistics of the Philippines Retrieved March 18, 2011, from http://nscb.gov.ph/poverty/FAQs/default.asp

National Statistical Coordination Board. (2007b). Population Statistics Retrieved February 5, 2011, from http://nscb.gov.ph/secstat/d_popn.asp 
National Statistical Coordination Board. (2011a, January 31). Annual GDP Sizzled to its Highest Growth Rate in the Post Marcos Era at 7.3 Percent; Q4 2010 GDP grew by 7.1 percent Retrieved February 5, 2011, from

http://nscb.gov.ph/sna/2010/4th2010/2010qpr4.asp

National Statistical Coordination Board. (2011b, February 8). One Family Per 100 was Lifted Out of Food Poverty in 2009 Retrieved February 8, 2011, from http://nscb.gov.ph/pressreleases/2011/PR-22011-SS2-01_pov2009.asp

Nicholls, A. (2010). Editorial: Continuations and Beginnings. Journal of Social Entrepreneurship, 1(1), 1-4.

Nicholls, A., \& Cho, A. H. (2006). Social Entrepreneurship: The Structuration of a Field. In A. Nicholls (Ed.), Social Entrepreneurship: New Models of Sustainable Social Change (pp. 99-118). New York: Oxford.

Now on the Spot. (2010, October 18). Hydraulic ram pump simply a great idea! Retrieved January 31, 2011, from http://www.nowonthespot.org/?p=77

Nustad, K. G. (2007). Development The devil we know? In A. Ziai (Ed.), Exploring Post-development Theory and Practice, Problems and Perspectives (pp. 35-46). London and New York: Routledge.

Ombion, K. (2009, September 18). small techs, HIGH YIELDS. Paper presented at the Negosyo Para sa Iba, Negosyong Kakaiba, Negosyo Ka Nga Ba?, A Conference on Social Entrepreneurship, Quezon City, Philippines.

Oracion, E. G., Miller, M. L., \& Christie, P. (2005). Marine protected areas for whom? Fisheries, tourism, and solidarity in a Philippine community. Ocean and Coastal Management, 48, 393-410.

Organisation for Economic Co-operation and Development. (2009). 2009 DAC Report on Aid Predictability. Paris: OECD.

Organisation for Economic Co-operation and Development. (2010). Query Wizard for International Development Statistics Retrieved March 4, 2010, from http://stats.oecd.org/qwids/

Pastores, K. A. (2010, August 8). Rags, Riches, and Hotels, The Manila Times.net. Retrieved from http://www.manilatimes.net/index.php/sunday-times/23242-ragsriches-and-hotels

Peet, R. (1999). Poststructuralism, Postcolonialism, Postdevelopmentalism. In R. Peet \& E. Hartwick (Eds.), Theories of Development (pp. 123-162). New York: Guilford Press.

Peredo, A. M., \& McLean, M. (2006). Social Entrepreneurship: A Critical Review of the Concept. Journal of World Business, 41, 56-65.

Perrini, F., \& Vurro, C. (2006). Social Entrepreneurship: Innovation and Social Change Across Theory and Practice. In J. Mair, J. Robinson \& K. Hockerts (Eds.), Social Entrepreneurship (pp. 57-85). New York: Palgrave MacMillan. 
Philippine Overseas Employement Administration. (2009). 2009 Overseas Employment Statistics. Retrieved February 8, 2011

http://www.poea.gov.ph/html/statistics.html

Philippine Social Enterprise Network. (2009, September 18). Social Enterprise Quality Index. Paper presented at the Negosyo Para Sa Iba, Negosyong Kakaiba, Negosyo Ka Nga Ba?, A Conference on Social Entrepreneurship, Quezon City, Philippines.

Philippine Social Enterprise Network. (2010a). About Philippines Social Enterprise Network, Inc. Retrieved March 28, 2010, from http://philsocialenterprisenetwork.com/about.html

Philippine Social Enterprise Network. (2010b). Members' Links Retrieved March 17, 2011, from http://philsocialenterprisenetwork.com/links.html

Pieterse, J. N. (1998). My Paradigm or Yours? Alternative Development, PostDevelopment, Reflexive Development. Development and Change, 29(3), 343373.

Pieterse, J. N. (2000). After Post-development. Third World Quarterly, 21(2), 175-191.

Prasad, N. (2006). Privatisation Results: Private Sector Participation in Water Services After 15 Years. Development Policy Review, 24(6), 669-692.

Prayukvong, W. (2005). A Buddhist economic approach to the development of community enterprises: a case study from Southern Thailand. Cambridge Journal of Economics, 29, 1171-1185.

Que, M. T. P., \& Adriano, M. T. A. (2009). Rags2Riches, Making a Social Statement in Style. In M. R. M. Hechanova-Alampay (Ed.), For the People With the People: Developing Social Enterprises in the Philippines (pp. 72-81). Quezon CIty: Ateneo de Manila University Press.

Rags2Riches, Inc. (2010a). From waste, to wealth, to world-class Retrieved July 30, 2010, from http://rags2riches.ph/v2/?s=aboutus

Rags2Riches, Inc. (2010b). Our History Retrieved July 25, 2010, from http://rags2riches.ph/v2/?s=ourhistory

Rahman, M. A. (1995). Participatory Develoopment: Toward Liberation or Co-optation? In G. Craig \& M. Mayo (Eds.), Community Empowerment: A Reader in Participation and Development (pp. 24-32). London: Zed Books.

Rahnema, M. (1992). Poverty. In W. Sachs (Ed.), The Development Dictionary: A Guide to Knowledge as Power (pp. 158-176). London: Zed Books.

Robinson, A. (2003). Management Models for Small Towns Water Supply: Lessons learned from case studies in the Philippines. Washington, DC: The World Bank.

Robinson, J. (2006). Navigating Social and Institutional Barriers to Markets: How Social Entrepreneurs Identify and Evaluate Opportunities In J. Mair, J. Robinson \& K. 
Hockerts (Eds.), Social Entrepreneurship (pp. 95-120). New York: Palgrave MacMillan.

Roque, A. (2006, June 25). Good for farmers' pockets, friendly to the environment, Philippine Daily Inquirer.

Ruiz, M. (2010, January 27). Business Partners, not Beneficiaries. Gamechanger: Why Not Innovate Pilipinas? Retrieved July 30, 2010, from http://ruizmark.com/2010/01/27/business-partners-not-beneficiaries/

Sachs, W. (1992). Introduction. In W. Sachs (Ed.), The Development Dictionary: A Guide to Knowledge as Power (pp. 1-5). London: Zed Books.

Sandoval, C. S. (2009). Kamay Krafts Multi-Purpose Cooperative: Turning Trash into Gold. In M. R. M. Hechanova-Alampay (Ed.), For the People With the People: Developing Social Enterprises in the Philippines (pp. 10-24). Quezon City: Ateneo de Manila University Press.

Schuurman, F. J. (1993). Modernity, Post-Modernity and the New Social Movements. In F. J. Schuurman (Ed.), Beyond the Impasse: New Directions in Development Theory (pp. 187-206). London: Zed Books.

Schwab Foundation for Social Entrepreneurship. (2010a). Criteria for Selection into the Schwab Foundation Network Retrieved October 7, 2010, from http://www.schwabfound.org/sf/SocialEntrepreneurs/SearchandSelectionProcess/ Criteria/index.htm

Schwab Foundation for Social Entrepreneurship. (2010b). Profiles: Bulos, Gemma Retrieved October 7, 2010, from http://www.schwabfound.org/sf/SocialEntrepreneurs/Profiles/index.htm?sname= $229143 \&$ sorganization $=0 \&$ sarea $=0 \&$ ssector $=0 \&$ stype $=0$

Sen, A. (2000). Social Exclusion: Concept, Application, and Scrutiny. Manila, Philippines: Asian Development Bank.

Senajon, C. M. B., \& Hechanova-Alampay, M. R. M. (2009). Hapinoy: The Business Partner of the Poor. In M. R. M. Hechanova-Alampay (Ed.), For the People With the People: Developing Social Enterprises in the Philippines (pp. 25-34). Quezon City: Ateneo de Manila University Press.

Shrestha, N. (1995). Becoming a Development Category. In J. Crush (Ed.), Power of Development (pp. 266-277). London, New York: Routledge.

Small and Medium Enterprise Development Council. (2004). SME Development Plan 2004-2010. Makati City: Department of Trade and Industry.

Smith, B. R., \& Barr, T. F. (2007). Reducing Poverty Through Social Entrepreneurship The Case of Edun. In J. A. F. Stoner \& C. Wankel (Eds.), Innovative Approaches to Reducing Global Poverty (pp. 27-40). Charlotte: Information Age Publishing.

Social Enterprise Development Partnership, Inc. (2010). SEDPI Trains 'I Am A Changemaker' Finalists Retrieved August 14, 2010, from http://www.sedpi.com/ 
Soederberg, S. (2007). Taming Corporations or Buttressing Market-Led Development? A Critical Assessment of the Global Compact. Globalizations, 4(4), 500-513.

Stein, C. H., \& Mankowski, E. S. (2004). Asking, Witnessing, Interpreting, Knowing: Conducting Qualitative Research in Community Psychology. American Journal of Community Psychology, 33(1/2), 21-35.

Steinberg, J. D. (2000). The Philippines: A Singular and a Plural Place (4th ed.). Boulder, Colorado: Westview Press.

Storey, A. (2000). Post-development Theory: Romanticism and Pontius Pilate Politics. Development, 43(4), 40-46.

Storey, D., Bulloch, H., \& Overton, J. (2005). The Poverty Consensus: Some limitations of the 'popular agenda'. Progress in Development Studies, 5(1), 30-44.

Stronach, I. (2005). Philosophy and Hermeneutics- Key Concepts. In B. Somekh \& C. Lewin (Eds.), Research Methods in Social Sciences. London, Thousand Oaks, New Delhi: SAGE Publications.

Taylor, C., \& Gibbs, G. R. (2010, December 1). What is Qualitative Data Analysis (QDA)? Retrieved February 21, 2011, from http://onlineqda.hud.ac.uk/Intro_QDA/what_is_qda.php

The International Bank for Reconstruction and Development. (2005). Philippines: Meeting Infrastructure Challenges. Manila: The International Bank for Reconstruction and Development / The World Bank.

The Local Government Code of the Philippines, Republic Act 7160, Republic of the Philippines (1991).

The Schwab Foundation for Social Entrepreneurship. (2010). Profiles: Roy Sanjit (Bunker) Retrieved May 5, 2010, from http://schwabfound.weforum.org/sf/SocialEntrepreneurs/Profiles/index.htm?snam $\mathrm{e}=129161 \&$ sorganization $=0 \&$ sare $=0 \&$ ssector $=0 \&$ stype $=0$

Thomas, A. (2000). Meanings and Views of Development. In T. Allen \& A. Thomas (Eds.), Poverty and Development in the 21st Century (pp. 23-48): Open University/Oxford University Press.

Thompson, J., \& Doherty, B. (2006). The Diverse World of Social Enterprise. International Journal of Social Economics, 33(5), 361-375.

Thompson, J. L. (2008). Social Enterprise and Social Entrepreneurship: Where Have We Reached? A Summary of Issues and Discussion Posts. Social Enterprise Journal, 4(2), 149-161.

United Nations. (2009). The Millennium Development Goals Report 2009. New York: United Nations.

United Nations Development Program. (2010). Beyond the Midpoint: Achieving the Millennium Development Goals. New York: UNDP. 
Weerawardena, J., \& Mort, G. S. (2006). Investigating Social Entrepreneurship: A multidimensional model. Journal of World Business, 41, 21-35.

Wheldon, A., \& Pepler, K. (2007). Local manufacture and installation of hydraulic ram pumps, for village water supply. from The Ashden Awards for Sustainable Energy http://www.ashdenawards.org/winners

Williams, G. (2004). Evaluating participatory development: tyranny, power and (re)politicisation Third World Quarterly, 25(3), 557-578.

Yin, R. K. (2003). Applications of Case Study Research (2nd ed.). Thousand Oaks: Sage Publications.

Ziai, A. (2007). The Ambivalence of Post-development Between reactionary populism and radical democracy. In A. Ziai (Ed.), Exploring Post-development Theory and Practice, Problems and Perspectives (pp. 111-128). London and New York: Routledge. 


\section{APPENDIX 1}

Annual Per Capita Poverty Threshold, Poverty Incidence and Magnitude of Poor Population, by Region

\begin{tabular}{|c|c|c|c|c|c|c|}
\hline \multirow[t]{3}{*}{ Region } & \multirow{2}{*}{\multicolumn{2}{|c|}{$\begin{array}{l}\text { Annual Per Capita } \\
\text { Poverty Threshold } \\
\text { (in Pesos) }\end{array}$}} & \multirow{2}{*}{\multicolumn{2}{|c|}{$\begin{array}{c}\begin{array}{c}\text { Poverty Incidence } \\
\text { Among Population } \\
(\%)\end{array} \\
\text { Estimates }(\%)\end{array}$}} & \multirow{2}{*}{\multicolumn{2}{|c|}{$\begin{array}{c}\begin{array}{c}\text { Magnitude of Poor } \\
\text { Population }\end{array} \\
\text { Estimates }\end{array}$}} \\
\hline & & & & & & \\
\hline & 2006 & 2009 & 2006 & 2009 & 2006 & 2009 \\
\hline PHILIPPINES & 13,348 & 16,841 & 26.4 & 26.5 & $22,173,190$ & $23,142,481$ \\
\hline NCR & 16,487 & 19,802 & 5.4 & 4.0 & 594,368 & 447,891 \\
\hline $\begin{array}{l}\text { Cordillera } \\
\text { Administrative } \\
\text { Region }\end{array}$ & 12,976 & 16,122 & 23.0 & 22.9 & 338,270 & 346,193 \\
\hline Region I & 14,350 & 17,768 & 26.6 & 23.3 & $1,192,868$ & $1,085,078$ \\
\hline Region II & 12,212 & 15,306 & 20.0 & 18.8 & 563,902 & 545,053 \\
\hline Region III & 15,374 & 18,981 & 15.2 & 15.3 & $1,406,844$ & $1,457,004$ \\
\hline Region IV-A & 14,284 & 17,779 & 12.3 & 13.9 & $1,303,044$ & $1,566,359$ \\
\hline Region IV-B & 12,610 & 15,769 & 42.2 & 35.0 & $1,122,040$ & 980,542 \\
\hline Region V & 13,645 & 17,146 & 45.2 & 45.1 & $2,335,684$ & $2,422,267$ \\
\hline Region VI & 12,432 & 16,036 & 28.6 & 31.2 & $1,848,604$ & $2,113,255$ \\
\hline Region VII & 14,468 & 17,848 & 38.8 & 35.5 & $2,425,645$ & $2,368,361$ \\
\hline Region VIII & 11,885 & 15,910 & 39.0 & 41.4 & $1,565,067$ & $1,731,617$ \\
\hline Region IX & 11,810 & 15,160 & 39.8 & 43.1 & $1,273,852$ & $1,361,287$ \\
\hline Region X & 12,987 & 16,568 & 39.7 & 39.6 & $1,529,932$ & $1,586,668$ \\
\hline Region XI & 13,469 & 17,040 & 31.7 & 31.3 & $1,258,629$ & $1,278,985$ \\
\hline Region XII & 12,530 & 15,762 & 33.1 & 35.7 & $1,203,715$ & $1,332,061$ \\
\hline Caraga & 12,935 & 16,858 & 44.0 & 47.8 & 978,574 & $1,131,004$ \\
\hline ARMM & 12,358 & 16,334 & 42.8 & 45.9 & $1,232,152$ & $1,388,856$ \\
\hline
\end{tabular}

Source: (National Statistical Coordination Board, 2011c) 


\section{APPENDIX 2}

Steps in PODS Training

\begin{tabular}{|c|c|c|c|}
\hline $\begin{array}{l}\text { Strategic } \\
\text { Planning }\end{array}$ & $\begin{array}{l}\text { Business } \\
\text { Planning }\end{array}$ & $\begin{array}{c}\text { Bookkeeping } \\
\text { and } \\
\text { Recording }\end{array}$ & $\begin{array}{c}\text { Continuity } \\
\text { project }\end{array}$ \\
\hline $\begin{array}{l}\text { - Formulation of vision, } \\
\text { goals and objectives } \\
\text { including dream/ } \\
\text { vision map }\end{array}$ & $\begin{array}{l}\text { - Formulation of } \\
\text { operational/ } \\
\text { maintenance/ } \\
\text { production plan; } \\
\text { financial plan; } \\
\text { advocacy/marketing } \\
\text { plan; policies }\end{array}$ & $\begin{array}{l}\text { - Training on accounting } \\
\text { practices }\end{array}$ & $\begin{array}{l}\text { - Monitoring and } \\
\text { Evaluation system }\end{array}$ \\
\hline
\end{tabular}

